\title{
Free as a bird? : the effect of choice restrictions on consumer decision making
}

Citation for published version (APA):

Klesse, A. K. (2014). Free as a bird? : the effect of choice restrictions on consumer decision making. [Doctoral Thesis, Maastricht University]. Datawyse / Universitaire Pers Maastricht. https://doi.org/10.26481/dis.20140206ak

Document status and date:

Published: 01/01/2014

DOI:

10.26481/dis.20140206ak

Document Version:

Publisher's PDF, also known as Version of record

\section{Please check the document version of this publication:}

- A submitted manuscript is the version of the article upon submission and before peer-review. There can be important differences between the submitted version and the official published version of record.

People interested in the research are advised to contact the author for the final version of the publication, or visit the DOI to the publisher's website.

- The final author version and the galley proof are versions of the publication after peer review.

- The final published version features the final layout of the paper including the volume, issue and page numbers.

Link to publication

\footnotetext{
General rights rights.

- You may freely distribute the URL identifying the publication in the public portal. please follow below link for the End User Agreement:

www.umlib.nl/taverne-license

Take down policy

If you believe that this document breaches copyright please contact us at:

repository@maastrichtuniversity.nl

providing details and we will investigate your claim.
}

Copyright and moral rights for the publications made accessible in the public portal are retained by the authors and/or other copyright owners and it is a condition of accessing publications that users recognise and abide by the legal requirements associated with these

- Users may download and print one copy of any publication from the public portal for the purpose of private study or research.

- You may not further distribute the material or use it for any profit-making activity or commercial gain

If the publication is distributed under the terms of Article $25 \mathrm{fa}$ of the Dutch Copyright Act, indicated by the "Taverne" license above, 


\section{FREE AS A BIRD?}

\section{THE EFFECT OF CHOICE RESTRICTIONS ON CONSUMER DECISION MAKING}


(C) Copyright AK Klesse, Maastricht 2014

All rights reserved. No part of this publication may be reprinted or utilized in any form or by any electronic, mechanical or other means, now known, or hereafter invented, including photocopying and recording, or in any information storage or retrieval system, without permission from the copyright owner.

ISBN 9789461592965

Universitaire Pers Maastricht

Cover Design: 6grad51Design

Layout and Printing by: Datawyse Maastricht 


\title{
FREE AS A BIRD?
}

\section{THE EFFECT OF CHOICE RESTRICTIONS ON CONSUMER DECISION MAKING}

\author{
PROEFSCHRIFT \\ ter verkrijging van de graad van doctor \\ aan de Universiteit Maastricht, \\ op gezag van de Rector Magnificus, Prof. dr. L.L.G. Soete \\ volgens het besluit van het College van Decanen, \\ in het openbaar te verdedigen \\ op donderdag 6 februari 2014 om 16:00 uur \\ door
}

Anne-Kathrin Klesse 
Promotor

Prof. dr. Ko de Ruyter

\section{Copromotor}

Dr. Caroline Goukens

Dr. Kelly Geyskens

\section{Beoordelingscommissie}

Prof. dr. Martin Wetzels (Voorzitter)

Prof. dr. Anita Jansen

Dr. Jonathan Levav (Stanford Graduate School of Business) 
No one is free, even the birds are chained to the sky.

Bob Dylan 


\section{ACKNOWLEDGEMENTS}

In my PhD dissertation, I focus on the effect of choice restrictions on consumer decision making. However, for my acknowledgements I consciously decided to break free from restrictions concerning length since I want to fully express my gratitude to all the people who supported me in accomplishing this achievement.

First, I am indebted to my promoter Prof. Dr. Ko de Ruyter. Without your guidance, critical questions, and excellent tips on positioning my articles this dissertation would not be what it is. I also highly appreciated the freedom you gave me in designing and conducting my experiments. This and your extremely generous support enabled me to go beyond mere lab experiments and made it possible to conduct two longitudinal studies - weight loss programs - that improved the value of this dissertation.

Further, I would like to express my sincerest appreciation to my co-promoters, Dr. Caroline Goukens and Dr. Kelly Geyskens. Ladies, thank you for the many interesting and inspiring discussions about this research. Your creativity, tendency to think "outside the box" and enthusiasm about my ideas were extremely motivating and helped me lift my research to a higher level. Whenever I got stuck, you were there to help me and I usually left your office with good ideas on how to solve problems or set up another experiment. I highly appreciated that you always took time for me even when your schedules were very busy. Caroline, I consider myself extremely lucky that I could write my PhD with you by my side. When I began my PhD, I was by no means sure whether I would actually pursue an academic career but within the first three month I was convinced that I would never want to do anything else than research. You definitely had a big share in this change of plans. Kelly, you are one of the nicest persons that I know and I am extremely grateful that you joined my PhD projects.

Certainly, I would like to express my gratitude to the other members of my doctoral committee: Prof. Dr. Anita Jansen, Dr. Jonathan Levav and Prof. Dr. Martin Wetzels. I feel very privileged to have such distinguished academics in my committee and appreciate your suggestions and feedback that definitely helped improve this dissertation. Jonathan, I am grateful that I could visit you in Stanford. Working together with you is a lot of fun but most importantly very inspiring and has helped me become a better researcher. I have already learned a lot about how to avoid "cute" language and write up ideas convincingly. Thank you very much.

Also I am indebted to all colleagues from the Department of Marketing and Supply Chain Management. I like to thank each single one of you for making the last four years such a great experience. A special "thank you" goes to the three angels-Eefje, Nicole and Pascalle-from B 1.24. Pascalle, thank you for handling my bills, the nice 
talks, and for teaching me important rules that make life (and especially the weekends) a lot more fun. Eefje, talking to you always made me feel good. Further, I like to thank all block coordinators-Bram, Evelyn, Gaby, Hans, Kathleen, Lieven, Lisa, Martin, Dominik, and Simon-for making it possible to integrate my experiments in your courses.

I especially like to thank all the PhDs (present and past) of the department for the nice PhD trips, parties or chit chats in the hallway. Iraz, Johannes, Katja, Liz, Niek and Mirjam, you were amazing roommates and made my time in $\mathrm{F} 1.17$ enjoyable and unforgettable. Iraz, Katja, and Niek, during the last four years you were not only my colleagues but became very good friends. Johannes, I highly appreciate your help with statistical questions and the many interesting articles that you forward to me. Hannes, thank you for being my "manipulation photographer." It is great to be colleagues again. Nina, since you are a PhD at Maastricht my time here has become even more enjoyable. Knowing that you are willing to take care of my problems like they were your own is an extremely comforting feeling. Besides our "professional" collaboration, I would like to thank you for always being there for me. You are a wonderful friend (and paranymph).

I am also indebted to my new colleagues at Tilburg University-especially Anick, Aurelie, Barbara B., Bart S., Elaine, Ernst, Henk, Rik, Vincent, and Yangjie-for making me feel "at home" from the first day on, always being there for me and giving me all the time I needed to finish this dissertation. I consider myself very lucky to work in such an inspiring and creative environment. Further, I would like to thank my "academic" friends-Anne B. and Jiska-who I met early during my PhD. I enjoyed the nice talks about research as well as private life on conferences and meet-ups. Even if we just met in my last year of the PhD, I also like to thank Emily. You are amazing and it is a pleasure working with you. A big "thank you" also goes to all Master thesis students and research assistants that helped me set-up and conduct experiments. Without your reliability, support, and creative input the data collection process would have been much more difficult.

Last but not least, I'd like to express my appreciation to my "non-academic" friends and my family: Anna, one of the nicest things about studying in Maastricht was meeting you. Even if we do not see each other that often, I know that you are always there for me. Juki, it is a nice feeling to have such an "old" friend. Sam, thank you for the time we spend together and all the support that you gave me during my PhD. Elise and Antoine, I met you only recently but already now I would not know what to do without you. You are simply the best. Elise, it means a lot to me that you agreed to be my paranymph.

Mama und Papa, mein grösster Dank gebührt Euch: Ihr seid immer für mich da, steht mir stets mit Rat zur Seite und habt mich bisher immer in allem unterstützt. Ich 
erinnere mich noch gut daran, dass ich hin und her überlegt habe, ob ich einen PhD beginnen soll. Ich war mir sehr unsicher und Eure ermutigenden Worte haben mich darin bestärkt diesen Schritt zu gehen. Für diese Dinge und so vieles mehr bin ich Euch unendlich dankbar. Marie und Johanna, Ihr seid spitze: vielen Dank für das Lesen meiner Paper oder das Anhören meiner Präsentationen und die netten Besuche in Maastricht. Ich bin unendlich stolz auf Euch und froh so tolle Schwestern zu haben. Oma Hedel, bei Dir möchte ich mich ganz besonders dafür bedanken, dass Du mir stets die besten Ideen und Einfälle wünschst. Diese Wünsche haben sicherlich dazu beigtragen, dass Ihr nun meine Dissertation in den Händen haltet. Regina, ich könnte mir keine bessere Patentante wünschen. Oma Ingrid und Opa Hans, auch bei Euch möchte ich mich ganz herzlich bedanken: Ihr seid immer für mich da und ich finde es unheimlich klasse, dass Ihr so großes Interesse an meiner Arbeit zeigt.

Jeder von Euch hat auf seine Art und Weise zu dieser Arbeit beigetragen und dafür bin ich Euch unendlich dankbar!

Anne-Kathrin 


\section{TABLE OF CONTENT}

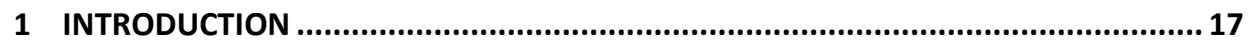

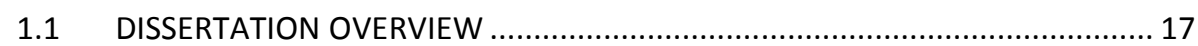

1.2 FREEDOM OF CHOICE VERSUS RESTRICTED CHOICE.................................. 18

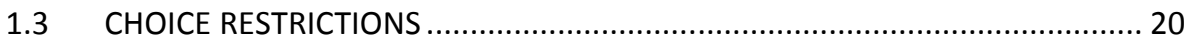

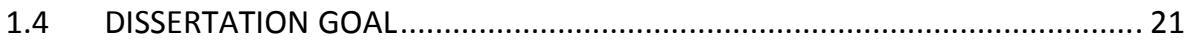

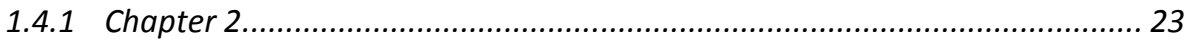

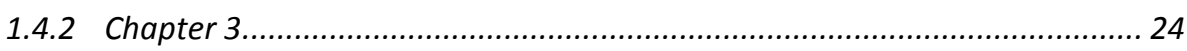

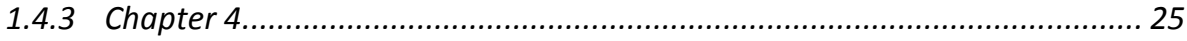

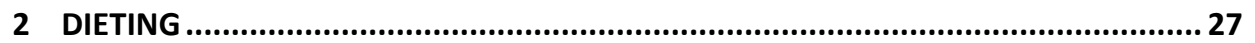

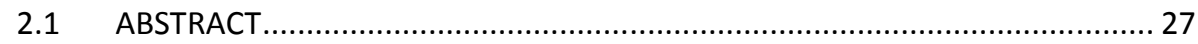

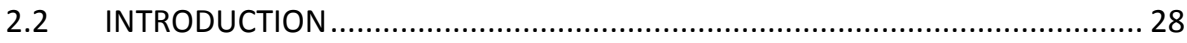

2.3 THE CONSEQUENCES OF WEIGHT WATCHING ........................................... 29

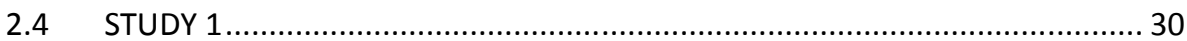

2.4.1 Method

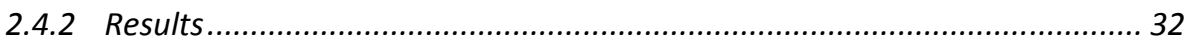

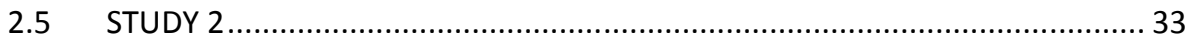

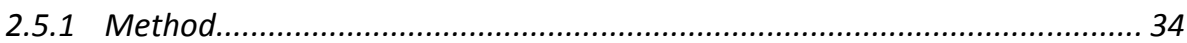

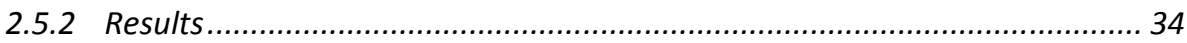

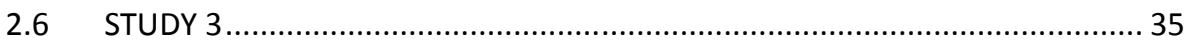

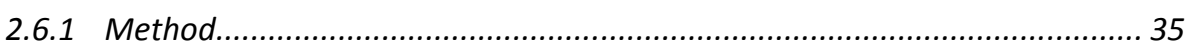

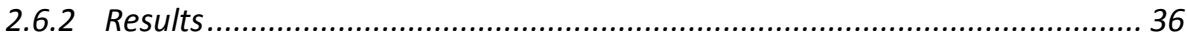

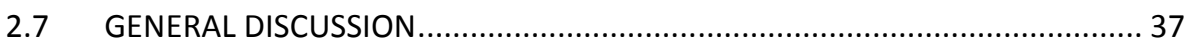

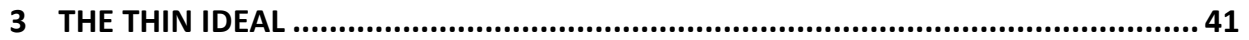

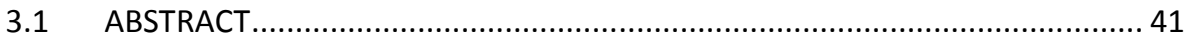

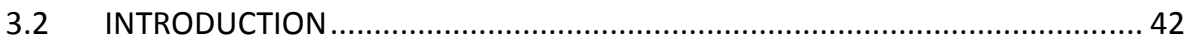

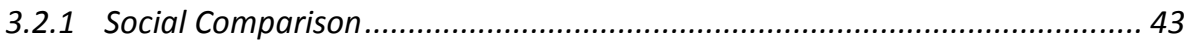

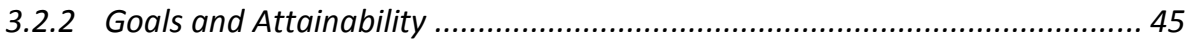

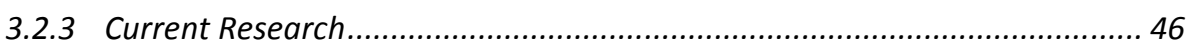

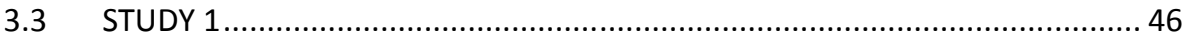

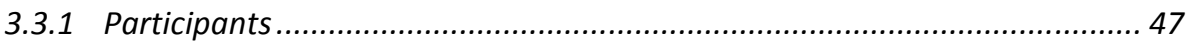




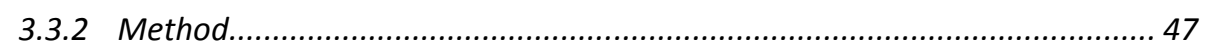

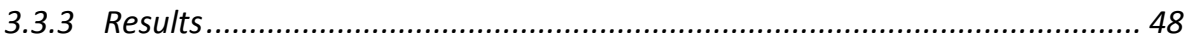

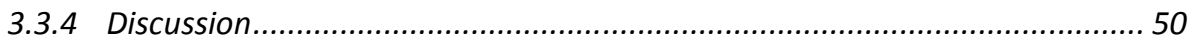

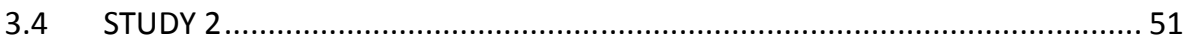

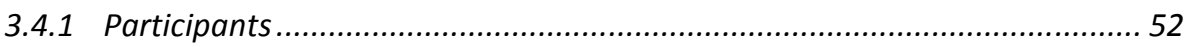

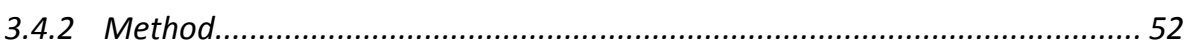

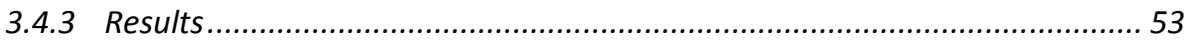

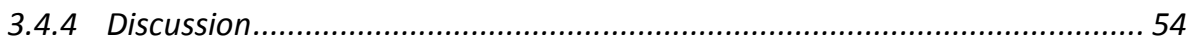

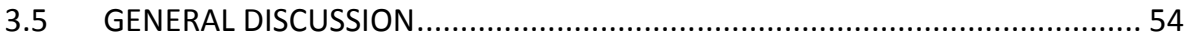

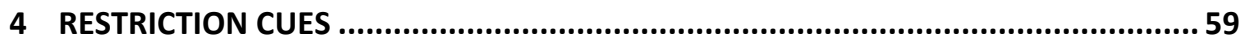

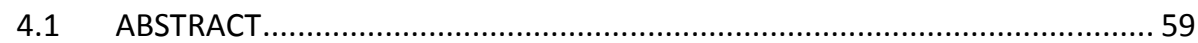

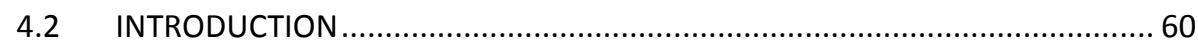

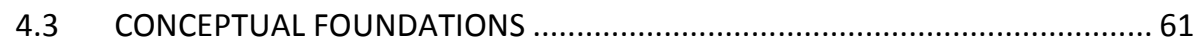

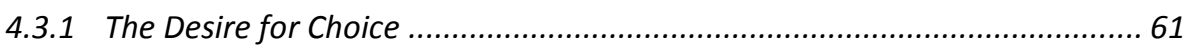

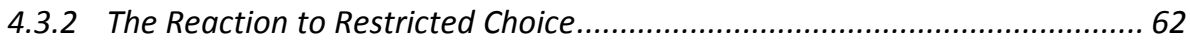

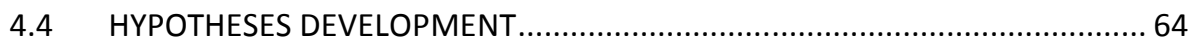

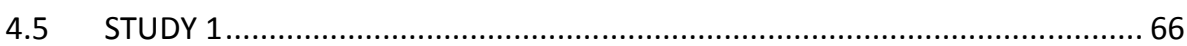

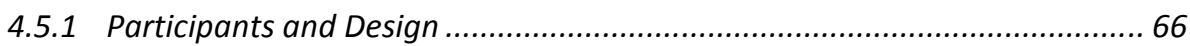

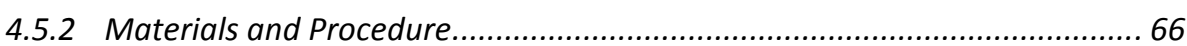

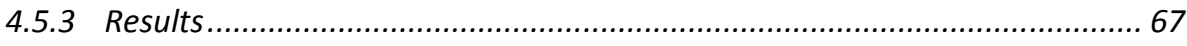

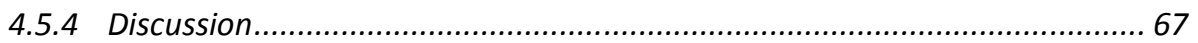

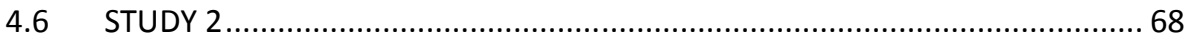

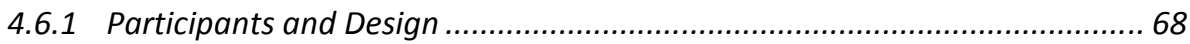

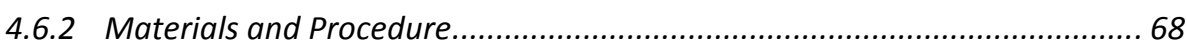

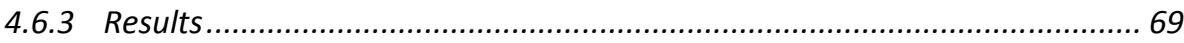

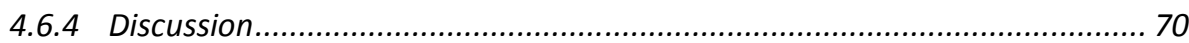

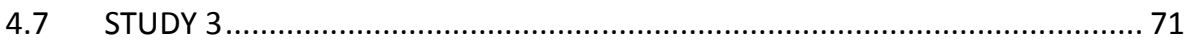

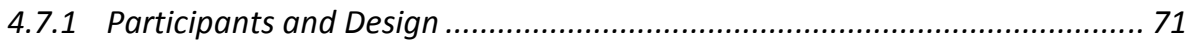

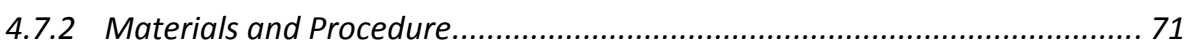

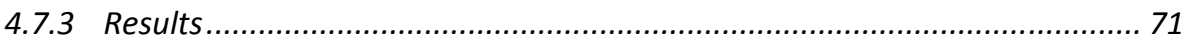

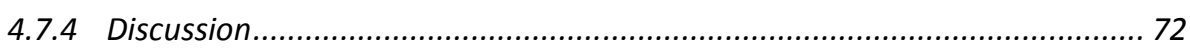

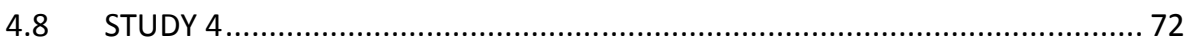

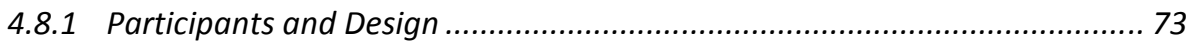

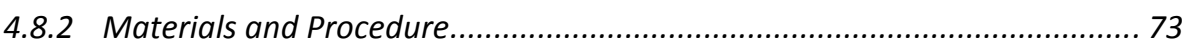

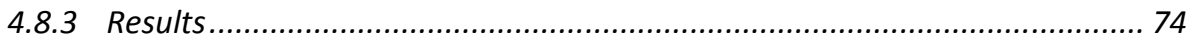




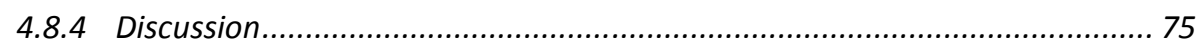

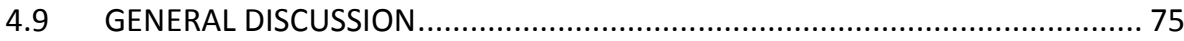

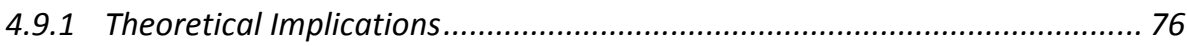

4.9.2 Managerial Implications .................................................................... 77

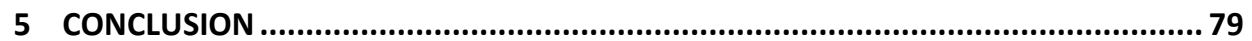

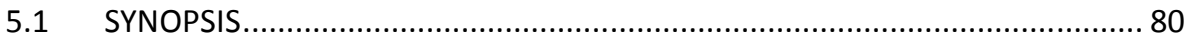

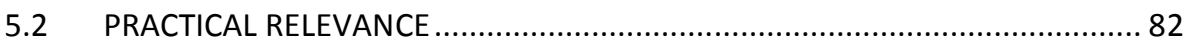

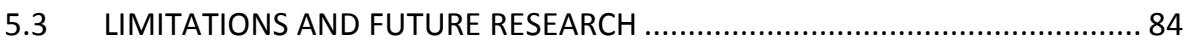

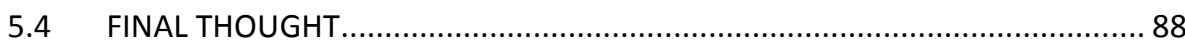

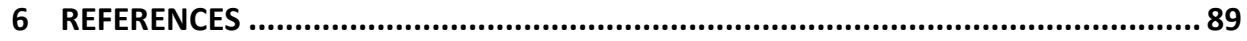

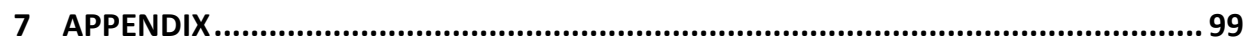

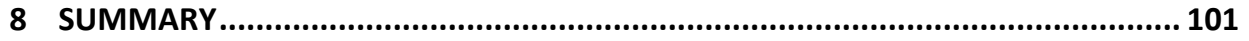

9 SAMENVATTING (Summary in Dutch) ....................................................... 103 


\section{LIST OF FIGURES}

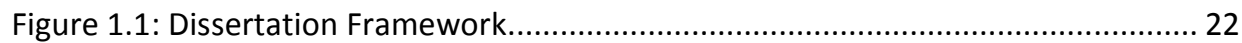

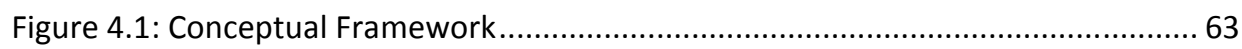

Figure 4.2: Variety Cue X Desire to Make Choice Interaction Effect.............................. 70

Figure 4.3: Variety Cue X Choice Interaction Effect .................................................... 74

Figure 5.1: Dissertation Framework with Outcomes ..................................................... 80 


\section{LIST OF TABLES}

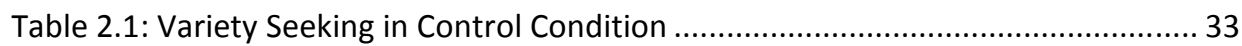

Table 2.2: Variety Seeking in Mental Budget Condition ................................................. 33 


\section{INTRODUCTION}

\subsection{DISSERTATION OVERVIEW}

In this chapter, we introduce the general topic of this dissertation-choice restrictions-and highlight the practical as well as theoretical relevance of studying the effect of choice restrictions on consumer decision making. We begin with a short discussion on the concept of free choice that has evolved to a central theme in many domains of Western life. Strikingly, while society highlights the importance of free choice closer scrutiny reveals that many decisions are actually restricted. In this chapter, we introduce the concept of choice restrictions, provide a definition, distinguish in internal and external choice restrictions and elaborate on the conceptual focus as well as research objectives of this dissertation. 


\subsection{FREEDOM OF CHOICE VERSUS RESTRICTED CHOICE}

"We have to believe in free-will. We've got no choice." Isaac Bashevis Singer

Choice has become a central theme in daily life. For instance, marketers frequently utilize the idea of free choice to advertise their products: "Choice - no woman should be without one" (Kenneth Cole shoes ${ }^{\circledR}$ ) and "Go ahead, be choosy - we are" (Ritter Sport chocolate ${ }^{\circledR}$ ) are examples of slogans that utilize choice as a means to market products. In line with these slogans, many brands have a wide variety of different flavors or features in their product portfolio. To give only one example, the assortment of Lays chips ${ }^{\circledR}$ contains more than twenty product varieties, including Natural Chips ${ }^{\circledR}$, Chips Sticks $^{\circledR}$, Superchips ${ }^{\circledR}$, and Chips Sensations ${ }^{\circledR}$ like Mexican Peppers ${ }^{\circledR}$ or Oriental Spicy $^{\circledR}$. Similarly, retailers compete to offer the largest assortments and try to include as many product types and flavors as possible (lyengar and Lepper 2000). Consequently, a supermarket in the U.S. carries on average 38,718 items (FMI 2010).

Certainly, choice is not only pervasive in the retail domain but has become more and more salient in various different domains of daily life. For instance, as a student of Stanford University you can choose between 17 different degrees (e.g., B.A., B.S., M.D., and LL.M) and more than 50 departments and interdisciplinary programs. Further, as a visitor of New York you have the choice between more than 23,400 restaurants (NYC Statistics 2010). In case, the offer-although extensive-does not meet individuals' preferences, companies even frequently allow consumers to customize their products or services. Fast food restaurants offer their customers the opportunity to create their own dish, pizza or sandwich (Fletcher and Wolfe 2004) and, similarly, some universities allow students to design their individual course portfolio. That is, if the choices available do not meet individuals' preferences companies encourage them to engage in customization and choose exactly the option(s) that they desire most.

These examples suggest that, both, when making everyday decisions as well as when faced with more profound challenges, such as choosing a career, we encounter endless options that enable us to choose the alternative that meets our preferences best (Markus and Schwartz 2010). At first sight, it seems that we are, to a great extent, free in the choices we make. However, closer scrutiny reveals that, still, many decisions are in some way or the other restricted (Botti et al. 2008). Consider, for instance, a dieter who faces the large variety of snacks offered in a supermarket. Although there is a lot of choice available, her decision is confined by the dietary restriction. The desire to lose weight limits her choice to a few of the available snack options (e.g., only the light versions). Similarly, imagine a consumer who wants to buy jam. While he can choose between various different flavors, he might find his favorite kind to be out of 
stock. Or, imagine a consumer in a convenience store: he faces a significantly smaller variety of products to choose from than in a regular supermarket or hypermarket. All these examples have in common that, for one reason or the other, choice is actually restricted rather than free.

Importantly, these instances are not merely hypothetical examples but they occur frequently: nowadays, dieting has become a national pastime in the United States. According to the Boston Medical Center, approximately 45 million Americans diet each year (Livestrong 2010) and, hence, restrict their choice of what and how much to eat. In addition to situations in which individuals decide to restrict themselves they encounter instances in the retail environment in which they find their freedom of choice externally restricted: specifically, while many big supermarket chains compete to offer the largest assortments, there are also store concepts that deliberately limit the assortment variety. For example, convenience stores offer only a limited range of brands and products with an average of 3000 items in as many as 400 categories (Payne 2011). This concept becomes increasingly popular and the number of convenience stores has increased by 1,785 stores in 2011 to a total of 148,126 stores in the U.S. (NACS Online 2011).

These examples pinpoint that consumers frequently restrict themselves or encounter situations in which they are externally restricted. However, in a society where freedom has come to mean almost exclusively freedom of choice (Markus and Schwartz 2010), it seems natural to emphasize the numerous opportunities in which individuals can exercise free choice and to overlook situations in which choice is restricted. A careful consideration of existing research in this domain shows that there exists an extensive stream of research which explores the numerous positive consequences of choice (Leotti, lyengar, and Ochsner 2010; Patall, Cooper, and Robinson 2008) and highlights negative consequences of too much choice (Beattie et al. 1994; lyengar and Lepper 2000; Schwartz 2004). In addition, research compares situations in which individuals can choose to those where the decision is externally made. The findings demonstrate that regardless of whether choice is trivial or even illusory, making a choice brings about more enjoyment, intrinsic motivation, and higher task performance (Burger 1989; Cordova and Lepper 1996; Deci 1981; Deci and Ryan 1985; Langer 1975; Langer and Rodin 1976). While there is a lot of research on choice and the benefits of choosing, significantly less research investigates the impact of restricted choice.

Considering this, the question that arises is how do situations in which individuals are restricted in their freedom of choice influence their state of mind and behavior? Certainly, there is research that deals with situations that can be considered choice restrictions, such as dieting (Hofman et al. 2010; May, Andrade, Kavanagh, and Penfound 2008; Papies, Stroebe, and Aarts 2009) or assortment size (Chernev 2003, Kahn and Wansink 2004), but these researches generally do not explicitly focus on the 
restricting nature of these situations. To our knowledge, only Botti et al. (2008) devoted explicit attention to the effect of choice restrictions on consumer behavior. Looking at situations, such as dieting or being confronted with limited assortment variety, from the perspective of choice restrictions facilitates the investigation of behavioral downstream effects (i.e., variety-seeking behavior and compliance) that have mostly been neglected so far.

\subsection{CHOICE RESTRICTIONS}

"Look around, and you see everywhere the exertions and acts of individuals restricted, regulated, or promoted, on the principle of the common welfare" - Friedrich List

Generally speaking, choice restrictions are situations in which individuals' freedom of choice is restricted. More specifically, a choice restriction can be defined as any internally or externally imposed boundary that restricts individuals' choices (Botti et al. 2008). The distinction between internal and external choice restrictions points to the source of the restriction. Specifically, internal choice restrictions constitute restrictions that individuals impose on themselves. These self-imposed restrictions can be motivated by the desire to be beneficial to or punish one's self or others (Botti et al. 2008). For instance, self-restrictions that are beneficial to the individual range from restricting one's caloric intake and limiting the amount of time spent on leisure activities to restricting spending. Self-restrictions that benefit others compass altruistic behavior such as saving money to donate it to charity (Botti et al. 2008).

External choice restrictions, on the contrary, refer to situations in which individuals' freedom of choice is restricted externally by a third party. As indicated in the quotation by Friedrich List, we frequently encounter legal restrictions, some of which fulfill the purpose to protect mankind (e.g., smoking laws). In addition, our choices can be confined by economic restrictions. Retailers and companies frequently strategically limit consumers' freedom of choice to increase profit. Specifically, companies might introduce limited editions or offer products only during a certain time period (e.g., winter editions) and, in doing so, intend to increase consumers' evaluations of these products. These so-called scarce products restrict consumers in their freedom of choice to acquire them whenever they would like. Similarly, the rather limited product assortment in a convenience store might constitute an external restriction. A convenience store offers fewer yoghurt flavors (i.e., less variety) than a hypermarket, might restrict the availability of different features (e.g., organic yoghurt), limit the range of different feature levels (e.g., non-fat, low-fat, whole-fat), and stocks fewer units of each product type (Botti et al. 2008). Accordingly, it confines consumers' freedom of choice, for example, because a certain flavor/feature is not included in the assortment. 
In addition, the absence of information or access to only limited information can constitute a choice restriction (Pratkanis and Farquhar 1992). Finally, although it is maybe slightly less salient, our decisions are also subject to social restrictions. These include certain social taboos, norms or guidelines about what type of choice behavior is acceptable or rather inappropriate (Botti et al. 2008).

Taken together, choice restrictions are omnipresent and can be very different in nature: they might be self-imposed, enforced by law, or rather "soft" in that sense that they do not necessarily require compliance. Botti et al. (2008) proposed a conceptual framework in which they treat choice restrictions as a general phenomenon that impacts consumer behavior in various ways. The authors call for future research that provides empirical generalizations in an attempt to understand and predict the influence of choice restrictions (Botti et al. 2008).

We believe that a deeper understanding of how choice restrictions influence consumer decision making is important from a theoretical as well as a practical point of view. First, as indicated, there is research that compares situations in which individuals exercise choice themselves to those where the outcomes are externally dictated. Comparing choices made under restrictions to those made free from restrictions will add to and advance this research stream. Second, since nowadays choice is largely taken for granted in modern markets, individuals have become used to perceive the world in terms of opportunities for choice (Markus and Schwartz 2010) and constantly try to expand the choices available to them (lyengar 2010). This might make situations in which choice is restricted more salient and, hence, could trigger extreme reactions.

Considering, the prevalence of situations in which consumers are restricted in their freedom of choice (e.g., when dieting or shopping in a convenience store), it becomes managerially relevant to explore how such situations impact consumer decision making. Specifically, if consumers make different choices in situations where they face limited product offerings (e.g., in convenience stores) or when they restrict themselves (e.g., while being on a diet), companies and retailers benefit from understanding how feeling restricted might change and influence consumer decision making.

\subsection{DISSERTATION GOAL}

The goal of this dissertation is to zoom in on situations in which consumers feel restricted in their choice and explore the effect of such instances on consumer decision making. In doing so, the overarching purpose is to compare decisions made when feeling restricted in one's choice to those made free from feelings of restricted choice. Importantly, this dissertation focuses on consumer reactions to restrictions as a general phenomenon. That is, instead of dealing with one particular type of restriction, the 
manuscripts in this dissertation explore different choice restrictions and behavioral consequences.

In line with Botti et al. (2008), we distinguish in internal and external choice restrictions. Importantly, the decision of which restrictions to focus on was mainly influenced by the endeavor to assure practical relevance. Specifically, we intended to explore the consequences of restrictions that individuals encounter on a daily basis. As pointed out, dieting has become increasingly common and about 50 million Americans diet each year (Sovereign Health Group 2013). This makes studying dieting-as an internal restriction-timely and relevant. Importantly, the media significantly contributes to stimulating individuals' desire to lose weight by constantly confronting us with skinny, idealized and airbrushed models. Accordingly, it is practically relevant to examine the influence of both restrictions-dieting and the thin ideal-in conjunction.

Currently, there has been a change in the retail environment. There are many retailers that cut back on variety (Brat, Byron, and Zimmerman 2009) and the concept of convenience stores-carrying fewer items than normal stores-becomes increasingly popular (NACS 2013). Both of these trends result in the fact that consumers are increasingly confronted with limited assortment variety-an external restriction-and, hence, make it important to explore the consequences for consumer decision making.

This dissertation consists of three empirical papers in which we explore the effect of these types of choice restriction on consumer decision making. Each of the following three chapters presents one manuscript and devotes attention to a different type of choice restriction. The framework in figure 1.1 (adapted from Botti et al. 2008) provides an overview of the source and type of choice restriction as well as behavioral reaction under investigation in each of the following three chapters. In the summary of each chapter, we will highlight the similarities as well as differences between them and indicate how each of them adds to the overall goal of this dissertation.

Figure 1.1: Dissertation Framework

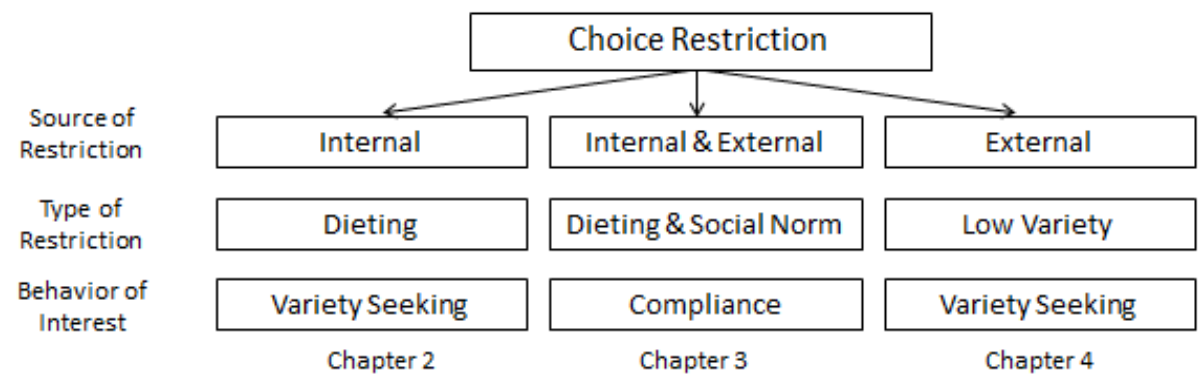




\subsubsection{Chapter 2}

Do Weight Watchers Want More Options? How Activating Self-Regulatory Concerns Triggers the Need for Variety

In chapter 2, we look at an internal choice restriction-dieting-that has become a popular pastime. Nowadays, even individuals that are underweight or of normal weight regulate their food intake. That is, individuals voluntarily impose self-regulatory demands in an attempt to lose or maintain weight. For instance, when trying to lose weight, Americans rely more on restricting their food intake than on exercising (Saad 2011). According to the definitions put forward by Botti et al. (2008), dieting constitutes an internally self-imposed restriction that is motivated by the desire to do something beneficial for oneself. Considering the prevalence and importance that dieting has nowadays, it seems worthwhile to focus on dieting as an internal choice restriction and explore its behavioral consequences. In this chapter, we are especially interested in its effect on variety-seeking behavior defined as individuals' tendency to seek diversity in their choices of services or goods over time (Kahn, Kalwani and Morrison 1986). Investigating the influence of dieting on individuals' need for variety is not only managerially relevant for companies that target dieters-Weight Watchers ${ }^{\circledR}$ - but also of public purpose. Maintaining a healthy weight and reducing one's body weight in the long-term is very challenging for people (Jeffery et al. 2000; Mann et al. 2007) and, hence, being aware of how dieting influences individuals' decision making is very valuable.

In chapter 2, we will present three laboratory experiments in which we explicitly manipulate whether individuals impose self-regulatory demands. Specifically, in all studies we compare individuals with and without self-regulatory demands (i.e., internal restriction) on their variety-seeking behavior. This enables us to explore explicitly whether internally self-imposed restrictions bring about an increased need for variety. Our findings demonstrate that individuals with active self-regulatory concerns are more likely to switch away from a snack previously eaten (e.g., waffle) and try out a new snack (e.g., cake). In addition, we find that individuals with active self-regulatory concerns select a greater variety of different toppings when customizing their own chocolate bar or cake. Taken together, the findings reveal that restricting one's food intake brings about an increased need to integrate variety in one's food choices. We suggest the desire to maximize pleasure from eating as a possible explanation why imposing self-regulatory demands fosters variety seeking. 


\subsubsection{Chapter 3}

Repeated Exposure to the Thin Ideal and Its Implications for the Self: Two Weight Loss Program Studies

This chapter is similar to chapter 2 in the type of restriction-dieting-under investigation. Importantly, however, in this chapter we do not compare individuals with and without self-regulatory concerns but exclusively focus on individuals that restrict their food intake in the endeavor to lose weight. Specifically, we manipulate whether dieters are repeatedly confronted with a thin model cue. According to Botti et al. (2008), social taboos or norms about what is acceptable and what is not, constitute social restrictions. Idealized models in the mass media signal that beauty and thinness should be central life goals for everyone (Dittmar 2008) and, in doing so, set a certain standard that individuals should try to live up to. Further, extreme and highly controversial statements like "nothing tastes as good as skinny feels" by model Kate Moss promote being skinny as desirable (Daily Mail 2011). Although such social restrictions are not strictly enforced but rather vague, it is very difficult to remain unaffected by the continuous exposure to these normative socio-cultural ideals (Dittmar 2008).

The purpose of this manuscript is to explore how being repeatedly confronted with the thin ideal (i.e., thin media models) influences individuals' compliance with this social norm. That is, we investigate how the internal restriction (i.e., goal to lose weight) interacts with the external restriction (i.e., the ideal to be thin). According to Botti et al. (2008), an important factor predicting the valence of an individual's reaction to a restriction is the extent to which a restriction accords with an individual's goal. They argue that if a restriction coincides with a goal, reactions will be positive and compliant, while if a restriction is discordant reactions will be negative. Following this argumentation we would expect that individuals who have the goal to lose weight react positively (i.e., comply) when exposed to the thin ideal since it is in line with their own goal. Accordingly, confrontation with the thin ideal should increase individuals' commitment to their dietary restriction.

Applying a goal perspective to explain the effect of exposure to thin models on dieters' commitment to lose weight, we conducted two (one-week) weight loss program studies in which participants in the treatment condition were repeatedly exposed to a thin model and control conditions to a neutral dieting-related cue (Study 1) or a normal-sized model (Study 2). Unlike expected, however, the results highlight that constant exposure to the thin ideal does not foster compliance but decreases commitment to the dieting goal. Specifically, women exposed to the thin model engaged in more goal-inconsistent behavior (i.e., consuming unhealthy snacks), and had less success in losing weight. 
Our findings suggest that constant exposure to the social norm (i.e., thin ideal) weakened, instead of strengthened, individuals' commitment to their dietary restriction. In doing so, our results provide a boundary condition for the relationship proposed by Botti et al. (2008). Although the social restriction (i.e., thin ideal) was in line with individuals' own goal (i.e., to lose weight), constant exposure to it fostered disengagement from the dieting goal rather than compliance. We highlight that this is due to the unattainability associated with the social norm. That is, if individuals realize that they will not be able to attain the thin ideal anyway, the likelihood to comply with the social norm decreases.

\subsubsection{Chapter 4}

Merely Encountered, but Still Threatened; When Low Variety Activates a Need for Freedom

Just as in chapter 2, we focus on variety seeking as the behavior of interest. However, in this chapter we deal with the construct choice restrictions in a fundamentally different way. In the previous two chapters ( 2 and 3 ), we compared individuals who were restricted in their choice to those free from feelings of restriction. That is, we explored the effect of actual choice restrictions (i.e., dietary restriction and social restriction). In this chapter, on the contrary, we focus on the influence of cues (i.e., limited assortment variety) that signal restricted choice rather than situations in which consumers are actually restricted. Specifically, we investigate whether the mere exposure to limited assortment variety (for instance, on advertisements) influences subsequent variety-seeking behavior.

Considering that individuals are frequently exposed to advertising or commercial slogans utilizing the idea of free choice (i.e., "We never forget you have a choice" by British Caledonian Airline ${ }^{\circledR}$ ), we argue that mere exposure to limited assortment variety triggers the feeling of restricted choice even if no actual restriction is involved. Further, we conjecture that, consequently, individuals exposed to such cues seek more variety in a subsequent choice in order to offset the feeling of restricted choice and regain their freedom. As part of this empirical investigation, we present four laboratory studies that consistently show that mere exposure to cues signaling restricted choice triggers more variety-seeking behavior in a subsequent, unrelated choice. We reveal that the feeling of restricted choice mediates the effect of mere exposure to limited assortment variety on variety seeking. Importantly, we argue that varietyseeking behavior functions as a means to regain one's freedom of choice. In line with this reasoning, we demonstrate that the effect on variety seeking diminishes if individuals are given another opportunity to regain their freedom (i.e., choosing a pen) before they have the possibility to seek variety. These findings suggest that variety seeking 
constitutes a means to offset feelings of restricted choice and imply that situations in which choice is absent rather than abundant will trigger consumers' need for variety. 


\title{
2 DIETING
}

\author{
DO WEIGHT WATCHERS WANT MORE OPTIONS? \\ HOW ACTIVATING SELF-REGULATORY CONCERNS TRIGGERS THE NEED FOR VARIETY
}

\subsection{ABSTRACT}

In this research, we intend to establish a relationship between weight watching and variety seeking. First, we highlight that dieters are more likely to seek variety than nondieters. Second, and more importantly, we demonstrate that activating self-regulatory concerns fosters this increased need for variety. That is, we show that also non-dieters seek more variety in case self-regulatory concerns are activated, for instance, by telling them to impose a mental budget of how many snacks they allow themselves (Study 1 and 2) or by asking questions about their eating behavior and weight (Study 3).

Keywords: dieting, weight watching, self-regulatory concerns, variety seeking 


\subsection{INTRODUCTION}

Nowadays, when dining out or grocery shopping consumers can select between a wide variety of different dishes, flavors and product types. On top of that, consumers are often given the option to buy variety packs, such as, celebrations ${ }^{\circledR}$ (i.e., a mixture of small candy bars such as $\operatorname{Twix}^{\circledR}$, or $\operatorname{Mars}^{\circledR}$ ), that facilitate variety seeking. On the upside, these strategies correspond with individuals' strong preference for variety in food consumption (Kahn and Ratner 2005) and provide them with higher consumption utility (Kahn and Wansink 2004) as well as favorable consumption memory (Ratner, Kahn, and Kahneman 1999). On the downside, however, food variety fosters increased consumption (Rolls et al. 1981) and constitutes an important factor in the etiology of obesity (Raynor and Epstein 2001).

While retailers and companies offer consumers an increased variety of food products, many consumers are, actually, inclined to restrict their food intake. Specifically, weight watching has become a recurring theme in present-day life (Kruger, Galuska, Serdula, and Jones 2004). When reading magazines, watching TV or browsing the internet, one frequently encounters weight-loss shows or is bombarded with information on dieting programs. This creates the impression that watching one's weight has become the status quo. As a consequence, more and more people diet and even individuals who are underweight or of regular weight indicate that they monitor their weight (Marketing Charts 2011).

Considering these recent developments-an increase in product variety on the one hand and an increase in the intention to lose weight on the other hand-in combination, the question that presents itself is whether weight concerns could potentially influence individuals' need for variety. That is, would individuals who restrict their food intake engage in variety seeking to a greater or lesser extent than individuals free from self-regulatory concerns? Individuals that watch their weight adhere to self-imposed demands rather than hunger feelings when deciding what and how much to consume (Herman and Polivy 1984) which might decrease the pleasure associated with eating (Westenhoefer and Pudel 1993). In this context, existing research highlights that especially eating the same type of food quickly results in boredom (Epstein et al. 2009) while variety seeking is associated with higher enjoyment (Ratner, Kahn, and Kahneman 1999). Taken those findings together, we propose that individuals that restrict their food intake might engage in variety seeking to a greater extent than individuals without regulatory concerns.

We think exploring a potential relationship between weight concerns and variety seeking is important for two reasons. First, since nowadays weight concerns seem to be ubiquitous and even individuals of normal weight are triggered to believe that they should watch their weight, it becomes crucial to explore the relationship between 
weight watching and variety seeking. Second, if we establish that self-regulatory concerns increase individuals' need for variety, this means that particularly those individuals who are watching their weight are most susceptible to the negative consequences of variety, i.e., increased food intake. That is, when confronted with varied product assortments individuals that watch their weight would be most likely to seek variety and, in doing so, run the risk of overeating.

\subsection{THE CONSEQUENCES OF WEIGHT WATCHING}

When individuals are concerned about their weight, they restrict their food intake and adhere to self-imposed demands, such as foregoing certain types of food or eating only a restricted number of calories instead of listening to physiologically determined satiety boundaries (Herman and Polivy 1984). Importantly, existing research demonstrates that restricting one's food intake brings about stronger hedonic responses to highly tempting food (Hofmann et al. 2010), causing attentional biases (Papies, Stroebe, and Aarts 2009), emotional imagery about food (May, Andrade, Kavanagh, and Penfound 2008) as well as food cravings and intrusive thoughts (Kavanagh, Andrade, and May 2005). In fact, when individuals restrict their food intake, food is constantly on their mind and plays a central role in their daily life. In this context, it has been demonstrated that individuals that restrict their food intake evaluate food stimuli in terms of pleasure that can be derived from eating (Hofmann et al. 2010).

As becomes apparent, restricting one's food intake often provokes a struggle between, on the one hand, adhering to self-imposed demands while, on the other hand, maximizing pleasure from eating (Stroebe et al. 2008). It has been shown that eating the same kind of food easily results in habituation (Epstein et al. 2009) and decreases enjoyment of that particular food, a process commonly referred to as satiation (Coombs and Avrunin 1977). If consumers repeatedly consume a product, they become satiated, at least temporarily, with the attributes of that specific product and prefer to switch to another product (Lattin and McAlister 1985). Considering this, it is striking that many diets are rather monotone in nature as they highlight one particular food category (e.g., rice) and advice dieters to consume predominantly this type of food rather than to seek variety in their diet.

Eating a variety of different food items, however, reduces the habituation process and increases the motivation to continue eating. This brings about an increase in food intake (Rolls, Rolls, Kingston, and Megson 1981; Raynor and Epstein 2001). Further, existing research highlights that variety is associated with a more favorable consumption memory (Ratner, Kahn and Kahneman 1999). It has been shown that individuals who integrated variety in their choice rated their consumption experience in retrospect as more favorable than those who included only more-preferred items with little 
variety. In addition, existing research established that, for instance, eating jelly beans of many different colors, as compared to few types of color, is expected to bring about higher anticipated levels of consumption utility (Kahn and Wansink 2004).

Taken these findings together, we suggest that restricting one's food intake potentially increases variety seeking since it provides a means to compensate for the decreased pleasure that comes with adhering to these self-imposed demands. We conducted three studies to investigate a relationship between self-regulatory concerns and variety seeking. First of all, we compare dieters to non-dieters on their likelihood to seek variety in Study 1. However, to show that restricting one's food intake is responsible for bringing about this increased need for variety we also explicitly manipulate self-regulatory concerns in our studies. In Study 1 and 2, we operationalize these concerns by using mental budgeting (Kahneman and Tversky 1984). Mental budgets are numerical representations of one's behavioral goals and provide a concrete reference point or standard for a given behavior (Heath, Larrick, and Wu 1999). For instance, a mental budget stated as "I will drink only two cups of coffee per day" converts an abstract goal into more concrete terms. In combination with an avoidance goal (i.e., refrain from eating), a mental budget constitutes a self-imposed demand that individuals will consider when making subsequent consumption decisions (Krishnamurthy and Prokopec 2009). Inherent to this operationalization is that participants have a clear reference point (i.e., have a goal in mind). In Study 3, we manipulate selfregulatory concerns without telling participants to impose a concrete demand but by asking questions about their eating behavior and assessing their weight (Coelho do Vale, Pieters, and Zeelenberg 2008).

\subsection{STUDY 1}

Study 1 is designed to explicitly test our hypothesis that the act of restricting oneself brings about variety seeking. For this purpose, we compare dieters and non-dieters and, additionally, manipulate self-regulatory concerns by means of mental budget. This helps demonstrate that not only dieters seek more variety than non-dieters but that also non-dieters would engage in more variety seeking if they are asked to adhere to self-imposed demands.

\subsubsection{Method}

Study 1 utilizes a 2 (mental budget vs. no mental budget) $\times 2$ (dieter vs. non-dieter) between-subject design. One hundred forty-nine students ( 88 men; $M_{\text {age }}=21.72, S D=$ 1.64) participated in this study in exchange for extra course credit. They were invited to the lab to participate in two seemingly unrelated studies. The first part served to activate self-regulatory concerns (i.e., mental budget) by means of a questionnaire 
about participants' opinion and behavior towards snacks. To be precise, participants were asked to fill out an online questionnaire and indicated, for instance, where they commonly buy snacks (e.g., at a vending machine) and what kind of package design they prefer (e.g., colorful). Importantly, while all participants answered these general questions about snacks, only the participants in the mental budget condition $(n=84)$ were exposed to additional information at the end of this questionnaire: specifically, they read that people love to snack but that on average they try to limit their snack consumption to 2.13 snacks a day. After this, they were asked to type in the number of snacks they would allow themselves today. This act of indicating how many snacks one allows oneself to consume constitutes a restriction in the eating behavior of the participant. Wording, formulation and content were adapted from Krishnamurthy and Prokopec (2009). Importantly, participants in the control condition $(n=65)$ neither read that people limit their snack consumption to 2.13 snacks a day nor made a budget of how many snacks they would consume today.

Subsequently, all participants took part in an ostensibly unrelated study (i.e., a taste test). Participants were randomly assigned to either taste a small piece of chocolate cake or chocolate waffle. After eating the snack, participants filled out a questionnaire intended to get to know their taste perceptions. Within this questionnaire, participants responded to statements such as "I liked the taste of the cake (waffle)" or "The cake (waffle) tasted freshly-baked." Afterward participants were thanked for their participation and left the lab one by one. In an adjacent room, a researcher offered them to take a piece of waffle or cake as an additional reward. Importantly, neither the cake nor the waffle was wrapped ensuring direct consumption. Since variety-seeking behavior increases in public (Ratner and Kahn 2002), the researcher turned away to imply privacy while the participant made his/her decision. However, his/her choice was noted imperceptible to the participant.

One week later participants received the link to an online questionnaire which among other scales included the restraint scale (Herman and Polivy 1980). The restraint scale consists of 10 items assessing individuals' concern for dieting and weight fluctuations. The maximum possible score on this scale is 35 (= highly restrained) while the lowest possible score is 0 (= not restrained). In line with existing research (e.g., Fedoroff, Polivy and Herman 1997; Jarry et al. 2006; Polivy, Heatherton, and Herman 1988; Roefs et al. 2005), we will classify participants as dieters and non-dieters according to the score on the restraint scale. Following Heatherton et al. 1988, we apply the cut-off value 16 to distinguish in non-dieters (i.e., below a score of 16) and dieters (i.e., a score of 16 and above). 


\subsubsection{Results}

We excluded four participants who indicated that they did not like the piece of waffle $(n=2)$ or cake $(n=2)$ they received during the taste test ${ }^{1}$. Further, we excluded one participant because he indicated an allergy restriction. This leaves 63 participants in the control condition (43 men; $\mathrm{M}_{\text {age }}=21.89, \mathrm{SD}=1.62$ ) and 81 in the mental budget condition (43 men, $\mathrm{M}_{\text {age }}=21.56, \mathrm{SD}=1.60$ ). Importantly, the two conditions are not significantly different in terms of gender and age (all Fs $<1$ ). Using the restraint scale (Herman and Polivy 1980) with a cut-off point of 16 (Heatherton et al. 1988), results in 97 unrestrained eaters ( $n=42$ in control condition) and 47 ( $n=21$ in control condition) restrained eaters. Non-dieters scored on average 10.07 on the restraint scale and dieters scored on average 20.73 .

We measured variety seeking as switching away from the food item just eaten (Kahn 1995). This means that participants engaged in variety seeking if they tasted the cake (waffle) during the experiment and afterward chose the waffle (cake). Because product type (i.e., waffle or cake) eaten during the taste test did not influence individuals' likelihood to seek variety, we collapsed the data across product types. We performed a direct logistic regression to assess the impact of our manipulation-no mental budget (coded 0) versus mental budget (coded 1) and dieting status-non-dieter (coded 0 ) versus dieters (coded 1 ) and their interaction effect on the likelihood to seek variety-no (coded 0 ) versus yes (coded 1 ). The full model was statistically significant, $\chi 2(3, n=144)=9.48, p<.05$, indicating that the model was able to distinguish between respondents who sought variety and those that did not. The model explained between $6 \%$ (Cox and Snell R square) and $8 \%$ (Nagelkerke $R$ squared) of the variance in varietyseeking behavior. Specifically, the results reveal dieting status $(p<.05$, beta $=.95)$ as a significant positive predictor. Dieters were significantly more likely to seek variety than non-dieters. Further, the model revealed mental budget as a (marginally) significant positive predictor $(p<.06$, beta $=.79)$. Participants who generated a mental budget were (marginally) significantly more likely to choose a different snack than those without a mental budget. The interaction effect of the two is insignificant (beta $=-.71$, NS). Table 1 (control condition) and 2 (mental budget condition) provide a detailed overview of participants' choices by highlighting how many dieters and non-dieters sought variety in each condition.

\footnotetext{
${ }^{1}$ Two of these four participants did not eat the piece completely although we clearly indicated that they should. 
Table 2.1: Variety Seeking in Control Condition

\begin{tabular}{|l|l|l|}
\hline & No Variety Seeking & Variety Seeking \\
\hline Non-dieters & $25(59.5 \%)$ & $17(40.5 \%)$ \\
\hline Dieters & $6(28.6 \%)$ & $15(71.4 \%)$ \\
\hline
\end{tabular}

Table 2.2: Variety Seeking in Mental Budget Condition

\begin{tabular}{|l|l|l|}
\hline & No Variety Seeking & Variety Seeking \\
\hline Non-dieters & $22(40 \%)$ & $33(60 \%)$ \\
\hline Dieters & $7(26.9 \%)$ & $19(73.1 \%)$ \\
\hline
\end{tabular}

First, this study shows that dieters are more likely to seek variety than non-dieters. Second, and more importantly, it demonstrates that the act of imposing self-regulatory demands prompts variety seeking: also non-dieters seek more variety if they generated a mental budget of how many snacks they want to consume. Specifically, the main effect of mental budget highlights that the act of imposing a self-regulatory concern (i.e., how many snacks to consume) results in an increased likelihood to switch away from the snack previously consumed.

Notably, we tried to avoid that the pieces of cake and waffle were perceived as a preload by deliberately keeping them small. However, it is possible that individuals with self-regulatory demands still felt that they infringed on their dieting rules by eating the piece of cake or waffle. In this context, existing research highlights that even mere exposure to food stimuli can cause the breakdown of dietary restraint (Fedoroff, Polivy, and Herman 1997; Jansen and van den Hout 1991). Consequently, it is possible that individuals with self-regulatory demands desired to try out different snacks because they considered their diet as ruined anyway and engaged in "what the hell" thinking (Herman and Mack 1975). To account for this alternative explanation, we explore participants' variety-seeking behavior without any prior consumption situation in the second study.

\subsection{STUDY 2}

Study 1 demonstrates that activating self-regulatory concerns prompt individuals' need for variety. In this study, we intend to provide further evidence for this by focusing on non-dieters (classified as such upfront by means of the restraint scale, cut-off value 16; $\left.M_{\text {restraint }}=9.73, S D=3.86\right)$. As in Study 1 , we again manipulate whether they impose a mental budget of how many snacks they want to allow themselves for that day. To test robustness of our effect we made two changes: first, we conceptualize variety seeking as taking varied product bundles (Simonson 1990). Second, to address the alternative explanation in light of the "what the hell effect" (Herman and Mack 1975), we do not 
confront participants with real food but ask them to select toppings for a chocolate bar in an online questionnaire.

\subsubsection{Method}

Fifty-six students (34 men; $M_{\text {age }}=21.80, S D=2.4$; Body Mass Index $(B M I): M_{B M I}=22.11$, $S D=2.31$ ) participated in this study in exchange for extra course credit. They were invited to the lab to participate in two seemingly unrelated studies. On arrival they were randomly assigned to the mental budget condition $(n=30)$ or a control condition $(n=26)$.

First, they took part in a study about snacking behavior and filled out an online questionnaire. Identical to the previous study, participants in the mental budget condition were asked to type in the number of snacks they would allow themselves today while participants in the control condition only answered the general questions about snacking behavior. Afterward all participants proceeded with a seemingly unrelated study about customization. They were informed that the chocolate brand Chocri offers its customers to create their own chocolate bar by indicating which topping(s) they would like to add to their chocolate bar. For this purpose, participants saw a plain chocolate bar (i.e., milk chocolate) which was divided in six parts. In addition, they were presented with six toppings (i.e., cappuccino chocolate chips, caramel pieces, chocolate sizzle rocks, colorful chocolate dragées, rice crispies, and nougat pieces) and read that they had to choose six toppings which they would like to add to their chocolate bar. Importantly, they could choose one topping a couple of times or make a mixture of different ones. Further, they were informed that they could win the chocolate bar that they created.

\subsubsection{Results}

We measured variety seeking as the number of different toppings chosen (Simonson 1990) and excluded one outlier on this measure (SD > 2.5). This leaves 26 participants in the control condition (16 men; $\mathrm{M}_{\mathrm{age}}=21.88, \mathrm{SD}=1.86 ; \mathrm{M}_{\mathrm{BMI}}=21.65, \mathrm{SD}=1.85$ ) and 29 participants in the mental budget condition (17 men, $M_{\text {age }}=21.62, S D=2.96 ; M_{B M I}=$ 22.50, SD $=2.65$ ). Importantly, we compared the mental budget condition and control condition on gender, age and BMI. However, none of these analyses revealed statistically significant differences between the two groups (all Fs $<1$ ).

Then, we conducted an ANOVA to explore potential differences between our conditions in the likelihood to choose a variety of different toppings. The results show that participants who imposed a mental budget chose (marginally) significantly more different toppings $\left(\mathrm{M}_{\text {MentalB }}=3.52, \mathrm{SD}=.77\right)$ than those who did not impose a mental budget $\left(\mathrm{M}_{\text {Control }}=3.12, \mathrm{SD}=.74, \mathrm{~F}(1,53)=3.93, p<.06\right)$. Note that the effect of mental 
budget on variety seeking improves when controlling for participants' $B M I(F(1,53)=$ $5.99, p<.05)$.

The finding that activating self-regulatory concerns (by means of mental budget) increases variety seeking is in line with the first study. Further, it helps address the alternative explanation in light of the "what the hell effect" (Herman and Mack 1975). Since we replicate our effect although participants did not consume food prior to selecting their chocolate toppings, we can exclude this alternative account. Taken together, Study 1 and 2 highlight that imposing self-regulatory demands increases variety seeking. Notably, both studies utilized mental budgets to activate self-regulatory concerns. Inherent to the nature of this manipulation is that participants had a clear reference point (i.e., goal) in mind. We claim that self-regulatory demands foster variety seeking as a means to compensate for their regiment and derive maximum pleasure from eating. However, this does not mean that the self-regulatory demands need to be specific. We rather argue that the general intention to restrict ones' intake drives the effect. To establish this point, we will use a different manipulation to activate selfregulatory concerns in study 3 .

\subsection{STUDY 3}

In Study 3, we manipulate self-regulatory concerns without instructing participants to formulate a mental budget but by asking general questions about their eating behavior and weight. Specifically, in line with Coelho do Vale, Pieters, and Zeelenberg (2008), participants for whom we activate self-regulatory concerns participate in a "dieting study" before they were given the possibility to seek variety. It has been demonstrated that this manipulation activates self-regulatory concerns (Coelho do Vale, Pieters, and Zeelenberg 2008).

\subsubsection{Method}

Forty-five students (16 men; $\mathrm{M}_{\mathrm{age}}=22.60, \mathrm{SD}=2.23 ; \mathrm{M}_{\mathrm{BMI}}=22.33, \mathrm{SD}=2.97$ ) participated in this study in exchange for extra course credit. They were invited to the lab to participate in two seemingly unrelated studies. Participants in the "activated selfregulatory concerns" condition $(n=24)$ first took part in the "dieting study." As part of this study, they had to complete the 10-item Restraint Eating Scale (Herman and Polivy 1980 ) including questions such as "How conscious are you of what you are eating" and "Do you give too much time and thought to food." After completing these questions, participants read that we would like to assess some of their body measures so that we BMI. They were lead to a scale placed in front of a table that was decorated with several magazines. On top of the magazine staples, a magazine featuring a thin woman under the headline "Bikini diet" and one with a topless, sportive man on the cover 
were visible. This fulfilled the purpose to further induce self-regulatory concerns. Although existing research (Coehlo do Vale, Pieters, and Zeelenberg 2008) placed a mirror in front of the scale to increase self-awareness and, therewith, self-regulatory concerns, we refrained from this since self-awareness has been shown to influence variety seeking (Goukens, Dewitte, and Warlop 2009). Once participants were weighed, they returned to their computer and continued with answering questions about their weight and eating behavior.

After this study, participants for whom we activated self-regulatory concerns proceeded with the second study (i.e., cake study). Participants for whom we did not activate self-regulatory concerns $(n=21)$ directly began with the cake study. All participants were informed that we wanted to investigate the effect of customization on taste perception. For this purpose, each of them was guided to a mixing cubicle where they obtained a round cake (with a diameter of 3.7 inches) covered with whipped cream. The experimenter explained that they can customize the cake by choosing seven different toppings (i.e., Smarties, chocolate flakes, chocolate sprinkles, fruit sprinkles, small almond cookies, Milka pralines filled with nougat and Maltesers ). Participants got to know that they could take any toppings they would like but that it was important to equally cover the whole surface of the cake. We mentioned this explicitly to guarantee that the overall quantity of toppings added to the cake was comparable. Once participants had chosen the toppings, they had to fill out a questionnaire, measuring their taste perceptions. After completion of this study, participants in the activated condition were thanked and could leave. Participants in the nonactivated condition continued with the study about their eating behavior and body weight.

\subsubsection{Results}

We asked participants to indicate the attractiveness for each of the toppings on a scale from 0 (i.e., not at all attractive) till 100 (i.e., very attractive). Nine participants ( $n=3$ in the control condition and $n=6$ in the treatment condition) indicated zero for one or more toppings and were excluded from the analysis. Further we excluded four people that guessed the purpose of the study. Specifically, two of the participants established a link between the "dieting study" and the "cake customization study" and speculated that we were interested in the effect of weight satisfaction/dissatisfaction on their subsequent behavior (i.e., customizing the cake). The other two participants guessed that we were interested in the number of different toppings that they chose (i.e., variety-seeking behavior). This leaves 17 participants in the control condition (8 men; $M_{\text {age }}$ $=22.00, \mathrm{SD}=1.94 ; \mathrm{M}_{\mathrm{BMI}}=22.55, \mathrm{SD}=3.11$ ) and 15 in the treatment condition ( 6 men; $\left.M_{\text {age }}=23.07, S D=2.46 ; M_{B M I}=22.04 ; 3.73\right)$. We compared the mental budget condition and control condition on gender, age and BMI. None of these analyses revealed 
statistically significant differences between the two groups (all Fs $<1$ ). Also we calculated the overall attractiveness of all toppings by summing up the attractiveness score (i.e., highest score possible $=100$ ) for all seven toppings. Importantly, the control condition $\left(M_{\text {attractive }}=399.32, S D=82.62\right)$ and the treatment condition $\left(M_{\text {attractive }}=377.60\right.$, $\mathrm{SD}=81.10)$ did not differ in the overall attractiveness score.

We compared the two conditions on their variety-seeking behavior: participants for whom self-regulatory concerns were activated chose significantly more different toppings $\left(M_{\text {MentalB }}=3.73, S D=.71\right)$ than participants for whom we did not activate selfregulatory concerns $\left(\mathrm{M}_{\text {Control }}=3.0, \mathrm{SD}=1.33, \mathrm{~F}(1,30)=3.90, p<.06\right)$. Note that the effect of mental budget on variety seeking decreases slightly when controlling for participants' $\mathrm{BMI}(\mathrm{F}(1,30)=3.74, p=.07)$.

\subsection{GENERAL DISCUSSION}

In this research, we establish a relationship between weight watching and variety seeking. First, we demonstrate this effect using different conceptualizations of weight watching: we show that dieters seek more variety than non-dieters (Study 1) and that the same pattern of results is found when explicitly manipulating self-regulatory concerns, either by telling participants to generate a mental budget (Studies 1 and 2) or by asking them questions about their eating behavior and their weight (Study 3). This suggests that not only dieters but also individuals for whom self-regulatory concerns are activated engage in variety seeking to a greater extent. Second, we demonstrate the effect utilizing a range of different conceptualizations of variety seeking such as switching away from the snack previously consumed (Study 1), customizing a chocolate bar (Study 2) and decorating one's cake (Study 3).

To our knowledge, we are the first to demonstrate a causal relationship between restricting one's food intake and variety seeking. We believe that this finding is of important theoretical and practical relevance for at least three reasons. First of all, existing research has demonstrated that eating a variety of different food items results in increased food intake (Rolls, Rolls, Kingston, and Megson 1981; Raynor and Epstein 2001). Our research adds to and advances this finding by suggesting that particularly individuals who restrict their food intake have a heightened need for variety and, thereby, are most susceptible to these negative consequences of variety. In doing so, we reveal variety seeking as one culprit that contributes to the fact that individuals who watch their weight frequently fail in their attempts to reduce their body weight (Jeffery et al. 2000). Second, in all our studies we manipulate self-regulatory concerns, for instance, by telling individuals to generate a mental budget or asking questions about their weight to manipulate self-regulatory concerns. The fact that these subtle manipulations are sufficient to trigger an increase in variety seeking suggests that daily 
activities such as watching weight-loss shows or stepping on the scale each morning can increase variety seeking. Third, our research highlights that the multitude of monotone diets promoted nowadays controverts dieters' increased desire for variety. As suggested by their specific names (e.g., banana diet, or cookie diet) many diets advice consume to mainly eat one specific type of food. For instance, individuals following the cookie diet are explicitly limited to one particular type of cookie (Zelman 2012). This requirement does not coincide with the inherent need for variety that comes with restricting one's food intake.

Importantly, existing research points towards differences between males and females with respect to eating behavior and weight consciousness (Frederickson et al. 1998; Herman and Polivy 2010). Following up on these findings, we tested in all three studies whether gender influenced the likelihood to seek variety and whether the activation of self-regulatory concerns might have had different effects depending on gender but none of these analyses reached statistical significance. Noteworthy, however, is that in all three studies females were significantly more likely to be categorized as restrained eaters than male participants; a finding that corresponds with existing research.

We acknowledge that our research findings leave important questions unanswered. First, noteworthy is that in our studies, we exclusively focused on varietyseeking behavior regarding diet-inconsistent products (e.g., cake or chocolate). In addition, it is interesting to explore whether self-regulatory concerns also trigger greater variety-seeking behavior when choosing diet-consistent products (e.g., low-fat yogurt). Second, the question arises whether dieters should be encouraged to follow a varied diet. On the one hand, variety seeking might help individuals to adhere to their selfregulatory demands because it is in line with their inherent needs. Thus, a "variety diet" might make it easier to adhere to the self-regulatory demands and, potentially, increase individuals' success in keeping or losing weight. On the other hand, however, considering that variety seeking results in increased food intake (Kahn and Wansink 2004; Rolls, Rolls, Kingston, and Megson 1981), eating different types of food fosters food intake and, in doing so, constitutes a major threat to losing weight. Note that in our studies variety-seeking behavior was not associated with greater consumption amounts since the overall quantity consumed was kept constant. That is, regardless of how many different toppings participants added on the cake, the consumption amount (i.e., the total cake) was the same. Accordingly, we acknowledge that given the current data we can only speculate that individuals who watch their weight might eat more because they have a greater need for variety than individuals without self-regulatory concerns. In a future study, one should test whether greater variety-seeking behavior as a consequence of self-regulatory concerns indeed prompts increased food intake. 
Finally, we argue that activated self-regulatory concerns increase individuals' need for maximum pleasure while eating (Westenhoefer and Pudel 1993), something that can be achieved by integrating more variety in one's food choices (Kahn and Wansink 2004). However, we also acknowledge that it might be that the inherent preference for variety is a trait which is fostered when feeling restrained, making it an adaptive trait which was once useful to survive periods of food scarcity (Kahn 1998). Expanding the variety of foods you eat is what million years of evolution have designed the human body to do (Ungar and Teaford 2002). Indeed, an adaptive food consumption system must prevent energy deficits (Pinel, Assanand, and Lehman 2000), and thus in situations of shortage would ideally foster dietary flexibility. Particularly, restricting one's food intake might signal scarcity and, hence, trigger the adaptive behavior of being more open to a diverse set of food, and consequently foster an inherent preference for variety. This would be consistent with parallel animal research showing that undernutrition in rats enhances exploratory behavior in food choice (Alamy et al. 2005). The link between food scarcity and variety seeking certainly merits further attention.

In summary, while an impressive array of research has explored the consequences of self-regulatory concerns on consumption amounts, our research highlights that these concerns bring about an increased need for variety. This suggests that dieters' increased tendency to seek variety might constitute a reason why they don't manage to lose weight since eating different things increases food intake. 


\title{
3 THE THIN IDEAL
}

\author{
REPEATED EXPOSURE TO THE THIN IDEAL AND ITS IMPLICATIONS FOR THE SELF: \\ TWO WEIGHT LOSS PROGRAM STUDIES ${ }_{2}$
}

\subsection{ABSTRACT}

Exposure to thin models results in self-esteem shifts that influence people's motivation to diet. This research applies a goal perspective to explain this effect of exposure to thin models on dieters' motivation to lose weight. Two (one-week) weight loss program studies include treatment conditions in which participants repeatedly were exposed to a thin model and control conditions with either a neutral dieting-related cue (Study 1) or a normal-sized model (Study 2). Women exposed to the thin model perceived their dieting goals as less attainable, engaged in more goal-inconsistent behavior (i.e., consuming unhealthy snacks), and had less success losing weight. The effect of exposure to a thin model on weight loss success is mediated specifically by the perceived attainability of the thin ideal.

Keywords: thinness ideal, exposure to models, self-concept, goal attainability

\footnotetext{
${ }^{2}$ This manuscript is adapted from Klesse, Anne-Kathrin, Caroline Goukens, Kelly Geyskens, and Ko de Ruyter, "Repeated Exposure to the Thin Ideal and Implications for the Self: Two Weight Loss Program Studies." International Journal of Research in Marketing, 29 (4), 355-362.
} 


\subsection{INTRODUCTION}

Each of us has a sense of who we are. Existing literature uses several different terms to describe this sense of self, self-identity, or self-concept (Ellemers, Spears, and Doosje 2002; Markus and Kunda 1986). To know our self means that we perceive our possession (or lack) of certain character traits, skills, or physical attributes and believe that we belong to certain social groups (Dittmar 2008). People frequently derive selfimages by comparing themselves with others (Festinger 1954), which has direct consequences on how they evaluate themselves, how satisfied they are with whom they represent, and how they ideally would like to be (Richins 1991).

Because body image is an important part of identity (Harter 1999), comparisons with images presented in mass media affect people's self-evaluations, usually by establishing an ideal of what we want to look like. For example, models presented in mass media are thinner than the average female population (Levine and Smolak 1996); fashion models often have body mass indexes (BMI) as low as 16 , significantly below the lowest point (18.5) in the range of BMI values that indicate a biologically healthy weight (Feldman 2006). Comparisons with a (role) model on such salient and relevant dimensions (e.g., thinness) can strongly influence how a person thinks and feels about the self (Epstude and Mussweiler 2009). Especially for female dieters, most of whom have internalized a thin ideal to define their personal appearance value system, body weight and size are highly accessible domains of identity and ideal self (Ogden 1995). Consequently, these women are very susceptible to thin model cues (Wegner 1994; Wheeler and Berger 2007).

The consequences of exposures to thin models have been well researched and primarily demonstrate that self-esteem and body satisfaction decrease when dieters are exposed to thin media images (Grabe, Ward, and Hyde 2008). Yet some studies also suggest positive outcomes, such that viewing a thin model might have inspirational effects (Collins 1996; Joshi, Herman, and Polivy 2004; Mills, Polivy, Herman, and Tiggemann 2002). Recent research explicates these contradictory findings by demonstrating that the effects depend on the extremity of the model cue (Smeesters and Mandel 2006; Smeesters, Mussweiler, and Mandel 2010). That is, extreme comparison standards foster a contrast effect (Myers and Biocca 1992; Richins 1991) that can induce changes in self-esteem, motivation to lose weight, and even food intake (Dittmar and Howard 2004; Heinberg and Thompson 1995; Mills et al. 2002).

However, existing experimental research on the behavioral consequences of model exposures for eating behavior has been limited to single exposure settings and assessments of self-esteem, motivation to diet, or eating behavior immediately following the exposure. We argue instead that a longer time perspective is needed, along with a concurrent investigation of the motivation to pursue a weight loss goal and 
eating behaviors. That is, exposure to model cues influences eating behavior, which also constitutes feedback about goal progress. If exposure to a thin model triggers dieters to disinhibit food intake (Mills et al. 2002), those dieters might interpret their increased consumption as lack of progress in attaining the goal to lose weight. Such feedback on perceived goal progress then may initiate a shift in motivation to pursue the goal, because when people receive feedback regarding their progress toward a particular goal, it influences their expectations of goal attainability (Brendl and Higgins 1995) and, thus, perhaps their motivation to engage in goal-consistent behavior.

To draw a complete picture of how model cues influence the motivation to lose weight and eating behavior, we need to take a long-term perspective. In this article, we investigate the effects of repeated exposures to a thin model on the motivation to diet and eating behavior over a longer time span, which enables us to contribute to existing research in several ways. First, whereas prior research has ignored the intertwined effects of exposure and eating behavior on the motivation to lose weight, we consider both factors concurrently over a longer time span. Second, modern consumers cannot realistically be exposed only once to a thin model cue; intentionally or unintentionally, they frequently encounter such cues. Dieters, who have internalized a thin ideal, should be particularly sensitive to these thin model cues (Wegner 1994; Wheeler and Berger 2007). We therefore investigate the effects of this constant exposure on eating behaviors and motivation to lose weight. Third, achieving a goal such as losing weight does not depend solely on individual motivation in any given situation but rather demands engagement in goal-consistent behavior over time. Therefore, exploring the effect of exposure to thin models over time, in a setting that mimics typical dieting scenarios, seems more adequate.

\subsubsection{Social Comparison}

Appearance, beauty, and the perfect body have long been central influences on women's identity. Women are socialized early to understand that their bodies should be used to attract others (Thompson, Heinberg, Altbe, and Tantless-Dunn 1999), and they learn to see themselves as objects to be evaluated by their appearance (Frederickson and Roberts 1997). This pressure is repeatedly reinforced by strong sociocultural ideals of female beauty, which have become synonymous with ultra-thinness (Wiseman, Gray, Mosimann, and Ahrens 1992). In this context, women compare themselves to media models, who are substantially thinner than the majority of the female population, through a natural drive to evaluate their own attributes and abilities (Festinger 1954). These upward comparisons to someone superior on the comparison dimension (i.e., a thin model who is superior on the thinness dimension; Wertheim, Paxton, Schutz, and Muir 1997) strongly influence how people think and feel about themselves (Epstude and Mussweiler 2009). The effects of upward comparisons to thin (idealized) 
models often are conceptualized in terms of "contrast effects," which refers to the tendency to evaluate the self more negatively after viewing highly attractive others (Thornton and Moore 1993). Richins (1991) demonstrates that women are less satisfied with their own physical appearance after exposure to thin, attractive models. However, there also may be positive effects of upward comparisons (Collins 1996; Mussweiler and Strack 2000). For example, viewing highly attractive models may have inspirational effects and result in positive shifts in self-perception (Collins 1996). Mills et al. (2002) show specifically that dieters rate themselves as thinner after exposures to idealized body images.

Recent research (Smeesters, Mussweiler, and Mandel 2010; Smeesters and Mandel 2006) sheds further light on these contradictory findings by demonstrating that the extremity of the model determines the effects of exposure on people's appearance beliefs and self-esteem. Comparisons with a moderate standard (e.g., moderately thin model) trigger standard-consistent self-knowledge and result in assimilation, such that self-judgments move in the direction of the comparison standard (Mussweiler and Strack 2000). In contrast, comparisons with an extreme standard (e.g., extremely thin model) foster standard-inconsistent self-knowledge and result in contrasts, such that the self gets judged as opposite from the comparison standard (Richins 1991). If the distance between the assessor and the model is large (e.g., normal BMI respondents exposed to extremely thin models), exposure to the model leads to a contrast effect and reduces self-esteem (Smeesters, Mussweiler, and Mandel 2010), which might motivate people to lose weight (Dittmar and Howard 2004; Heinberg and Thompson 1995; Smeesters, Mussweiler, and Mandel 2010) and change their eating behaviors (Anschutz, Engels, Becker, and van Strien 2008; Seddon and Berry 1996; Smeesters, Mussweiler, and Mandel 2010; Strauss, Doyle, and Kreipe 1994; Warren, Strauss, Taska, and Sullivan 2005).

Existing research also has demonstrated that exposure to thin models influences subsequent food intake. But some studies conclude that people eat less after exposure to thin models (Smeesters, Mussweiler, and Mandel 2010), and others find that dieters stop inhibiting their eating behavior and increase their food intake (Mills et al. 2002). For dieters, exposure to a thin model might increase the perceived distance between their actual self and the desired end state, because it fosters contrast effects (Smeesters, Mussweiler, and Mandel 2010). The proposition that distance between the assessor (e.g., dieter) and the comparison standard (e.g., thin model) determines the consequences of exposure is in line with goal research (Brown 1948; Hull 1932; Levin 1938) that demonstrates that the distance between the current self and a desired end state determines the motivation to pursue a certain goal. 


\subsubsection{Goals and Attainability}

Theories on goal pursuit emphasize a key driver: the desire to reduce a perceived discrepancy between the actual state and the desired end state (Carver and Scheier 1998; Kruglanski et al. 2002). When a desirable end state has been activated and adopted as a goal, people continuously assess their progress by comparing their actual state (e.g., current weight) with the activated end state (e.g., thin model's perceived weight). Feedback on perceived progress toward the goal may influence expectations about goal attainability (Brendl and Higgins 1995) and thereby influence the motivation to work toward the goal in two dynamic ways.

On the one hand, proximal goals should increase individuals' motivation and induce better performance than distal goals. Bandura and Schunk (1981) find that proximal goals, compared with distant goals, provide immediate and achievable incentives and thus are more effective in mobilizing goal-attainment efforts. Similarly, according to the goal gradient hypothesis (Brown 1948; Hull 1932; Levin 1938) and "goals loom larger" effect (Brendl and Higgins 1995), as well as the classic theory of achievement motivation (Atkinson 1964) or theory of reasoned action (Fishbein and Ajzen 1974), the motivation to attain a certain goal increases as the desired end state approaches. If a goal appears closer and easier to attain, individuals become more confident (Tubbs, Boehe, and Dahl 1993) and allocate more effort to reach it. However, if a goal appears very difficult to attain, continued investments of time and effort seem unlikely to pay off, so the goal seeker might disengage from the effort. Following this reasoning, we posit that the interactive effects of increased food intake and exposure to thin models decrease dieters' commitment to their goal.

On the other hand, research on the unconscious effects of subtle cues on behavior suggests that primes activate more enduring effects when they are perceived as distant from an active self-concept. Sela and Shiv (2009) demonstrate that situational primes consistent with self-concepts are more likely to affect behavior in a semantic activation pattern; cues discrepant from the self-concept likely affect it in a goalactivation pattern. Thus, a perceived discrepancy between the active self-concept and the cue signals that the goal has not been attained, which functions as a motivator (Dijksterhuis, Chartrand, and Aarts 2007; Sela and Shiv 2009). The assertion that primes are especially motivating with a greater discrepancy between the active selfconcept and the prime (Sela and Shiv 2009) is in line with dynamic self-regulation research. This research stream demonstrates that a focus on what remains to be done to achieve a desired end state is a sign of low progress and increases motivation to adhere to the goal (Koo and Fishbach 2008). Following this reasoning, the intertwined effects of exposure to thin models and increased food intake should increase the perceived discrepancy between the dieter and the model and thus increase the motivation to attain the weight loss goal. 
These two accounts thus make different predictions about the influences of exposure to thin model cues on the dieter's commitment to obtain a thinner self and on her identity construction. According to research on modern identity, it has shifted "from a fixed set of characteristics determined by birth to a reflexive, ongoing, individual project shaped by appearance and performance" (Zukin and Maguire 2004, p. 180). That is, a person's sense of self is guided, constantly refined, and updated by what happens, as well as what he or she has done and hopes to become. Individual success or failure in achieving the goal of losing weight thus should have direct consequences for identity building.

\subsubsection{Current Research}

We investigate whether being exposed to a very thin model decreases the motivation to lose weight and triggers disengagement from the goal (prediction I) or increases that motivation and fosters goal-consistent behavior (prediction II). In this research we focus on normal to moderately overweight women who view very thin model cues, a common situation in everyday life. We specifically include dieters as participants, because they appear most susceptible to thin model cues as a result of their efforts to obtain a thinner self (Wegner 1994; Wheeler and Berger 2007). Because exposure to thin models might result in more food intake (Mills et al. 2002), which increases the discrepancy between current selves and the desired end state, it becomes especially relevant to explore how the motivation to attain a thinner self evolves over time. Unlike existing research, we do not rely on a single exposure to a thin model but rather expose participants repeatedly to a thin ideal.

\subsection{STUDY 1}

We organized a weight loss program for students to explore whether repeated exposure to a thin model, rather than a neutral, dieting-related cue, influenced the dieters' motivation and success in reaching a thinner self. Specifically, we invited female students who wanted to lose weight to participate in a one-week program. They received an eating diary in which they were to note exactly what they ate after every consumption occasion (i.e., breakfast, lunch, dinner, and all snacks). Half the participants received a diary with a cover picture of a thin model (treatment); the other half used diaries with a neutral, dieting-related image of a measuring tape on the cover (control). To avoid any potential bias that might arise if only the control condition saw a process-related cue, we included the picture of the measuring tape within the diary provided to participants in the treatment condition. 


\subsubsection{Participants}

Dieting is especially common among young women (Morgan 2007), so our sample of female undergraduate students is highly appropriate. We sent an e-mail to all first-year female students and explained that we were looking for women who wanted to lose weight and would like to participate in a one-week weight loss program. They were told that they would receive $50 €$ for their participation. We recruited 54 female undergraduate students with an average age of 19.96 years (SD $=1.70$ ) who wanted to lose an average of $6.85 \mathrm{~kg}(\mathrm{SD}=4.15)$ and had an average $\mathrm{BMI}$ of 23.25 (SD = 4.00), which is near the upper bound of the normal and healthy BMI range (i.e., 18.5-24.9).

\subsubsection{Method}

Because losing weight is the top New Year's resolution for many people (Dorsett 2010), we considered the beginning of the (calendar) year a perfect time to conduct the study. Before the study began, participants completed an online questionnaire that collected some general information, then chose among four time slots to schedule their first meeting. This choice, unbeknownst to the participant, also assigned her to the treatment (i.e., model cue) or control (i.e., dieting-related cue) condition. Using participants' answers to the online questionnaire, we compared participants in the two conditions with respect to how many kilos they wanted to lose and their motivation to lose weight. None of the analyses indicated any significant differences (all Fs $<1$ ).

The weight loss program spanned one week. The available time slots allowed participants to participate in meetings at four different times during the day. Each meeting followed a strict procedure: the participants learned that many women want to lose weight but unfortunately often use extreme diets, pills, or medicine that may be effective in the short term but result in the so-called yo-yo effect in the long run. The researcher explained that in addition to limiting food intake, it was important for them to monitor their food consumption. Therefore, each participant received an eating diary and had to write down, for one week, everything she ate and drank. These diaries were created in cooperation with a renowned health center (Infraligne ${ }^{\circledR}$ ) that helps people lose weight. As we noted though, half of the diaries featured a thin model on the cover, with pictures of the measuring tape on the pages, whereas the other half showed the neutral, dieting-related picture on the cover and every note page. An instruction manual explained how participants should complete their diary and highlighted the importance of taking the diary with them and noting their consumption right away, including everything they ate or drank, without exceptions. At the end of the first session, the participants were weighed and received their eating diaries. They wrote their current weight and desired weight on the first page of the diary, and they were informed that they would be weighed again one week later. The researcher 
asked them to put on the same clothes during the second meeting, to ensure that differences in weight could not be attributed to lighter or heavier clothes. Participants also received a phone number that they could call any time with questions; we also sent them two e-mails and called them once to confirm they were writing down everything they ate and drank.

The second meeting took place exactly one week later. The participants first completed a questionnaire that we designed to investigate their perceived goal attainability ("I am able to work effectively toward my long-term goal"), motivation to write in their diary ("I was very motivated to write in my eating diary"), and appearance selfesteem (e.g., "I am dissatisfied with my weight" from the Appearance Self-Esteem Scale, Heatherthon and Polivy 1991). The items were measured on seven-point agreedisagree Likert scales. Then participants assigned a grade to their performance during the weight loss program (1-10, 10 being very good). Finally, each participant was weighed again, and this weight was written on the last page of the diary.

\subsubsection{Results}

Overall, participants were highly compliant with their diary entries. Six participants did not seem to take the weight loss program seriously and wrote only sporadically in their diary; we excluded them from the analysis. All other participants followed the rules explained in the manual and indicated that they carefully noted their consumption. This leaves 24 participants in the control condition and 24 in the treatment condition. We compared the two conditions on their $\mathrm{BMI}\left(\mathrm{M}_{\text {control }}=24.27, \mathrm{SD}=5.44 ; \mathrm{M}_{\text {treatm }}=\right.$ $22.70, S D=1.99)$, age $\left(M_{\text {control }}=19.71, S D=1.27 ; M_{\text {treatm }}=20.38, S D=2.02\right)$, kilos they want to lose $\left(M_{\text {control }}=7.13, S D=4.12 ; M_{\text {treatm }}=7.04, S D=4.13\right)$ and motivation to lose weight $\left(M_{\text {control }}=77.08, S D=15.53 ; M_{\text {treatm }}=83.23, S D=12.55\right)$. None of these analyses reached statistical significance (all $F s<1$ ) assuring equivalence between the two groups.

Perceived attainability. We assessed whether the treatment and control conditions differed in their perception of goal attainability. The analysis revealed a significant difference $(F(1,46)=6.29, p<.05)$ between the control condition $\left(M_{\text {control }}=5.08\right.$, $S D=1.50)$ and the treatment condition $\left(M_{\text {treatm }}=4.08, S D=1.25\right)$. Participants exposed to the thin ideal were less confident that they would be able to attain their goal than participants in the control condition. This finding is in line with our argument that exposure to thin models causes the goal to be perceived as more difficult to attain. However, the question remains whether this perception motivates or demotivates them to work toward their dieting goals.

Goal success. By adopting a broader time span, we can investigate participants' actual weight loss, which should signal their level of motivation to work toward their dieting goals. We subtracted the weight measured at the end of the week from their 
initial weight measured at the beginning of the study. To express the difference in weight not in absolute terms but in relation to participants' initial body weight, we divided the difference by their initial body weight. The comparison of the control condition $\left(\mathrm{M}_{\text {control }}=.87, \mathrm{SD}=1.08\right)$ with the treatment condition $\left(\mathrm{M}_{\text {treatm }}=-.23, \mathrm{SD}=2.11\right)$ reveals a significant difference $(F(1,46)=5.24, p<.05)$. Specifically, participants in the control condition managed to lose weight, whereas those in the treatment condition were less successful in achieving their goal; they even slightly gained weight. In turn, we can infer that participants exposed to the thin ideal consumed more food than participants in the control condition.

Because snacking (both too much and too often) contributes substantially to weight gain (Science Daily 2000), we compared the diaries of members of the control and treatment conditions according to the number of unhealthy snacks (e.g., chocolate, chips, cake, donuts) they consumed ${ }^{3}$. We define a snack as anything eaten between meals or after dinner. Participants in the treatment condition ate significantly more snacks $\left(M_{\text {treatm }}=10.45, S D=9.03\right)$ than participants in the control condition $\left(\mathrm{M}_{\text {control }}=5.91, \mathrm{SD}=4.47 ; \mathrm{F}(1,46)=4.89, p<.05\right)$. We acknowledge however that this finding does not necessarily indicate that they consumed more calories, because this measure did not include calorie amounts.

Thus, we conducted a further analysis to compare the number of calories in eaten, unhealthy snacks. Three independent judges checked the number of calories in each snack listed in the diaries and calculated the total number of calories consumed over the week ${ }^{4}$. The participants in the treatment condition $\left(\mathrm{M}_{\text {treatm }}=1284.75, \mathrm{SD}=\right.$ 1023.15) consumed significantly $(F(1,46)=4.92, p<.05)$ more calories than those in the control condition $\left(M_{\text {control }}=754.15, S D=571.08\right)$, which explains why they gained weight. Thus, the weight loss program that showed them a picture of a very thin model did not help them decrease the discrepancy between their actual weight and their desired weight but instead increased it even more.

The question that arises is whether the consumption of calories was different from the offset or whether this difference appeared over the one-week period. Accordingly, we compared the amount of calories that participants in the treatment condition versus in the control condition consumed in the beginning (days 1 and 2) and at the end (days 7 and 8) of the week. We found no significant difference initially: participants in the treatment condition consumed snacks containing 122 calories on average $(S D=199.19)$, and participants in the control condition consumed snacks containing

\footnotetext{
${ }^{3}$ We asked three independent judges to count the number of snacks consumed by each participant. The results of all judges were highly correlated $(r=.846, r=.745 ; p<.001)$. Consequently, we added the scores and calculated the average.

${ }^{4}$ To determine the number of calories in each snack, the judges used the following web pages: www.caloriecount.com, www.dietbites.com, and www.livestrong.com. Their results were highly correlated $(r=.856, p<.001)$, so we used the average for our analysis.
} 
around 88 calories ( $S D=134.19 ; \mathrm{F}<1$ ). However, we uncovered a significant difference at the end of the week, such that the control condition participants consumed an average of 60 calories (SD $=111.13$ ), whereas the treatment condition consumed an average of 174 calories $(S D=205.14 ; F(1,46)=6.04, p<.05)$. Although this finding is surprising, considering that the participants were trying to lose weight, it is in line with our finding that they perceived the dieting goal as less attainable. Because expectancies for eventual attainment of a particular goal can determine whether people persist or disengage (Carver and Scheier 1998), and the treatment condition caused the goal of losing weight to appear unattainable, the participants considered it reasonable to stop putting effort into their goal of losing weight.

Self-evaluation. To assess whether participants exposed to the thin model, who performed significantly worse than members of the control condition, are aware of their bad performance, we compared the conditions with respect to the grade that participants assigned themselves. Participants in the treatment $\left(\mathrm{M}_{\text {treatm }}=7.25, \mathrm{SD}=\right.$ $1.42)$ and control $\left(M_{\text {control }}=7.21, S D=1.95\right)$ conditions assigned almost identical grades to themselves $(F(1,46)=.007, N S)$. That is, participants exposed to the thin model did not realize that the model cue negatively influenced their eating behavior, in line with extant research on goal activation (Chartrand, Huber, Shiv, and Tanner 2008), which states that situational cues influence goal-consistent or inconsistent behavior without people's awareness. This finding is striking: were participants in the two conditions really pursuing the same goal throughout the week? We might argue that participants exposed to the thin model simply revised their goal downward when they perceived that their initial target was not attainable. The questionnaire that participants had to complete at the end of the study included a question that asked explicitly whether participants had changed their desired weight; only three respondents (two in the treatment condition) indicated that they revised their goal (downward). Thus, participants in the treatment condition did not consciously revise their goal and assess their performance according to this newer, more attainable target.

\subsubsection{Discussion}

The results of Study 1 reveal that repeated exposure to a thin model, rather than a dieting-related cue, triggers perceptions of a weight loss goal as unattainable. Existing research similarly demonstrates that people are more confident about attaining goals that require less work to complete (Tubbs, Boehne, and Dahl 1993). An extremely thin model represents a desired end state that is distant from the current self. The large discrepancy between the actual self and the thin model then signals the significant effort required to achieve the desired ideal, triggers people to engage in goalinconsistent behavior (i.e., consuming unhealthy snacks) and makes them less successful in losing weight. 
Accordingly, Study 1 provides evidence in support of our prediction I: being confronted with a thin model prompts dieters to disengage from the goal of losing weight. These findings negate the account provided by Shiv and Sela (2009), who argue that the model cue encourages people to reach their goal by representing a distant, desired end state (prediction II). The very large discrepancy between the dieter's actual self and the thin model might underlie this finding; if this distant model cue appears out of reach, it likely triggers the sense of unattainability. Instead, prediction II might hold for distant goals that still seem attainable. In Study 2, we assess the assumption that perceived attainability is responsible for the negative effect of exposure on goal success.

\subsection{STUDY 2}

For this study, we explicitly manipulate model thinness: the treatment condition features a very thin model (different from the one used in Study 1), whereas the control condition includes the same model, adjusted to look normal sized. We used Photoshop ${ }^{\circledR}$ tools to alter some body parts (i.e., arms, belly, legs, and face) of the thin model, so that the model looks normal rather than extremely thin. Thus, we can test whether exposure to a model as such or only exposure to an unrealistically thin model triggers the perception of an unattainable goal and causes a lack of motivation.

The findings from Study 1 also suggest that perceived attainability determines whether people engage in goal-consistent behavior that pushes them toward their desired end state. Following this reasoning, we might expect that perceived attainability mediates the effect of exposure to the thin model on participants' weight loss, though our mediation tests revealed no significant effect. Our measure of attainability ("I am able to work effectively toward my long-term goal") was rather broad, without explicitly citing the perceived difficulty of losing weight, so for Study 2, we measure attainability more precisely ("It is unrealistic for me to expect to reach my goal of losing weight") to determine the potential for mediation.

Our experimental design also helps us address a possible alternative explanation for the Study 1 results: being presented with a thin model might have evoked an outcome focus, whereas the dieting-related cue (i.e., measuring tape) might have activated a process focus. Existing research indicates that a process focus results in different levels of performance than an outcome focus. Gollwitzer and Brandstätter (1993) show that people complete difficult goals approximately three times more often when they adopted an implementation intention ("I intend to perform goal directed behavior $y$ when I encounter situation $z$ ") rather than merely goal intentions ("I intend to achieve $\left.x^{\prime \prime}\right)$. Similarly, Pham and Taylor (1999) demonstrate that students study more and earn better grades when they focus on processes rather than outcomes. Thus, perhaps the process focus stimulated by the measuring tape in the Study 1 control condition more 
effectively drove participants toward the goal of losing weight than did the outcome focus prompted by the thin model. If we can replicate our findings when both conditions feature the same model, differing only in the thinness, we can rule out this explanation.

Finally, we explicitly asked participants in Study 1 to monitor their food consumption behavior. The strict monitoring they experienced might have made them more aware of their consumption behavior. Thus in Study 2, we did not mention that the diaries had to be handed in but rather left participants with the impression that the diaries would be only for their personal use. Nor did we call or e-mail them during the week; we only indicated they could contact us with any questions or problems.

\subsubsection{Participants}

Similar to Study 1, we sent an e-mail to female undergraduate students and explained that we wanted to recruit female students who wanted to lose weight to participate in a one-week weight loss program, for which they would receive $50 €$. As a first requirement of participation, they had to complete an online questionnaire, which we used to prescreen participants with respect to their current weight and dieting intentions. We recruited 42 female undergraduate students who expressed a wish to lose weight. The online questionnaire showed that they are 20.98 years of age on average (SD $=1.41$ ), that they wanted to lose an average of $4.82 \mathrm{~kg}(\mathrm{SD}=4.61)$, and that they had an average BMI of $22.5(\mathrm{SD}=3.94)$, which lies at the upper boundary of the normal and healthy $\mathrm{BMI}$ range.

\subsubsection{Method}

We conducted this weight loss program in the last week of November; the study solicitation communicated that we were looking for students who wanted to shape up for the holiday season by losing some weight. Before the actual study began, participants completed the same online questionnaire as in Study 1 to provide general information and choose a time slot, which assigned them randomly to the treatment (i.e., thin model cue) or control (i.e., normal model cue) condition. This results in 24 participants in the treatment condition and 18 in the control condition. We again used participants' answers to the online questionnaire to compare the two conditions on their $\mathrm{BMI}$ $\left(M_{\text {control }}=22.52, S D=2.18 ; M_{\text {treatm }}=22.57, S D=4.91\right), A g e\left(M_{\text {control }}=20.78, S D=1.44\right.$; $\left.M_{\text {treatm }}=21.12, S D=1.39\right)$, Kilos they want to lose $\left(M_{\text {control }}=4.64, S D=28, M_{\text {treatm }}=\right.$ $4.96, S D=5.73)$ and motivation to lose weight $\left(M_{\text {control }}=79.57, S D=10.44 ; M_{\text {treatm }}=\right.$ $75.57, \mathrm{SD}=13.82$ ). None of these analyses reached statistical significance (all Fs $<1$ ) assuring equivalence between the two groups. 
The weight loss program took one week, and each meeting followed the same procedure as described for Study 1 . However, we did not stress explicitly that it was important for the participants to keep their eating diary precisely. After the introduction to the study, all participants received an eating diary. In the treatment condition, they received a diary that featured the thin model, whereas in the control condition, they saw a slightly bigger version of the same model.

A pretest $(n=35)$ confirmed that the thin model $\left(M_{\text {treatm }}=5.8, S D=1.38\right)$ was perceived as significantly thinner than the normal model $\left(M_{\text {control }}=4.8, S D=1.50 ; F(1,56)\right.$ $=6.81, p<.05)$. However, it revealed no significant difference in attractiveness ratings of the thin model $\left(M_{t}=5.46, S D=1.45\right)$ and the normal model $\left(M_{\text {control }}=5.70, S D=\right.$ $1.37 ; \mathrm{F}(1,56)=.41, p=\mathrm{NS})$. Nor did the pretest participants indicate any differences in how much participants desired to look like the thin model $\left(M_{\text {treatm }}=4.35, S D=1.62\right)$ or the normal model $\left(\mathrm{M}_{\text {control }}=4.23, \mathrm{SD}=1.50 ; \mathrm{F}(1,56)=.092, p=\mathrm{NS}\right)$.

Participants were weighed at the end of the first session, with their current and desired weight written on the first page of their diaries. Exactly one week later, the second meeting took place, in which we measured their perceived goal attainability ("It is unrealistic for me to expect to reach my goal of losing weight") explicitly to explore the potential mediating effect. Finally, at the end of the session, each participant was weighed, with her weight written on the last page of the diary.

\subsubsection{Results}

Perceived attainability. We assessed whether the two conditions differed in their perception of how attainable the goal is; this analysis revealed a marginally significant difference $(F(1,40)=63.87, p<.06)$ between the control condition $\left(M_{\text {control }}=2.17, S D=\right.$ $.86)$ and the treatment condition $\left(M_{\text {treatm }}=3.04, S D=1.73\right)$. Participants exposed to the thin model were less confident that they would be able to attain their goal than participants who confronted the normal model.

Goal success. In line with Study 1, we examined participants' success in achieving their goal to lose weight. We subtracted their weight at the end of the week from their initial weight, then divided the difference by their initial body weight. The comparison of the control $\left(\mathrm{M}_{\text {control }}=.01, \mathrm{SD}=.009\right)$ and treatment $\left(\mathrm{M}_{\text {treatm }}=.003, \mathrm{SD}=.013\right)$ conditions shows a significant difference $(F(1,40)=6.56, p<.05)$. The control condition managed to lose weight, but the treatment condition was not very successful and did not lose weight.

Mediation analysis. As indicated, we intended to test whether perceived attainability mediated the effect of our manipulation on goal success. As suggested by Zhao, Lynch, and Chen (2010), we did not follow the Baron-Kenny "three tests + Sobel" steps but the bootstrap test of the indirect effect to establish mediation. The results re- 
vealed a positive and significant mean indirect effect $(a \times b=.0022)$, and the $95 \%$ confidence interval excluded zero (.0051 to .0001).

\subsubsection{Discussion}

The results from our second weight loss program study consistently revealed that dieters exposed to a thin model did not succeed in losing weight, whereas those exposed to a normal-sized model were able to do so. These results add to and advance the findings from Study 1 in four main ways. First, they demonstrate that it is not exposure to a model as such that causes dieters to be less successful in attaining their goal but rather being confronted with a very thin model. Second, the perceived attainability of the dieting goal drives the effect; being exposed to a thin model decreases the perceived attainability of the desired end state and thereby fosters disengagement from the goal. Measuring perceived attainability more directly, as in Study 1, helped establish perceived attainability as the underlying mechanism. Third, we replicated our results even without closely monitoring the participants, which confirms the robustness of this effect. Even if participants did not worry that their diary entries would be checked, the same effects emerged in terms of goal success. However, because we did not state explicitly that the diaries were part of the study, we could not track the effect of exposure to the model cues on actual food consumption in Study 2. Fourth, using a different model generalized our findings, because it showed that it was not the appearance of the model herself but rather the perception of her thinness that exerted the negative effect on dieters' motivation to lose weight.

\subsection{GENERAL DISCUSSION}

Existing research has demonstrated repeatedly that exposure to thin models influences dieters' self-esteem, motivation to diet, and eating behavior, though only by testing single exposures and immediate assessments of motivational and behavioral consequences. We extend this research stream by showing that it is important to explore the consequences of exposure to thin model cues over time. In line with existing research, we have offered two contradictory predictions about the effects of constant exposure to a thin model on people's commitment to obtaining a thinner self. The findings of two separate weight loss program studies provide support for our prediction I. Repeated exposure to a thin model fosters disengagement from the goal. Specifically, in Study 1 we showed that dieters exposed to a thin model eat more unhealthy snacks than dieters exposed to a neutral dieting-related cue, which not only prevents them from getting closer to their goal of losing weight but even causes them to gain weight. With Study 2 we added to and advanced these findings by showing that it was specifically exposure to a very thin model that triggered the perception of the goal as 
unattainable. Participants exposed to a very thin model perceived their weight loss goal as less attainable than participants exposed to a normal model and therefore did not manage to lose weight, whereas their counterparts exposed to a normal model came closer to their desired weight.

These findings extend previous research on exposures to thin models in at least three important ways. First, existing research predominantly relies on shifts in selfesteem to explain the consequences of these exposures on behavioral outcomes. We adopt a goal perspective and thereby highlight that exposure to a very thin model changes the dieter's belief about the very attainability of a thinner self. Our findings reveal that the perception that a goal is unattainable demotivates dieters from investing effort in achieving the goal and causes them to disengage from the goal. Similarly, existing goal research demonstrates that low expectancies of attainability cause people to recognize that their continued investments of time and effort are unlikely to pay off, such that they give up on that particular goal (Carver and Scheier 1998). Although the omnipresence of thin models in contemporary marketing environments fosters desires for a thinner self, it simultaneously hampers the search for an ideal identity. That is, women adopt the thin ideal but also recognize it as difficult to attain, so they disengage from weight loss goals. Self-identity research also suggests that people can build a stock of knowledge about themselves and develop multiple self-schemata (Markus 1977), perhaps by thinking of recent experiences of success or failure they have had and the implications of those experiences for future possibilities (Baumeister 2010). We add to this research by showing that exposure to thin models alters the importance that people attach to some self-schemata and the actions needed to obtain this ideal self. In Study 1, for example, participants in the control condition ( $M_{\text {control }}$ $=5.33$ ) reported higher commitment to their dieting goals than participants in the treatment condition $\left(M_{\text {treatm }}=4.52 ; F(1,46)=4.26, p<.05\right)$. The latter engaged in more goal-inconsistent behavior (i.e., eating unhealthy snacks) after repeated exposures to a thin model, which implies that constant confrontation with an ideal self decreases people's motivation to achieve it.

Second, unlike existing studies, we have investigated the effect of repeated exposures to thin model cues over a longer time span. Goals such as losing weight cannot be achieved immediately, so our tests of the effect of exposure to thin models on motivation to lose weight are more realistic. The longer time span enables us to investigate effects on actual weight fluctuation; we can reveal the surprising finding that repeated exposures to thin models while dieting decreases dieters' success. Our study context is realistic (i.e., normal to moderately heavy women exposed to very thin model cues), and our findings imply that the prevalence of extremely thin model images in consumer culture is contributing to rising obesity rates. In this sense, our results add to the current debate on obesity and its causes (Flegal, Carroll, Ogden, and Curtin 
2010), with important consequences for companies, policy makers, and legislative bodies. For example, being exposed to thin images in shows such as America's Top Model commercials for diet-related products, and women's magazines makes it even harder for dieters to reach their ideal identities. In that sense, policy makers might consider imposing boundaries on how thin models depicted in these settings should be.

Our study also achieves good realism because consumers are frequently exposed to thin model cues. For example, a female consumer with a weight loss goal likely confronts a thin model on the packaging of her low-fat breakfast cereal, a multitude of very thin models as she reads a magazine during her lunch break, and more very thin models as she watches TV while preparing her dinner. Our study design, in which participants wrote in their eating diary every time they consumed something, thus resembles reality in that participants were repeatedly exposed to the thin model cue both before and after their consumption situations.

Third, we contribute to research on the influence of exposure to thin models by highlighting that it results in overeating, outside a laboratory setting. Other than one might expect, dieters do not compensate for indulging (Dhar and Simonson 1999; Novemsky and Dhar 2005), due to their exposure to thin models, by eating less in subsequent consumption situations but rather seem to keep eating, as Study 1 showed. These results may imply a "what the hell effect" (Cochran and Tesser 1996), such that increased food intake resulting from exposure to a thin model cue (Mills et al. 2002) gets interpreted as an indication of failure by dieters. Then re-exposure to the thin model when writing in the diary likely makes this initial lack of progress more salient and fosters such defeatist thinking, licensing the dieters to indulge further. This explanation accords with research that demonstrates that overly difficult goals are counterproductive (Soman and Cheema 2004). If strivers fail, they suffer demotivation and poorer performance than people who never considered the goal. In our treatment conditions, participants might have interpreted their increased food intake as a failure to achieve their goal, which reduced their commitment to it. Being confronted with an extremely thin model does not motivate individuals (prediction II) but rather fosters disengagement from the goal.

As do all studies, the present research needs to be interpreted in the context of its limitations. First, the attractive model on the diary cover in Study 1 could have increased participants' motivation to write in their diary, such that the treatment condition participants would have provided more detailed, explicit descriptions of how much and what they consumed. However, this alternative reasoning cannot explain the difference in weight loss/gain or the fact that we did not find a difference in participants' motivation to write in their diary. Second, Mills et al. (2002) have shown that restrained eaters experience a self-esteem boost after being exposed to thin media 
images, so perhaps participants in the treatment condition in Study 1 considered themselves more attractive after being exposed to the thin model and no longer experienced a need to lose weight. This alternative account could explain the decreased commitment to dieting goals, yet the comparison of the two conditions on their selfesteem (Heatherton and Polivy 1991) showed no significant difference. We assume that this deviation from extant research reflects the longitudinal nature of our study: Exposure to a thin media image might boost dieters' self-esteem immediately, but there seems to be no long-term influence.

Finally, our study suggests several directions for research. For example, selfidentity literature has shown that recent experiences of success or failure help people update their self-views (Baumeister 2010); failing to inhibit food intake might imply the difficulty of reaching a thin ideal and cause people to look for alternative ideals to boost their self-image (Rudman, Dohn, and Fairchild 2007). Additional research should search for compensatory mechanisms and explore whether people might try to compensate for their lack of motivation to lose weight by, for example, studying harder.

Further research also could explore the consequences for marketers and companies that advertise dieting or low-fat products using thin models. Consider, for example, a dieter who consumes a low-fat product featuring a thin model on the cover: does she attribute her lack of success in attaining her weight loss goal to the product and thus refrain from purchasing it again? Our research suggests that advertising campaigns or package designs that feature thin models might be counterproductive and hamper weight loss success, such that they even could foster dissatisfaction with the product. 


\title{
4 RESTRICTION CUES
}

\author{
MERELY ENCOUNTERED, BUT STILL THREATENED; \\ WHEN LOW VARIETY ACTIVATES A NEED FOR FREEDOM
}

\subsection{ABSTRACT}

In this research, we examine the effect of mere exposure to limited assortment variety on consumers' variety-seeking behavior in a subsequent, unrelated decision. Four laboratory experiments consistently reveal that exposure to limited assortment variety (by means of an advertisement) as compared to high variety triggers significantly greater variety-seeking behavior in an unrelated decision. Based on reactance theory (Brehm 1966), we argue that mere exposure to limited assortment variety (without actually making a choice) is sufficient to prompt the feeling of restricted choice and trigger the need to reassure one's freedom of choice through variety seeking. We provide evidence for our explanation in light of reactance theory by means of moderation and mediation: first, the effect of mere exposure to limited assortment variety is pronounced for those individuals who had the desire to make a choice from the first assortment. Second, the effect of exposure to limited assortment variety on variety seeking is mitigated if individuals are given another means to offset the feeling of restricted choice (i.e., making another choice).

Keywords: choice restriction, limited assortment variety, variety-seeking behavior 


\subsection{INTRODUCTION}

Nowadays, retailers are convinced that consumers prefer large assortments (Kahn and Lehmann 1991) and, hence, mostly follow the conventional wisdom, "more is better" (lyengar and Lepper 2000) in an attempt to improve market share (Hoch, Bradlow and Wansink 1999). However, other retailers adopt an "efficient assortment" strategy by excluding low-selling products from the assortment (Kurt Salmon Associates 1993 in Kök and Fisher 2007). That is, they limit assortment variety purposefully in an attempt to find the profit-maximizing level of variety or trade off consumers' wish for variety against their need for convenience (Progressive Grocer 2004). For instance, Kroger $^{\circledR}$ stripped out about $30 \%$ of its cereal varieties (Brat, Byron, and Zimmerman 2009) and Wal-Mart ${ }^{\circledR}$ Stores halved the number of brands for microwaveable popcorn, resulting in a reduction of the total variety of this product by $25 \%$ (Prevor 2009).

Strikingly, when deciding on how much variety to offer in one product category, retailers commonly take into account how it influences consumers' attitude and behavior towards this particular product category. Similarly, existing research predominantly focuses on the influence of assortment variety (and its reduction) on sales (Broniarczyk, Hoyer, and Mc Alister 1998) or variety seeking behavior (Kahn 1995) in this particular product category. Importantly, this perspective does not take into account that assortment variety might constitute a cue that tells consumers how much choice is available and, thereby, might even influence a myriad of unrelated choices that the consumer subsequently engages in during a visit to a supermarket. Consider, for instance, a consumer who walks by a shelf with a limited variety of chocolate bars and then proceeds to make a choice from the adjacent shelf featuring potato chips. Will the exposure to the limited variety of chocolate (as compared to high variety) influence his/her choice of potato chips?

In this research, we mimic such situations and address the question whether being confronted with low variety assortments influences consumers' variety-seeking behavior in an unrelated, subsequent decision. While it is fundamental to explore the impact of assortment variety on decisions made from that specific assortment, we believe that it is equally vital to consider such wider implications as consumers routinely encounter assortments without making a choice from them (e.g., in advertisements, in a supermarket, or on billboards) but proceed with choosing from another, unrelated assortment.

Drawing on research that documents the importance of choice (Markus and Schwartz 2010, we posit that low variety assortments trigger the feeling that only little choice might be available. In line with reactance theory (Brehm 1966), we conjecture that feeling restricted triggers the need to engage in actions aimed at regaining the perceived loss in freedom. Variety-seeking behavior has been revealed as such a 
means (Levav and Zhu 2009) and, thus, we hypothesize that it increases after exposure to limited assortment variety.

The data from four empirical studies support our theorizing and offer converging evidence in support of these predictions. We believe that this research provides novel insights into the influence of assortment variety on variety seeking by highlighting that it even influences variety seeking in unrelated, subsequent decisions. This has important practical implications as it suggests that when deciding on the assortment variety in one product category retailers should be aware that it does not only influence consumer behavior towards this particular category but affects unrelated decisions as well. Theoretically, this research contributes to existing research on the importance of choice (Markus and Schwartz 2010) as well as reactance theory (Brehm 1966; Brehm and Brehm 1981) by demonstrating that mere exposure to cues that signal restricted choice-without actually being restricted in one's choice-triggers actions aimed at regaining one's personal freedom. Furthermore, this investigation hopes to advance the general understanding of what motivates variety-seeking behavior. While Levav and Zhu (2009) demonstrate that consumers react to spatial confinement with seeking more variety, our research highlights that also exposure to restricted choice triggers variety seeking as a means to regain one's freedom. Our research extends this existing research by suggesting variety seeking as a reaction to any kind of restriction; not only physical as Levav and Zhu (2009) point out but also psychological.

\subsection{CONCEPTUAL FOUNDATIONS}

\subsubsection{The Desire for Choice}

It is well established that individuals value the choices they have and even constantly try to expand them (lyengar 2010). Further, converging evidence suggests that choice is highly desirable (Leotti, lyengar, and Ochsner 2010; Patall, Cooper, and Robinson 2008) and humans demonstrate a preference for choice over non-choice even when the choice as such is trivial and confers no additional reward (Bown, Read, and Summers 2003). This implies that choice itself has positive affective associations. In line with this, research in neuropsychology demonstrates that not only the act of making choices but even merely the anticipation of choice is associated with increased activity in a network of brain regions thought to be involved in rewarding (Leotti and Delgado 2011). Specifically, the authors demonstrate that merely expecting a choice (relative to anticipating having no choice) feels rewarding. Unlike most of the decision-making literature concerned with understanding the value and consequences of specific choices, this suggests that the opportunity to choose regardless of its specific outcomes is already inherently rewarding (Leotti and Delgado 2011). This finding is in line with the idea that choice is a sign of freedom and that freedom has come to mean almost ex- 
clusively freedom of choice (Markus and Schwartz 2010). Since choosing allows people to express themselves as individuals and to experience themselves as active agents who control their own destinies (Markus and Kitayama 1991), choice-regardless of its outcome-represents freedom.

Following this, it is not surprising that in nearly every domain of daily life, individuals can frequently choose from assortments featuring a wide variety of styles, flavors and colors (Markus and Schwartz 2010). Assortment variety-whether there are limited versus wide assortments available (Chernev 2003, 2005; Gourville and Soman 2005; Kahn and Lehmann 1991)-has evolved to a synonym for choice (Broniarczyk 2008) so that the variety of different options available represents a cue for how much choice is offered. While high-variety assortments suggest freedom of choice, limited assortments might be associated with being restricted in one's freedom of choice.

\subsubsection{The Reaction to Restricted Choice}

While individuals find choice appealing, they are sensitive to situations in which their freedom of choice is restricted. Specifically, reactance theory denotes that people are motivated to restore restricted freedoms, and respond negatively to any attempt to constrain their personal freedom (Brehm 1966; Wicklund 1974). Personal freedom means possessing the opportunity to choose between a set of realistically possible behavioral alternatives, referred to as free behaviors (Brehm 1966). Whenever humans perceive a threat to lose this freedom or feel that any of their free behaviors is eliminated, they are motivated to restore this freedom and re-establish the eliminated or threatened behavior (Brehm 1966). For instance, individuals would rate a record as more desirable if they could not receive it as a gift and had to choose something else instead (Brehm, Stires, Sensenig, and Shaban 1966).

Inherent to this stream of research is the idea that restricted freedoms are met with backlash. Importantly, however, individuals' reaction to a restriction especially depends on its absoluteness (Laurin, Kay, and Fitzsimons 2012). If a restriction is nonabsolute (i.e., incomplete, uncertain or temporally limited), reactance will be triggered. Laurin, Kay and Fitzsimons (2012) demonstrated that individuals who read about an absolute restriction (i.e., the government had decided to reduce the municipal speed limits) reported more positive attitudes toward reduced speed limits compared to individuals who read about a non-absolute restriction (i.e., that the legislation would come into effect if a majority of government officials voted in favor of it). Accordingly, particularly situations in which individuals are not certain that the restriction will come into play, prompt their need to react and regain their freedom. This suggests that individuals might be especially likely to react to anticipated rather than actually experienced restrictions. This assumption is in line with the finding by Leotti and Delgado

(2011) that merely anticipating a choice is rewarding and raises the question whether 
mere exposure to cues that subtly hint at restricted choice has equally strong (negative) consequences and prompts individuals to regain their personal freedom.

Since choice is viewed as a form of exertion of control over one's environment (Snibbe and Markus 2005; Stephens, Markus, and Townsend 2007) and as a way to assert freedom (Kim and Drolet 2003, 2009), one can speculate that situations in which individuals feel restricted especially prompt the need for making a choice in an attempt to regain one's personal freedom. In this context, Levav and Zhu (2009) demonstrated that particularly variety-seeking behavior fulfills the means to regain one's freedom. Specifically, the authors demonstrated that people in relatively small confining spaces tend to display greater variety seeking in their choices to offset the feeling of threatened freedom. That is, individuals who walked through a small aisle chose more different candy bars (rather than choosing the same a couple of times) when allowed picking three candy bars of their choice than participants who walked through a wide aisle (Levav and Zhu 2009).

Taken this existing research together, we conjecture that assortment variety (i.e., wide versus limited variety) might not only influence decisions from the specific assortment. In addition, it might also function as a cue that suggests how much (or little) choice is available and, thus, influence behavior in subsequent, unrelated decisions because it is motivated by the desire to offset feelings of restriction. Specifically, in this research, we propose that mere exposure to limited assortment variety prompts the feeling of restricted choice and, hence, triggers the need for behavior aimed at regaining one's personal freedom (through variety-seeking behavior). The framework that we propose for understanding how assortment variety influences variety-seeking behavior in a subsequent, unrelated decision is illustrated in figure 4.1.

Figure 4.1: Conceptual Framework

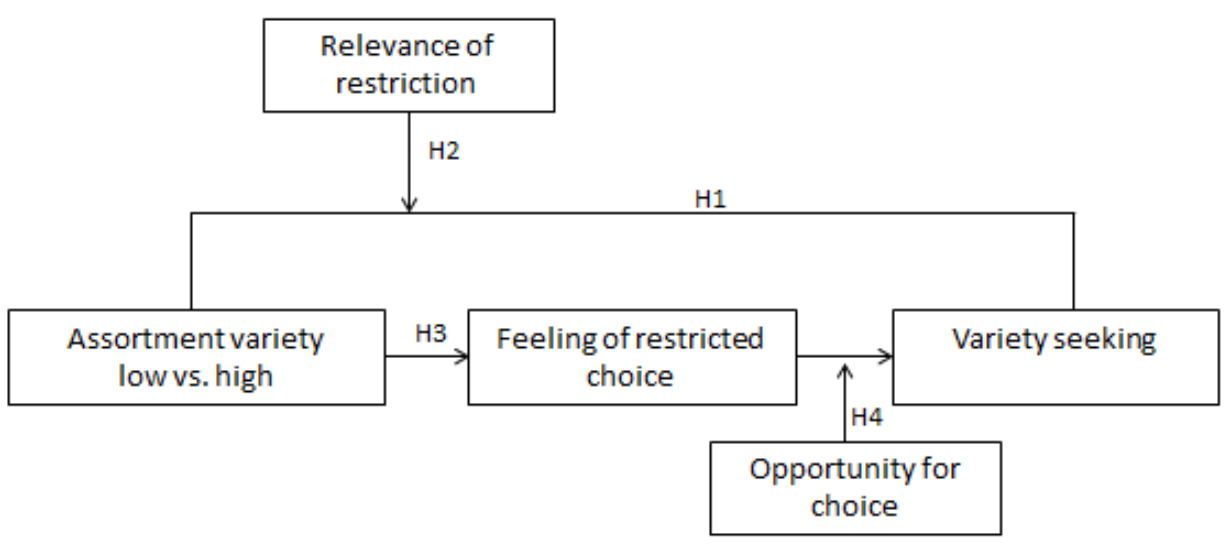




\subsection{HYPOTHESES DEVELOPMENT}

In the following, we intend to develop the hypotheses that link the constructs presented in our framework. First of all, we build on the idea that assortment variety has evolved to a synonym for choice (Broniarczyk 2008). If high-variety assortments suggest freedom of choice, it follows that limited assortments signal the opposite, namely restricted choice. Mere exposure to a limited assortment can be perceived as an anticipated restriction. Laurin, Kay, and Fizismons (2012) demonstrate that individuals are especially likely to react if restrictions are non-absolute; that is if they anticipate that their freedom might be restricted in the future. In line with this, we postulate that mere exposure to limited assortment variety similarly evokes the motivational state of reactance-even if individuals are not making a choice-and prompts individuals to engage in behavior aimed at regaining their personal freedom. Given that varietyseeking behavior fulfills a means to reassure one's personal freedom (Levav and Zhu 2009), we hypothesize:

H1: Mere exposure to low-variety assortments will prompt higher variety-seeking behavior in a subsequent unrelated decision than exposure to high-variety assortments.

Importantly, we base our argumentation for the main effect on reactance theory (Brehm 1966) and postulate that variety-seeking behavior functions as a means to offset one's feeling of restricted choice. Existing research on reactance theory reveals three distinct conditions that are met for reactance phenomena. Testing whether these conditions apply helps establish our findings as consistent with a reactance-based account.

First, while initially, psychological reactance was considered to be merely a function of the situation rather than a function of the individual, it is established that reactance is a motivational process and, hence might differ from individual to individual (Kay, Whitson, Gaucher, and Galinsky 2009; Laurin, Kay and Fitzsimons 2012; Wortman and Brehm 1975). Reactance should emerge in particular in response to restrictions seen as relevant. Said differently, individuals should not be motivated to react against restrictions that are irrelevant to them (Laurin, Kay, and Fitzsimons 2012). We deviate from this that the effect of limited assortment variety on variety-seeking behavior should be especially pronounced for individuals that perceive the restriction cue as relevant. That is, those individuals who desired to make a choice from the assortment presented to them will perceive the restriction as relevant and, hence, should be especially likely to react with greater variety seeking in a subsequent decision if reactance explains our effect. Following this reasoning, we hypothesize: 
H2: The effect of mere exposure to low-variety assortments on subsequent, unrelated variety-seeking behavior is strengthened for those individuals who desired to make a choice from the assortment but attenuated for those individuals who did not desire to make a choice from the assortment.

Second, the theory of psychological reactance states that people react against threats to their freedom of choice (Brehm 1966) and that the arousal of such reactance creates a motivation to reassure the threatened freedom. While choice enables each individual to pursue precisely those objects that satisfy his/her preferences best, situations of restricted choice mean that an individual is deprived of the opportunity to choose something that fits his/her needs best (Markus and Schwartz 2010). That is, while wide assortment variety signals freedom of choice, limited assortment variety, on the contrary, is associated with restricted choice. Given that individuals interpret their world in terms of choice (Savani et al. 2010) and are sensitive to situations that prompt them to anticipate being restricted, it follows that mere exposure to limited assortment variety triggers the feeling of restricted choice and, hence, creates the motivation to reassert the threatened freedom. Following this argumentation, we suggest that the feeling of restricted choice mediates the effect of mere exposure to limited assortment variety on variety-seeking behavior. We hypothesize:

H3: The feeling of restricted choice mediates the effect of mere exposure to assortment variety on variety-seeking behavior in a subsequent, unrelated decision.

Third, reactance theory (Brehm 1966) establishes that individuals attempt to regain their freedom by engaging in behavior similar to the behavior that has been threatened. Since limited assortment variety threatens individuals' ability to freely choose what they like, this implies that they develop an increased need for choice. Choosing has been revealed as a way to assert freedom (Kim and Drolet 2003) and particularly variety-seeking behavior fulfills the means to regain one's freedom (Levav and Zhu 2009). Importantly, this implies that variety seeking is just one means to offset the feeling of restricted choice and should be mitigated if individuals are given any other opportunity to regain their freedom. Since choosing in general has evolved to a sign for freedom (Markus and Schwartz 2010) merely the possibility of making a choice might constitute a means to reassure one's personal freedom. Accordingly, we argue that providing individuals with the possibility to make a choice after the exposure to limited assortments and before they can seek variety will mitigate the effect. We hypothesize: 
H4: If participants exposed to low-variety assortments have the opportunity to make a choice, they will seek less variety afterward than when they did not have the opportunity to make a choice before.

In the following section we present four laboratory studies intended to test our hypotheses. While the first study fulfills the purpose to test our main effect, the other three are designed to test the three distinct conditions that help establish our findings as consistent with a reactance-based account and set apart from alternative explanations.

\subsection{STUDY 1}

In Study 1, we test our first hypothesis that exposure to low-variety assortments triggers significantly greater variety seeking in a subsequent decision than exposure to high-variety assortments (H1). For this purpose, we expose participants to one of two advertisements that differ in the amount of variety that they present. While the highvariety advertisement depicts twelve different flavors; the low-variety advertisement shows only three different flavors but depicts each of them four times, to keep the total quantity shown constant. After exposure to the advertisement all participants make a subsequent, unrelated choice that enables us to measure their variety-seeking behavior.

\subsubsection{Participants and Design}

Study 1 used a two-cell (low vs. high variety) between-subjects design. Seventy-seven undergraduate students participated in exchange for course credit. We utilized an advertisement for Milka ${ }^{\circledR}$ chocolate and manipulated the variety of chocolate flavors that participants saw. A pretest $(n=33)$ ensured that the advertisements correctly presented either high or low variety. Participants who saw the high-variety advertisement were significantly more likely to agree, on a five-point Likert scale, with the statement, "The advertisement shows a high variety of different chocolate flavors" $\left(M_{\text {high }}=4.83\right.$, $\mathrm{SD}=.38)$, than were participants in the low-variety condition $\left(\mathrm{M}_{\text {low }}=2.20, \mathrm{SD}=.78\right.$; $\mathrm{F}(1,31)=161.36, p<.001)$. The low-variety $\left(\mathrm{M}_{\text {low }}=2.80, \mathrm{SD}=.78\right)$ and high-variety $\left(\mathrm{M}_{\text {high }}=2.94, \mathrm{SD}=.80 ; \mathrm{F}(1,31)=.27, \mathrm{NS}\right)$ advertisements were equally liked.

\subsubsection{Materials and Procedure}

At the beginning of the laboratory session, the researchers informed the participants that they would evaluate a print advertisement. After they were seated in their cubicles (stocked with a computer), the participants received the advertisement as a colored printout and looked at it for one minute. Participants in the low-variety condition 
( $n=43$ ) viewed the advertisement showing three chocolate flavors (i.e., hazelnut, milk, and nougat), whereas participants in the high-variety condition $(n=34)$ considered twelve different chocolate flavors. In both advertisements, two hands each held six chocolate flavors, were shown on a simple violet background. Once participants had a careful look at the advertisements, they filled out an online questionnaire that fulfilled the purpose to get to know their opinion about the advertisement. They evaluated aspects of the advertisement, such as background and color, on a questionnaire. Afterwards, the respondents were informed that they could win one of several Sweet Boxes as a reward for their participation. For this purpose they were given a contest form (on paper) and could choose between different chocolate bars (i.e., Twix ${ }^{\circledR}$, Mars ${ }^{\oplus}$, Snickers ${ }^{\oplus}$, Balisto ${ }^{\oplus}$, or Kit Kat ${ }^{\oplus}$ ). They had to indicate behind each candy bar how many they would like to choose of this type. They were limited to choose five candy bars in total. Once they made their selection they were asked to place the form in an envelope to ensure privacy of the decision (Ratner and Kahn 2002).

\subsubsection{Results}

We measured participants' variety seeking by counting the number of different candy bars that participants indicated on the contest form. The more different candy bars were chosen, the higher participants' variety-seeking behavior. Note that three participants failed to complete all parts of the experiment and, hence, were excluded from the analysis. This leaves 40 participants in the low-variety condition and 33 in the highvariety condition. We conducted an ANOVA to compare the low-variety and highvariety condition on their variety-seeking behavior which revealed a significant main effect $(F(1,72)=5.45, p<.05)$. Participants who saw the low-variety advertisement sought significantly more variety $\left(\mathrm{M}_{\text {low }}=3.38, \mathrm{SD}=.84\right)$ than those who saw the highvariety advertisement $\left(M_{\text {high }}=2.91, S D=.87\right)$. Note that one participant expressed that he did not want to win the Sweet Box. Excluding this participant from the analysis only slightly changes the difference between the low-variety condition $\left(\mathrm{M}_{\text {low }}=3.38, \mathrm{SD}=\right.$ $.84)$ and the high-variety condition $\left(\mathrm{M}_{\text {high }}=2.91, \mathrm{SD}=.88, \mathrm{~F}(1,71)=5.35, p=.05\right)$.

\subsubsection{Discussion}

Study 1 provides initial evidence for our first hypothesis that exposure to low-variety assortments triggers significantly more variety-seeking behavior than exposure to highvariety assortments in a subsequent decision. We argue that exposure to the lowvariety advertisement triggers the feeling of restricted choice and fosters varietyseeking behavior as a means to reassure one's personal freedom. An alternative, simpler explanation is that individuals exposed to the low-variety advertisement engage in more variety seeking in the next instance merely to compensate their need for variety 
(Menon and Kahn 1995). In the following studies (2-4), we will provide evidence for our explanation in light of reactance theory and against this alternative account.

\subsection{STUDY 2}

In Study 2, we intend to test generalizability of our main effect $(\mathrm{H} 1)$ by utilizing different stimuli. That is, instead of chocolate advertisements, we make use of ice cream menus. In addition, we intend to provide evidence for our argumentation in light of reactance theory: specifically, if reactance explains why individuals seek more variety when exposed to a low-variety advertisement than high-variety advertisement, we should find that the effect of assortment variety on variety-seeking behavior is pronounced for those individuals that perceive the choice restriction as relevant $(\mathrm{H} 2)$. In this study, we test for an interaction effect with an indicator of motivational involvement (i.e., desire to make a choice) to obtain first proof for our argumentation in light of reactance theory.

\subsubsection{Participants and Design}

Ninety-one undergraduate students (51 males, $\mathrm{M}_{\mathrm{age}}=2.16, \mathrm{SD}=1.55$ ) participated in exchange for course credit. We randomly assigned participants to the low-variety $(n=46)$ or high-variety condition $(n=45)$ and exposed them to variety cues by the means of an ice cream menu. We made use of two types of ice cream menus that differed in the variety of ice creams they depicted. In the high-variety condition, the menu showed 14 different flavors and in the low-variety condition, the ice cream menu depicted three different ice creams.

\subsubsection{Materials and Procedure}

The procedure was similar to that of Study 1 . Participants were invited to the lab and seated in individual cubicles. Then they received the ice-cream menu as a print out. Depending on condition they either received the ice-cream menu with three different ice-cream flavors or the menu with fourteen different ice-creams. After looking at the ice cream menu, they filled out an online questionnaire to evaluate the menu. Specifically, they were asked how much they liked the menu and had to evaluate different features of it (e.g., slogan and design). Afterwards, they got to know that as a reward for their participation they could win a voucher for four pasta dishes at an Italian restaurant opposite of the university. Participants were given the possibility to choose which dishes they want from a form listing six different dishes (Spaghetti alla Bolognese, Spaghetti Carbonara, Spaghetti Con Gamberetti, Penne alla Nonna, Tagliateele Verdi con Bistecca e Prosciutto, and Pasta Chino Alla Marco Pollo). For each of the dishes they indicated how often they would like to choose it. They were limited to 
choose six dishes in total. To ensure privacy of the decision we asked them to place the form in an envelope (Ratner and Kahn 2002).

\subsubsection{Results}

In line with Study 1, we measured variety-seeking behavior as the number of different options that participants chose. Note that all dishes included meat and, hence, did not meet the needs for vegetarians. Thus, we excluded two vegetarians from the data set. Further, we had to exclude two participants from the analyses because they failed to fill out the online questionnaire that assessed their desire to make a choice from the ice-cream menu (i.e., moderating variable) leaving 44 participants (27 men; $M_{\text {age }}=$ $20.14, \mathrm{SD}=1.53)$ in the low-variety condition and $43\left(23\right.$ men; $\left.M_{\text {age }}=20.19, \mathrm{SD}=1.61\right)$ in the high-variety condition.

First, we test whether exposure to the low-variety assortment results in significantly more variety-seeking behavior than exposure to the high-variety assortment. In line with Study 1, comparing the two conditions with regard to their variety-seeking behavior revealed a significant main effect $(F(1,85)=3.95, p=.05)$. Participants who saw the low-variety advertisement sought significantly more variety $\left(\mathrm{M}_{\text {low }}=3.48, \mathrm{SD}=\right.$ $.85)$ than those who saw the high-variety advertisement $\left(M_{\text {high }}=3.07, S D=1.06\right)$.

Second, we explore whether our effect is moderated by an indicator of motivational involvement (i.e., the desire to make a choice from the ice-cream menu). An ANOVA with variety cue as the independent variable and "desire to make a choice" as the moderator revealed a significant interaction $\left(M_{\text {desire }}=3.75, \mathrm{SD}=1.25\right)$ effect between the two variables $(F(1,84)=10.89, p<.01)$. As suggested by Spiller, Fitzsimons, Lynch and McClelland (2013), we use floodlight analysis (i.e., Johnson-Neyman procedure) to probe the interaction (Hayes and Matthes 2009). This test reveals the results of a spotlight analysis for each and every value of "desire to make a choice." The region of significance for the low-variety advertisement is all values of the desire to make a choice equal to or lower than 1.34 (i.e., those that really did not want to choose an ice cream) and all values greater or equal to 3.72 (i.e., those that wanted to choose an ice cream). Note that for low values of the moderator beta is positive indicating that exposure to the choice restriction cue (i.e., menu with little choice) results in less variety seeking. On the contrary, for high values of the moderator beta is negative indicating that exposure to the choice restriction cue (i.e., menu with little choice) prompts variety-seeking $(t(87)=-3.29, p<.01)$. 
Figure 4.2: Variety Cue X Desire to Make Choice Interaction Effect

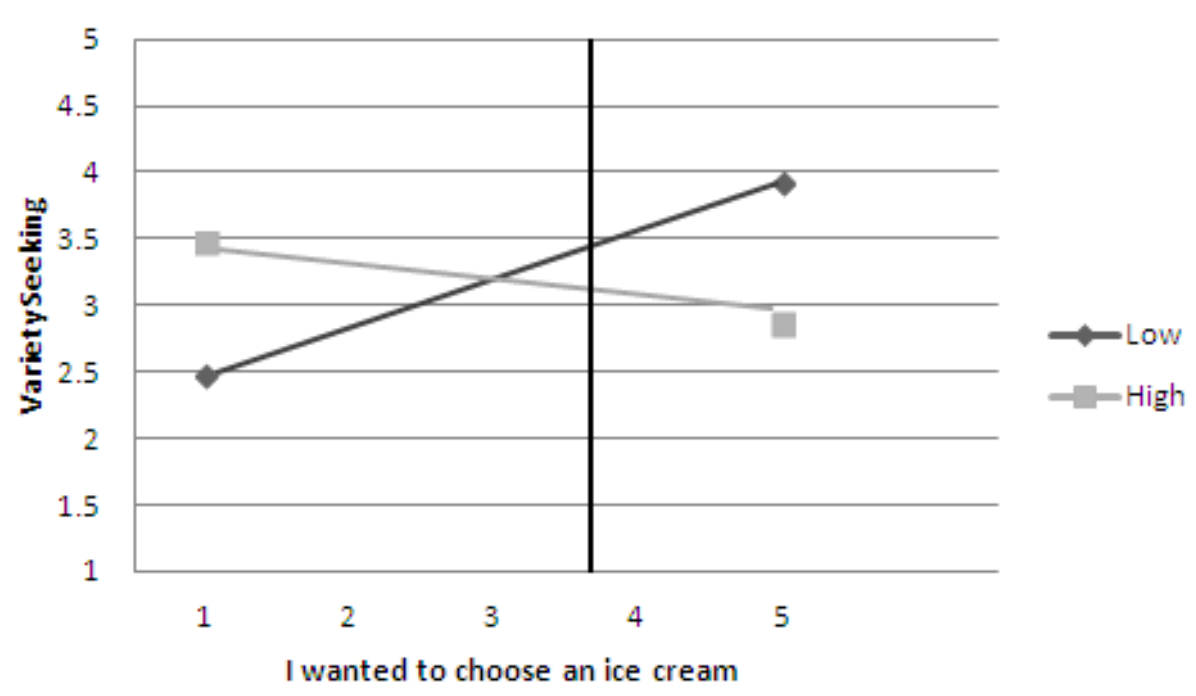

Note: Vertical line (3.72) represents region of significance per Johnson -Neyman technique.

\subsubsection{Discussion}

First, Study 2 provides further evidence for hypothesis 1 that mere exposure to lowvariety assortments compared to high-variety assortments evokes greater varietyseeking behavior in a subsequent decision. Utilizing a different cue (i.e., ice-cream menu) and asking participants to choose pasta dishes instead of candy bars, we replicate the effect of exposure to low-variety cues on variety-seeking behavior under slightly different conditions and, hence, demonstrate the robustness of the effect. Second, and more importantly, Study 2 provides first evidence for reactance as the driver of our effect. In line with Laurin, Kay, and Fitzsimons (2012), we tested for an interaction effect with an indicator of motivational involvement (i.e., desire to make a choice). Indeed, the effect of exposure to limited assortment variety on variety seeking was moderated by an indicator of motivational involvement (i.e., desire to make a choice) supporting hypothesis 2 .

While Study 2 provides first evidence for our argumentation in light of reactance theory by means of moderation, we intend to further shed light on the underlying mechanism by means of mediation. Specifically, we test whether the feeling of restricted choice mediates the effect of exposure to the low-variety assortment on variety seeking $(\mathrm{H} 3)$. 


\subsection{STUDY 3}

We argue that being confronted with low-variety assortments induces the feeling of restricted choice even if individuals are not asked to make a choice. Basically, we predict that merely being confronted with these cues triggers individuals to imagine how it would be to make a choice. The fact that they would feel restricted if they had to make a choice evokes a heightened need to offset this feeling and, hence, increases variety seeking. Study 3 fulfills the purpose to test this prediction (H3) explicitly by measuring participants' feeling of restricted choice.

\subsubsection{Participants and Design}

Sixty-nine participants (42 men; $M_{\text {age }}=28.88, S D=9.92$ ) participated in this study on Amazon Turk ${ }^{\circledR}$. We utilize the same advertisements as in Study 1 depicting a variety of different chocolate flavors. Participants were randomly assigned to the low-variety condition ( $n=33$ ) or the high-variety condition $(n=36)$.

\subsubsection{Materials and Procedure}

When entering the online survey, participants were informed that they have to look at an advertisement and afterwards evaluate it. On the next screen, participants were exposed to the advertisement which showed either three (i.e., low variety) or twelve different chocolate flavors (i.e., high variety) depending on condition. Afterward, participants were asked to evaluate the advertisement on several criteria (e.g., background, layout and slogan). Then, they were told that they would now continue with a seemingly unrelated part about candy bars. Specifically, participants were confronted with a choice set of five different options (i.e., $\operatorname{Twix}^{\circledR}$, Mars ${ }^{\circledR}$, Snickers $^{\circledR}$, Balisto ${ }^{\circledR}$, or Kit $\mathrm{Kat}^{\circledR}$ ) and asked to choose any five candy bars. They could choose one a couple of times or make a mixture of different ones. Importantly, they were limited to choose five candy bars in total. After the choice task, we asked participants to recall the advertisement that was shown to them in the beginning of the study and indicate how strongly they agree/disagree with the statement "If I had to make a choice, I would feel restricted" on a seven-point Likert scale ( 1 = strongly disagree, 7 = strongly agree).

\subsubsection{Results}

To explore whether exposure to the low-variety cue triggers greater variety-seeking behavior than exposure to the high-variety cue, we compared the two conditions on the variety of different candy bars chosen. An ANOVA revealed a significant difference between the low-variety advertisement $\left(\mathrm{M}_{\text {low }}=3.03, \mathrm{SD}=.88\right)$ and the high-variety advertisement $\left(\mathrm{M}_{\text {high }}=2.64, \mathrm{SD}=.723 ; \mathrm{F}(1,67)=4.08 p<.05\right)$. Further, to test our 
hypothesis that exposure to the low-variety advertisement would trigger the feeling of restricted choice, we compared our two conditions on the statement "If I had to make a choice, I would feel restricted." An ANOVA revealed a significant difference between the two conditions indicating that participants exposed to the low-variety advertisement $\left(M_{\text {low }}=3.00, S D=1.03\right)$ are significantly more likely to agree than participants exposed to the high-variety advertisement $\left(\mathrm{M}_{\text {high }}=2.00, \mathrm{SD}=.96 ; \mathrm{F}(1,67)=17.48, p<\right.$ .01). In a second step, we intend to test whether this feeling of restriction mediates the effect of assortment variety on variety-seeking behavior. As recommended by Zhao, Lynch, and Chen (2010), we did not follow the Baron-Kenny "three tests + Sobel" steps but the bootstrap test of the indirect effect to establish mediation. A mediation analysis with the feeling of restriction as the mediator demonstrates that this feeling explains why exposure to the low-variety advertisements prompt individuals to seek more variety than exposure to the high-variety advertisement since the bootstrap analysis revealed that the $95 \%$ confidence interval of the size of the indirect effect excluded zero (-.54 to -.010$)$ suggesting a significant indirect effect $(\mathrm{a} \times \mathrm{b}=-.26)$ (Preacher and Hayes 2004).

\subsubsection{Discussion}

Study 3 adds to the previous studies by providing further evidence for the underlying mechanism of our effect. Specifically, the mediation analysis reveals that the feeling of restricted choice explains why individuals exposed to the low-variety advertisement react with more variety seeking than those confronted with the high-variety advertisement. This confirms our third hypothesis that mere confrontation with low variety prompts individuals to imagine how it is when they would make a choice and, consequently, fosters the need to offset the feeling of restricted choice through variety seeking.

\subsection{STUDY 4}

Importantly, we argue that variety-seeking behavior functions as a means to regain one's personal freedom. Inherent to this argumentation is that variety seeking merely constitutes one possible reaction to offset the feelings of restriction and would be mitigated if participants are given another means to regain their freedom. We test this argumentation explicitly by means of a 2 (low versus high assortment variety) $x 2$ (choice: yes vs. no) between-subject design in which half of the participants make an unrelated choice before they fill out the variety-seeking measure. Specifically, we manipulate whether participants can choose a pen with which they want to write before they are given a reward form to measure their variety-seeking behavior. If individuals engage in heightened variety-seeking behavior to offset their feeling of restricted 
choice, making a choice in between should be sufficient to offset their feelings of restricted choice and, hence, mitigate the effect on variety seeking. Note that this set-up enables us to explicitly test our explanation in light of reactance against the alternative explanation that individuals confronted with the low-variety advertisement engage in greater variety-seeking behavior in the next instance merely to compensate their need for variety (Menon and Kahn 1995) rather than feelings of restriction. If this explanation holds and variety seeking indeed only helps individuals to compensate for the lack of variety presented on the advertisement making a choice should not be a sufficient means of compensation and the effect on variety seeking should prevail.

\subsubsection{Participants and Design}

One-hundred-fifteen undergraduate students ( 71 males; $\left.M_{\text {age }}=21.40, S D=1.69\right)$ participated in exchange for course credit. Again, in this study we use the chocolate advertisement presenting either low- or high variety as a cue to signal restricted choice. Participants are randomly assigned to the low-variety condition $(n=55)$ or high-variety condition ( $n=60)$. Further, participants are either assigned to the choice condition $(n=60)$ or the no-choice condition $(n=55)$.

\subsubsection{Materials and Procedure}

Consistent with Study 1 and 3, participants were randomly assigned to receive one of the two chocolate advertisements and looked at the print advertisement for one minute. Depending on the condition participants either saw three different chocolate flavors (i.e., low variety) or twelve different chocolate flavors (i.e., high variety). Afterward the print advertisement was taken away and participants were asked to fill out an online questionnaire evaluating aspects of the advertisement, such as background and color. Subsequently, participants were informed that they could win one of several Sweet Boxes as a reward for their participation. Unlike in our previous studies, participants were not given a pen at the beginning of the experiment. Instead, when handing them the reward form, a research assistant held a cup with Stabilo ${ }^{\circledR}$ pens of eight different colors (i.e., green, purple, black, red, turquoise, blue, brown, and light blue) in his hand. In the "no choice condition" the research assistant chose a pen (of basic color), handed it to the student, and said that he/she can keep this pen. In the "choice condition", on the contrary, the research assistant told the participant that they are free to choose a pen that they could keep. Afterward, all participants filled out the contest form selecting five candy bars of their choice out of five different options (i.e., Twix $^{\circledR}$, Mars $^{\circledR}$, Snickers ${ }^{\circledR}$, Balisto $^{\circledR}$, or Kit Kat $\left.{ }^{\circledR}\right)$. 


\subsubsection{Results}

We excluded one participant because he failed to complete the variety-seeking measure as well as 14 participants who did not understand they can keep pen. Specifically, in a follow-up questionnaire they indicated that they were not aware that the pen would be theirs. Further, four participants did not want to win the Sweet Box and, hence, were excluded from the analysis leaving 47 participants ( 25 males; 17 in nochoice condition) in the low-variety condition and 51 participants ( 35 males; 26 in nochoice condition) in the high-variety condition.

In line with our previous studies, we measured participants' variety-seeking behavior as the number of different candy bars they chose. An ANOVA revealed a (marginally) significant choice restriction cue $x$ choice interaction $(F(1,95)=3.25, p=.07)$. Planned contrasts showed that, consistent with the findings of our previous studies, in the no choice condition, participants who encountered the low-variety advertisement $\left(\mathrm{M}_{\text {low }}=3.53, \mathrm{SD}=.94\right)$ seek significantly more variety than those that encountered the high-variety advertisement $\left(M_{\text {high }}=3.00, S D=.80 ; F(1,95)=3.91, p=.055\right)$. On the contrary, in the choice condition there is no significant difference between participants who saw the low-variety advertisement $\left(M_{\text {low }}=3.03, S D=.93\right)$ and those that encountered the high-variety advertisement $\left(\mathrm{M}_{\text {high }}=3.24, \mathrm{SD}=1.23 ; \mathrm{F}=.50, \mathrm{NS}\right)$. Further, in the low-variety condition, variety-seeking behavior was higher for participants that could not choose a pen $\left(\mathrm{M}_{\text {lownoc }}=3.53, \mathrm{SD}=.94\right)$ than for participants that could choose a pen $\left(\mathrm{M}_{\text {lowc }}=3.03, \mathrm{SD}=.928 ; \mathrm{F}(1,95)=3.07, p=.08\right)$.

Figure 4.3: Variety Cue X Choice Interaction Effect

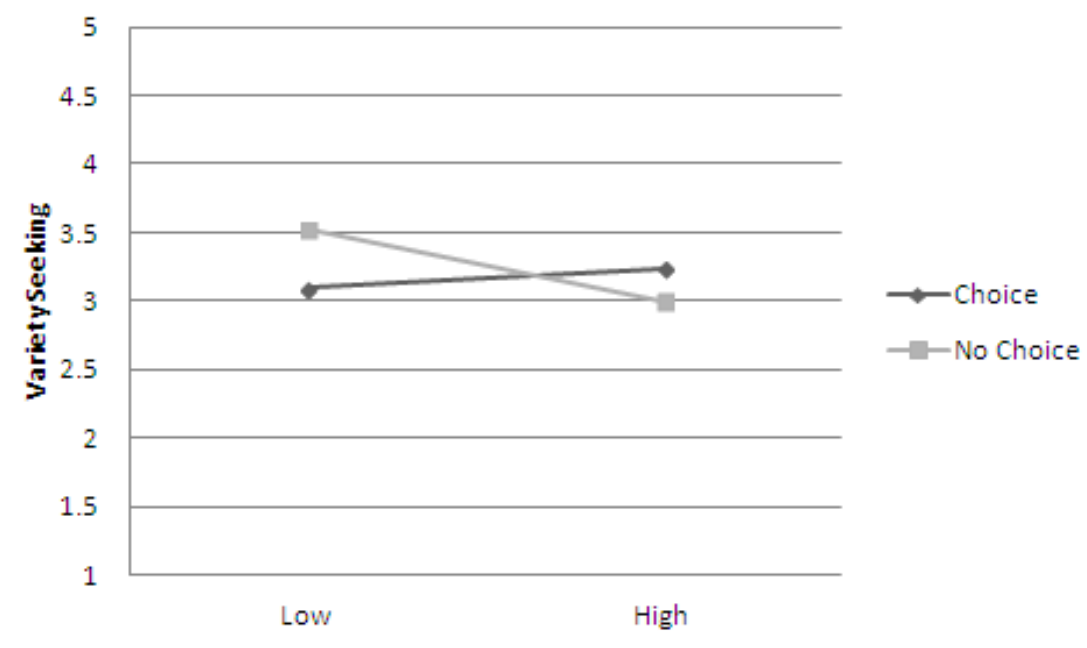




\subsubsection{Discussion}

Consistent with our predictions, choosing one's own pen before responding to the variety-seeking measure attenuates the effect of exposure to limited assortment variety on participants' subsequent variety-seeking behavior. First, this finding provides further evidence for our argumentation that mere exposure to low-variety assortments triggers reactance and prompts individuals to engage in behavior aimed at regaining their freedom. Second, this study helps rule out the alternative explanation that individuals confronted with the low-variety advertisement engage in greater variety-seeking behavior in the next instance merely to compensate their need for variety rather than feelings of restriction. If variety seeking would indeed only help them to compensate for the lack of variety presented on the advertisement making a choice should not have been a sufficient means of compensation and the effect on variety seeking should have prevailed.

\subsection{GENERAL DISCUSSION}

In this article, we tested the hypothesis that mere exposure to limited assortment variety triggers consumers' need to offset the feeling of restricted choice by seeking more variety in a subsequent, unrelated decision. We present the results of four laboratory studies. The first study documents our basic effect (H1): participants confronted with a low-variety advertisement (i.e., three different chocolate flavors) seek greater variety in a subsequent, unrelated choice than participants confronted with a highvariety advertisement (i.e., twelve different chocolate flavors). The remaining three studies fulfilled the purpose to thoroughly test our explanation in light of reactance theory. Each of them was designed to test one condition that should apply if reactance indeed explains why individuals seek more variety after exposure to the low-variety advertisement as compared to the high-variety advertisement. Specifically, in Study 2, we show an interaction effect between our manipulation (i.e., low versus high assortment variety) and individuals' desire to make a choice from the first assortment. In doing so, this study provides evidence for reactance as the driver of our effect since the effect of low-variety assortments on variety seeking was moderated by an indicator of motivational involvement (H2). Study 3 further links our findings to reactance theory by demonstrating that the feeling of restricted choice mediates the effect of exposure to a low-variety assortment on variety seeking (H3). Finally, in Study 4, we demonstrate that the effect is attenuated if participants are given the choice to select a pen before they engage in variety seeking $(\mathrm{H} 4)$. This helps rule out the alternative explanation that individuals confronted with the low-variety advertisement engage in greater variety-seeking behavior in the next instance merely to compensate their need for variety rather than feelings of restriction. 


\subsubsection{Theoretical Implications}

From a theoretical perspective, our work can be viewed in the context of research on assortment variety (Broniarczyk, Hoyer, and Mc Alister 1998; Chernev 2003; Kahn and Lehman 1991). Importantly, while this existing stream of research predominantly focused on the effect of assortment variety on decisions made from the specific assortment, this article is, to our knowledge, the first investigation into assortment variety as a cue that might influence subsequent, unrelated decisions. Taking research on the importance of choice (lyengar 2010; Leotti and Delgado 2011; Markus and Schwartz 2010) as a basis, we elucidate that individuals are equally sensitive to instances that signal restricted choice. Specifically, our finding that mere exposure to limited assortment variety triggers the feeling of restricted choice-even when individuals are not making a choice-complements research that documents the positive consequences of merely anticipating the opportunity for choice. While Leotti and Delgado (2011) show that merely anticipating a choice is rewarding, our research reveals that merely anticipating restricted choice triggers actions aimed at regaining one's personal freedom.

Note that in our investigation participants were merely presented with advertisements presenting limited versus high variety and had to evaluate the stimuli; that is, none of our studies included a reference to making a choice from the advertisement. Nevertheless, our findings highlight that participants automatically imagined making a choice and, hence, realized that they would feel restricted if they indeed had to choose an option. While existing research reveals that consumers constantly want to expand their choices (lyengar 2010), this finding demonstrates that at the same time they are on the lookout for situations that could restrict their freedom of choice. Further, our research adds to and advances research highlighting that the absoluteness of a restriction impacts individuals' reaction to it. Specifically, Laurin, Kay, and Fitzsimons (2012) show that especially non-absolute restrictions (i.e., the government might decide to reduce the municipal speed limit if the majority of the government officials votes in favor of it) trigger reactance. Note though that the restrictions (e.g., speed limits) tested by Laurin, Kay, and Fitzsimons (2012) are very different in nature to the restriction cue that we utilized: speed limits are legal restrictions that individuals have to comply with (Botti et al. 2008). Our restriction cue (i.e., assortment variety), on the contrary, represents a rather subtle form of (choice) restriction. The fact that even such subtle restrictions trigger individuals' need to reassure their freedom reinforces the idea that individuals are very sensitive to cues indicating restricted choice. This suggests that individuals might react similarly to other types of restrictions and raises the question whether our findings are, for instance, transferable to the scarcity effect. Many companies use scarcity appeals, such as "buy while stocks last," in sales promotions or on coupons or special offers (Inman and McAlister 1994). Such appeals trigger reactance and lead to enhanced value perceptions and purchase intentions toward 
products (Eisend 2008). Our findings imply that they might also trigger consumers to subsequently engage in greater variety-seeking behavior in an attempt to regain their threatened freedom.

Our empirical finding presents a novel antecedent for variety seeking by highlighting that variety-or the lack of it-can be restricting and liberating at the same time. Our findings show that exposure to limited assortment variety triggers the feeling of restricted choice and, hence, stimulates variety seeking as a means to offset this feeling. In doing so, our research adds to existing research that highlights variety seeking as a means to seek freedom when feeling spatially confined (Levav and Zhu 2009).

Importantly, our research focuses on the effect of one specific choice restriction cue (i.e., limited assortment variety) rather than exploring the effect of feeling restricted in general (unrelated to one specific cue). In order to establish variety-seeking behavior as a general means to offset feelings of restriction, we conducted a follow up study to gain first insight on this matter. Specifically, in a laboratory follow-up study ( $n=95,42$ males; $\left.M_{\text {age }}=20.66, S D=2.59\right)$ we exposed half of the participants to restriction cues (i.e., no parking signs, no entry and cell phones not allowed) and the other half to neutral cues (Appendix). After participants looked at the signs they continued with a seemingly unrelated task. Specifically, they were asked to imagine that they want to buy five yoghurts choosing between strawberry, blueberry, lemon, cherry, and raspberry yogurt. An ANOVA revealed a significant difference between participants exposed to neutral cues $\left(M_{\text {neutral }}=2.96, S D=1.16\right)$ and those exposed to the restriction cues $\left(\mathrm{M}_{\text {restr }}=3.56, \mathrm{SD}=.867 ; \mathrm{F}(1,90)=7.79, p<.001\right)^{5}$.

This finding provides first evidence that not only exposure to a specific choice restriction cue (i.e., assortment variety) in the retail context but also to completely unrelated restriction cues triggers variety seeking. Future research could follow up on this and explore whether environments that create the feeling of restrictions trigger greater variety-seeking behavior. This research does not need to be bound to specific restriction cues but could also explore, for instance, whether members of specific religious or political parties that are confronted with strict regulations and restrictions compensate by seeking variety.

\subsubsection{Managerial Implications}

Since consumers frequently encounter assortments without making a decision from it (e.g., when passing by a shelf or on billboards), it is practically relevant to extend existing research by exploring the influence on subsequent decisions. Our finding that variety-seeking behavior constitutes a reaction to choice restriction cues discloses a rather

\footnotetext{
${ }^{5}$ We excluded three participants because they misunderstood the choice task and chose more or less yogurts than five.
} 
counterintuitive process that is at odds with practical experience: nowadays retailers offer variety and choice in order to enable consumers to seek variety (Hoch, Bradlow, and Wansink 1999). This rationale is based on the fact that variety-seeking behavior, specifically choosing varied product bundles, is only possible if retailers provide consumers with many different brands, flavors or kinds of products. However, this rationale does not consider that the overall variety and amount of choices offered might influence to which extent consumers actually want to engage in variety-seeking behavior. Our findings suggest that consumers are more inclined to seek variety in stores where the assortment variety is limited rather than extensive. From this follows, that consumers might have a greater need to seek variety in a convenience store that offers, for instance, fewer chocolate flavors than a regular grocery store.

Importantly, stores have two options to cater to consumers' need for variety: they can offer a high variety of different flavors enabling consumers to take varied product bundles or they can offer only few different products but integrate new or lesser known products in the assortment enabling consumers to try out new options rather than choosing the same (known) option all the time. This means for manufacturers who apply a multi-brand strategy that they should offer their lesser known brands or new products preferably in stores with limited compared to high assortment variety. Specifically, this implies that although retailers possess the wisdom "the more the better" (Iyengar and Lepper 2000), our research denotes that less choice might come in handy when promoting special or new products.

Within all our studies, we test the effect of cues signaling restricted choice on individuals' variety-seeking behavior in a subsequent decision. This means that the assortment in one product category does not only influence choices from this specific assortment but also influence the likelihood of engaging in variety-seeking behavior in subsequent decisions. Since it is costly for retailers to provide wide variety, they can use our findings to strategically vary the assortment variety between different product categories. For instance, retailers might choose to limit the assortment variety near the entrance of a store and offer more variety in product categories towards the end of the store.

Considering this we believe that studying the effect of limited assortment variety on variety-seeking behavior in a subsequent, unrelated decision is practically relevant as consumers frequently encounter variety in one product category and then proceed with making an unrelated choice. We hope to add to existing research on the importance of choice (Leotti and Delgado 2011; Markus and Schwartz 2010) and consumers' reaction to restriction (Laurin, Kay, and Fitzsimons 2012) by highlighting that even mere exposure to subtle cues such as limited assortment variety can prompt behavior aimed at regaining one's freedom. 


\section{CONCLUSION}

REFLECTION

The overall objective of this dissertation was to study the effects of choice restrictions-actual or perceived-on consumer decision making. In this endeavor, we compared choices made under restriction to those made free from (feelings of) restrictions. Importantly, the goal of this dissertation was not to focus on one particular type of restriction but to deal with different forms-internal and external-of restrictions and shed light on choice restrictions as a general phenomenon that impacts various decisions made on a daily basis. In this chapter, we summarize the key findings of our empirical studies and illustrate the contributions as well as implications and directions for future research. 


\subsection{SYNOPSIS}

The overarching purpose of this doctoral dissertation was to zoom in on situations in which consumers are or feel restricted in their freedom of choice and investigate the effects of these instances on consumer decision making. In an endeavor to treat choice restrictions as a general phenomenon that brings about various behavioral consequences, each chapter explored a different restriction and/or consequence. Figure 5.1 shows the framework of this dissertation introduced earlier. However, in this version we added the outcome of our studies to briefly indicate the main finding of each empirical investigation.

Figure 5.1: Dissertation Framework with Outcomes

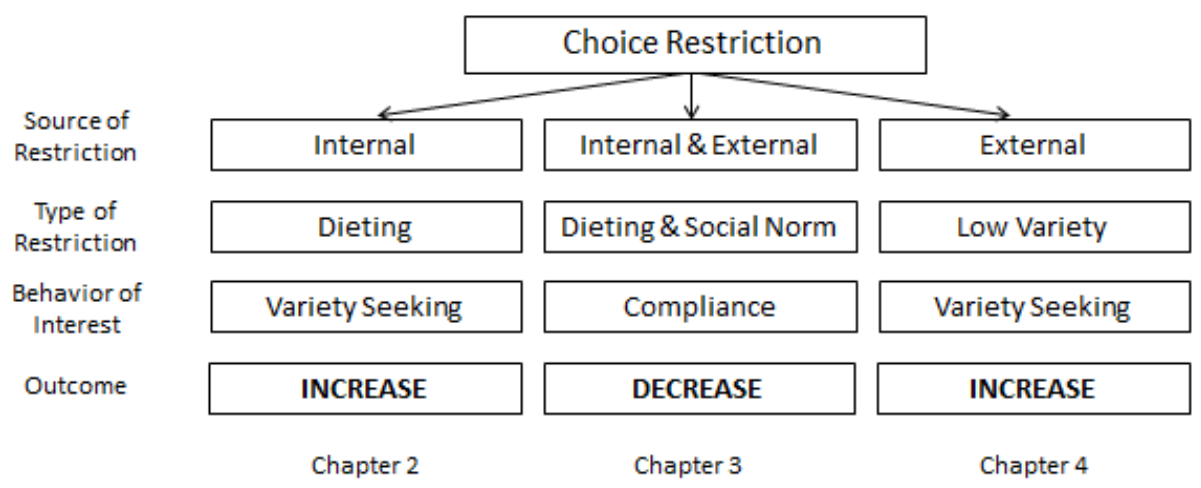

In Chapter 2, we focused on dieting as an internal choice restriction. The results highlight a relationship between weight watching and variety seeking. First, we demonstrate that dieters are more likely to seek variety than non-dieters. Second, and more importantly, we highlight that activating self-regulatory concerns drives this increased need for variety. Specifically, in three studies we explicitly manipulate self-regulatory concerns, for instance, by means of mental budgeting (Study 1 and 2) or asking questions about eating behavior and weight (Study 3 ). The results of all studies consistently demonstrate that individuals have a heightened need for variety when self-regulatory concerns are activated. This need expresses itself through an increased likelihood to switch away from a snack previously consumed (Study 1) or through choosing a variety of different toppings for chocolate (Study 2) and cake (Study 3). All in all, these findings point to the fact that particularly individuals who restrict their food intake are most likely to make use of the variety of different products offered nowadays. Importantly, our studies highlight that simple daily activities such as stepping on the scale in the morning are sufficient to activate this increased need for variety. We suggested the 
need to maximize pleasure derived from eating as a possible explanation for why individuals that restrict their food intake seek more variety.

Chapter 3 also devoted attention to dieting as an internal choice restriction. However, unlike the previous manuscript, we exclusively focused on individuals that restrict their food intake and manipulated whether they encounter an external restriction (i.e., the social norm to be thin). Specifically, the main purpose was to explore whether dieters comply with the social norm to be thin if repeatedly confronted with it. Unlike existing research, we investigated the effect of repeated exposure to the thin ideal over a longer time span acknowledging that goals such as losing weight cannot be achieved immediately. The results of two weight loss program studies denote that dieters who are repeatedly exposed to the thin ideal by means of a picture showing a very thin model express lower commitment to their dieting goal, engage in goalinconsistent behavior (i.e., eating unhealthy snacks) and, hence, are not successful in losing weight. In addition, the findings of Study 2 reveal perceived attainability of the thin ideal as the mediator of our effect. That is, the exposure to an extremely thin model triggers the belief that the thin ideal is not attainable and, hence, fosters disengagement from this ideal. Importantly, while existing research demonstrated that exposure to thin models fosters the desire to be thin, our findings highlight that, paradoxically, constant exposure to these images makes it even harder to achieve the thin ideal.

In Chapter 4, we approached the topic of choice restrictions from a slightly different angle: instead of looking at situations in which consumers are really restricted in their choice, we focused on limited assortment variety as a cue that signals choice restrictions. In four laboratory studies, we made use of cues prevalent in the retail environment (i.e., advertisements depicting limited assortment variety) and demonstrate that mere exposure to limited assortment variety, without actual restriction, triggers the feeling of restricted choice and prompts variety seeking as a means of compensation. We provide evidence for reactance as the driver of our effect since the effect of low-variety assortments on variety seeking is moderated by an indicator of motivational involvement (i.e., desire to make a choice). Further, we reveal the feeling of restricted choice (i.e., "If I had to make a choice, I would feel restricted") as the mediator of our effect and highlight that allowing individuals to make a choice (i.e., choosing a pen) before they have the possibility to seek variety attenuates the effect on variety-seeking behavior. The findings of this manuscript denote that, nowadays, individuals are very sensitive to any indication of restricted choice and, hence, slight signals of restricted choice already prompt individuals to engage in compensatory actions. 


\subsection{PRACTICAL RELEVANCE}

We believe that a deeper understanding of how feeling restricted in one's choice influences consumer decision making has important practical implications. Due to the diversity of choice restrictions (i.e., dieting, social norms, and assortment variety) as well as behaviors (i.e., variety-seeking behavior and compliance) under investigation, this dissertation is of practical relevance to various different parties-brands and retailers as well as the government and organizations concerned with human well-being-in the marketplace. In each chapter, we already referred to some practical implications. In the following, we will take a more general, comprehensive perspective.

Implications for brands and retailers: Chapter 2 and 4 explore the influence of choice restrictions-internal as well as external-on consumer variety-seeking behavior. The findings suggest that feeling restricted-be it because of dieting constraints, the exposure to limited assortment variety or other restriction cues-prompts a greater need for variety. While retailers offer a lot of choice to enable consumers to seek variety, our findings imply that especially situations in which consumers feel restricted will bring about a greater need for variety. The managerial implications following from this are potentially important for store stocking decisions and new product introductions. For instance, our results suggest to manufacturers who engage in a multibrand strategy that they should consider offering their new or lesser-known brands and products in convenience stores or small supermarkets since the limited product offering will prompt consumers' need for variety. Further, our findings denote that retailers should deliver a wide variety of products if the environment triggers feelings of restriction. Importantly, our follow-up study in chapter 4-in which we confronted participants with various restriction cues-denotes that consumers' variety-seeking behavior can be influenced by cues as subtle as "do not enter" signs. This implies that not only feelings of restriction related to the product assortment but also unrelated feelings of restricted choice can spur variety seeking. Finally, cafeterias or restaurants, for instance, in fitness studios, that predominantly cater to consumers who regulate their food intake should consider integrating a greater variety of food products in their assortment to satisfy their customers' need for variety. Concluding, practitioners might be currently unaware that feelings of choice restriction trigger variety seeking. Being conscious of this relationship, they might be able to (strategically) increase (or decrease) consumers' need for variety depending on the assortment strategy-the "more the better" or "efficient assortment" - that they follow.

Implications for organizations concerned with human well-being: Chapter 2 and 3 of this dissertation focus on dieting as an important internal restriction that individuals frequently impose on themselves. While chapter 2 highlights a relationship between dieting and individuals' need for variety, chapter 3 sheds light on the effect of 
constant exposure to unrealistically skinny media models. We believe that the findings of both chapters are timely and very relevant to policy makers as well as organizations founded to improve human well-being, for instance, the World Health Organization (WHO).

Nowadays, overweight and obesity are the fifth leading risk for global deaths and at least 2.8 million adults die each year as a consequence of being overweight or obese (WHO 2013). However, at the same time, anorexia-a deliberate self-starvation to lose weight-is the third most common chronic illness among adolescents (ANAD 2013). Dieting has become the status quo and many individuals restrict their food intakeeven those that are underweight or of normal weight-in order to reduce or maintain their body weight over an extended period of time. However, for many individuals it seems difficult to reach the desired outcome (Jefferey et al. 2000; Mann et al. 2007). In fact, whether it is a salad, soup or low carbohydrates diet, the average 45-year-old woman has been on sixty-one diets mostly without any success (Mail Online 2012). This dissertation points towards two potential reasons why diets might fail and, hence, provides valuable insights for dieters and organizations aimed at fighting obesity.

First of all, chapter 2 suggests that dieting comes with an increased need for variety. Since variety has been associated with higher food intake (Rolls et al. 1981; Kahn and Wansink 2004; Raynor and Epstein 2001), this could explain why dieters have difficulties to lose weight. It implies that dieters themselves as well as organizations that intend to help them accomplish their goal need to be aware of this "side-effect" that comes with restricting one's food intake. Second, chapter 3 highlights that constant exposure to extremely skinny media models (i.e., the thin ideal) makes it even more difficult for individuals to lose weight because it presents an unrealistic ideal and prompts the feeling that the dieting goal is not attainable. Therewith, our findings add to the ongoing discussion of whether extremely skinny models should be banned from fashion shows and TV programs. Specifically, the results of our weight-loss program studies denote that constant confrontation with our society's ideal to be thin might not only increase individuals' desire to "comply" with it but at the same time makes it even harder to reach it.

These findings call for government interventions to help adjust individual biases in self-image. As an example, Israel recently enacted a law that prevents using fashion and commercial models with a BMI below 18.5 and requires advertising agencies to indicate if computer-generated changes have been made to make models appear thinner (abc NEWS 2013). Even if such interventions might be considered yet another (choice) restriction, they seem justified considering that they help increase human well-being. 


\subsection{LIMITATIONS AND FUTURE RESEARCH}

Taken together, the findings compiled in this dissertation emblaze how choice restrictions, of internal and external nature, as well as mere indications of it, impact consumer decision making. Certainly, this dissertation can only zoom in on a few specific instances and leaves room for future research to address other choice restrictions and potential consequences for consumer decision making. We already suggested potential research ideas in the discussion sections of each of the manuscripts. While they were specific to the choice restriction and behavioral consequence discussed in the particular manuscript, we will now predominantly point out more general ideas for possible future research directions.

First, the term choice restriction inherently carries a negative connotation since it implies that individuals are limited in their freedom of choice. From existing research, we know that individuals do not like to be restricted. According to reactance theory (Brehm 1966), for instance, situations in which individuals cannot choose freely trigger reactance, a motivational state that is aroused whenever individuals perceive threats to their freedom. It expresses itself though the strong need to regain one's freedom (Wicklund 1974). This suggests that choice restrictions, generally, threaten one's freedom and evoke actions aimed at offsetting this aversive state as demonstrated in chapter 4. However, consider internal choice restrictions (i.e., dieting) that individuals impose voluntarily (i.e., motivated by the desire to do something beneficial for themselves). For instance, consider individuals who decide to limit their food intake to a certain amount of calories or ration the purchase quantities of products (e.g., cookies or cigarettes) that are likely to be consumed on impulse (Wertenbroch 1998). Although such (strategic) self-imposition of constraints restricts individuals' freedom of choice, it simultaneously might empower them. That is, the act of self-imposing restrictions might provide individuals with the feeling that they are in control of their own actions.

We think it is interesting to explore whether these internally imposed choice restrictions could indeed constitute a means of empowerment. In a first step, we suggest investigating whether the mere act of imposing such restrictions (e.g., dietary restriction) changes individuals' perception of how much control they have over their life. As a second step, we find it valuable to zoom in on potential down-stream effects. For instance, a question that arises is whether individuals that impose an internal restriction are more or less susceptible to the negative effects of external choice restrictions. Consider an individual that decides to limit his/her food intake to 1500 calories per day. Would he/she react differently to a limited assortment of yogurts than an individual without such an internal restriction? Specifically, would the act of imposing internal restrictions make individuals more or less prone to react (e.g., decreased choice satisfaction) negatively when encountering situations in which their freedom of 
choice is externally restricted? In this context it might be interesting to differentiate between external choice restrictions that are related to the internal restriction (e.g., limited assortment of yogurts) and those that are unrelated (e.g., limited assortment of pencils). Since individuals frequently impose internal restrictions on themselves, exploring the effect of internal and external choice restrictions in combination seems very valuable.

Second, existing research that compares situations in which individuals can choose to those in which choice is externally determined frequently demonstrated that individuals like the illusion of choice regardless of whether the resulting behavior is different or not (Langer and Rodin 1976; Langer 1975). Generally, individuals predict outcome satisfaction to be higher when they are allowed to choose themselves than when choice is externally determined, regardless of whether they are choosing from desirable or undesirable options (Botti and lyengar 2004). However, in fact, consumers presented with choice sets, including all undesirable options, reported greater satisfaction and happiness when an option was externally imposed rather than self-selected (Botti and McGill 2006; Botti and lyengar 2004). These findings denote that consumers' prediction of how choosing (as compared to not being able to choose) would affect their satisfaction is not in line with the actual experience.

We think it would be interesting to transfer these findings to the context of choice restrictions. That is, in addition to comparing situations in which individuals cannot choose to those in which they can, future research could zoom in on various instances in which individuals can choose but are, for one reason or the other, restricted. Existing research by Gilbert and Ebert (2002) denotes that people prefer to make changeable rather than unchangeable decisions not knowing that they are actually more satisfied if they are restricted and cannot change their mind. To just give one concrete example, consider two consumers that intend to make a purchase. While one of them possesses all necessary information, the other is rather limited in the information provided. Who of them would predict greater outcome satisfaction and who would actually be more satisfied with the purchased item? While existing research explored the consequences of too much information, frequently referred to as information overload (Malhotra 1982), to our knowledge research that focuses on too little information and its impact is scarce.

Third, we acknowledge that this dissertation focuses exclusively on every day decisions - such as what to eat-that do not require a lot of elaboration and thought. For future research, we suggest looking into more complex and maybe even highly consequential or undesirable decisions. In this context, research by Botti, Orfalli, and lyengar (2009) demonstrates that when facing tragic decisions such as, whether to discontinue infants' life support, externally made choices generate less negative feelings than self-made choices. This shows that under these circumstances choosing be- 
comes less desirable and raises the question how choice restrictions would influence, for instance, outcome evaluations. Consider, for instance, parents that have to decide between different treatments for their sick child. Would choosing between a very limited number of options as compared to choosing out of various different treatments change their feelings about the decision or their hope in the effectiveness of the treatment?

Fourth, all experiments in this dissertation-except for Study 3 in chapter 4 which was conducted on Amazon Turk ${ }^{\circledR}$ - utilized a student sample. While this is common procedure in the context of consumer research (Peterson 2001), an important issue frequently raised is whether students are representative of the general population. We believe that our study with participants from Amazon Turk ${ }^{\circledR}$ provides first evidence that our findings (i.e., the effect of limited assortment variety on variety seeking) generalizes to a sample that is less homogenous and older (i.e., $M_{\text {age }}=28.88, S D=9.92$ ) than a student sample. Nevertheless, generalization across age, socio-economic status and nationality remains a matter for further research. For instance, it would be possible to initiate another weight loss program study in cooperation with Weight Watchers $^{\circledR}$ that is targeted at all females-students, housewives, and working women-to explore whether our findings surrogate for individuals other than college students.

Fifth, importantly, in this dissertation we mainly investigate the situational effect of choice restrictions. In all our studies, we confront participants with a choice restriction and explore the immediate influence on (a) subsequent decision(s). For instance, we activated self-regulatory concerns or confronted participants with cues signaling restricted choice and then investigated the impact on subsequent varietyseeking behavior. While this approach provides useful insight in the immediate reactions to choice restrictions, it fails to acknowledge that the environment in general and the frequency with which one encounters choice restrictions, could potentially influence individuals' decision making as well. For future research, we think it would be valuable to take such a broader perspective and explore long-term effects of restricted environments. Specifically, one could wonder whether individuals that grew up in environments in which choice was restricted in many respects (e.g., East Germany till 1989) would seek more variety than individuals who grew up in less restricted settings. Similarly, could it be that children whose parents utilize a strictly authoritarian parental style and impose many restrictions on them tend to seek more variety? According to the findings in this dissertation, one might assume that children brought up in a very strict environment might indeed engage in variety seeking to a greater extent than those that enjoyed a rather liberal parental style. 
So far, we conducted a small pilot study $(n=94)^{6}$ to shed light on this question. As part of this study, we focused on parents' attitude towards allowing children to choose and eat candy. Specifically, in a questionnaire we asked parents whether they allowed their children to choose the candy they like and how much candy they allowed their children. Using these answers we computed a variable that we refer to as "strictness." In addition, in a small study school children were given the opportunity to choose four cookies out of a five item choice set. They were told that they can choose the same cookie a couple of times or choose many different ones. The more different cookies a child chose, the higher his/her variety-seeking behavior. We matched the varietyseeking behavior of the children with the answers of their parents and found a significant positive association between parents' strictness and children's variety-seeking behavior. This provides fist evidence that children who generally encounter restrictions seek more variety. One of the next intriguing steps would be to explore whether also restrictions unrelated to nutrition (e.g., whether children are restricted in how long they can watch TV or whether they have to do their homework first before they can play) influence variety seeking. These findings would provide a broader perspective on the influence of restricted environments on variety seeking. Further, they constitute a means to test the external validity of our findings because-unlike most of the other experiments -this study utilizes a non-student sample (i.e., children). Hence, exploring whether choice restrictions impact the variety-seeking behavior of children helps broaden the generalizability of our findings.

Finally, as becomes apparent, we devoted a lot of attention to variety-seeking behavior as the behavioral outcome of interest. Both, chapter 2 and 4, reveal variety seeking as a reaction to instances in which individuals are or feel restricted in their freedom of choice. In doing so, they add to research by Levav and Zhu (2009) which demonstrates that individuals who feel spatially confined react with more variety seeking to regain their sense of freedom. Taken together, these findings provide solid evidence that variety seeking constitutes a means to regain one's freedom. For future research, we deem it interesting to explore whether there are other behavioral reactions - in addition to variety seeking - that function as means to regain one's freedom when feeling restricted in one's choice. In Study 4 of chapter 4, we demonstrate that the effect of exposure to limited assortment variety on variety seeking diminishes if participants were given the possibility to make a choice before they could engage in variety seeking suggesting that making a choice is sufficient to offset the feeling of limited choice.

\footnotetext{
${ }^{6}$ Two primary schools ('Berkeloo' and 'De Heydonck') located in the Netherlands (Berkel-Enschot and Best) have been approached to participate in this experiment. The sample consists out of 94 Dutch children, all between the age of six and seven years old, from five different third-grade school classes.
} 
This raises the question whether individuals that encountered choice restrictions would, for instance, be more likely to customize a given product? Existing research demonstrates that customizing provides consumers with increased feelings of selfexpression (Mugge, Schoormans, and Schifferstein 2009) and the "power to choose" (Counts 2006). Levav and Zhu (2009) conjecture that feeling spatially confined triggers variety seeking because making unique choices is a form of self-expression and, hence, helps regain one's personal freedom. Following this line of reasoning, one might argue that customizing a product fulfills a similar purpose and, hence, could be prompted by feelings of restrictions. In this context, one might wonder whether this means that particularly companies which restrict consumers through a rather limited variety (e.g., Apple ${ }^{\circledast}$ ) could trigger customers to customize products. Generally, we believe that exploring this question would help to shed light on other possible behavioral consequences that are of managerial relevance.

\subsection{FINAL THOUGHT}

Free as a Bird? - This dissertation pinpoints situations in which individuals are (or feel), for one reason or the other, restricted in their choice. However, this work should by no means imply that we are always restricted in everything we do. Nevertheless, we believe that, especially nowadays, where freedom has come to mean almost exclusively freedom of choice (Markus and Schwartz 2010) it helps to be reminded that the choices we make are not always as free as we want to believe. If individuals think in terms of free choice this activates the belief that live outcomes stem from personal agency. Downstream effects of this are that individuals' empathy for disadvantaged others decreases (Savani, Stephens, and Markus 2011) and leads people, for instance, to justify wealth inequality (Savani and Rattan 2012). That is, believing to a great extent in free choice makes people less sympathetic to others and more likely to blame them for bad things (e.g., having a heart attack) that happen to them (Savani, Stephens, and Markus 2011). This can have negative consequences for the individual as well as society as a whole. Considering this, being aware of choice restrictions could, actually, be positive as it fosters the understanding that decisions of ourselves and others are often determined by external factors. So the next time you are (or someone else is) making a decision, be it as simple as choosing lunch or as complex as judging (or writing) this dissertation, consider possible factors that restrict your (others') choice. 


\section{REFERENCES}

Abc NEWS (2013), "Israeli Law Bans Skinny, BMI-Challenged Models" http://abcnews.go.com/International/israeli-law-bans-skinny-bmi-challenged-models/story?id=18116291 (accessed last 12-8-2013)

Alamy, Meryem, Mohammed Errami, Khalid Taghzouti, F. Saddiki-Traki, and W.A. Bengelloun (2005), “Effects of Postweaning Undernutrition on Exploratory Behavior, Memory and Sensory Reactivity in Rats: Implication of the Dopaminergic System," Physiology and Behavior, 86 (1-2), 195-202.

ANAD (2013), http://www.anad.org/get-information/get-informationanorexia-nervosa/ (accessed last 12-92013)

Anschutz, Doeschka J., Rutger C.M.E. Engels, Eni S. Becker, and Tatjana van Strien, (2008), "The Bold and the Beautiful. Influence of Body Size of Televised Media Models on Body Dissatisfaction and Actual Food Intake," Appetite, 51 (3), 530-537.

Atkinson, John W. (1964), An Introduction to Motivation. Princeton, NJ: D. Van Nostrand.

Bandura, Albert and Dale H. Schunk (1981), "Cultivating Competence, Self-efficacy, and Intrinsic Interest through Proximal Self-Motivation," Journal of Personality and Social Psychology, 41 (3), 586-98.

Baumeister, Roy R. (2010), "The Self," in Advanced Social Psychology. The State of the Science, Roy R. Baumeister, and Eli J. Finkel, eds. Oxford: University Press, 139-175.

Beattie, Jane, Jonathan Baron, John C. Hershey, and Mark D. Spranca (1994), "Psychological Determinants of Decision Attitude," Journal of Behavioral Decision Making, 7 (2), 129-144.

Botti, Simona, Kristina Orfali, and Sheena S. Iyengar (2009), "Tragic Choices: Autonomy and Emotional Responses to Medical Decisions," Journal of Consumer Research, 36 (3), 337-352.

, Susan Broniarczyk, Gerald Häubl, Ron Hill, Yanliu Huang, Barbara Kahn, Praveen Kopalle, Donald Lehmann, Joe Urbany, Brian Wansink (2008), “Choice Under Restrictions," Marketing Letters, 19 (3-4), 183-199.

and Ann L. McGill (2006), "When Choosing is Not Deciding: The Effect of Perceived Responsibility on Choice Outcome Satisfaction," in Advances in Consumer Research, Cornelia Pechmann and Linda L. Price (Eds.), 33, 512-13.

and Sheena lyengar (2004), "The Psychological Pleasure and Pain of Choosing: When People Prefer Choosing at the Cost of Subsequent Satisfaction," Journal of Personality and Social Psychology, 87(3), 312-326.

Bown, Nicola, Daniel Read and Barbara Summers (2003), "The Lure of Choice," Journal of Behavioral Decision Making, 16 (4), 297-308.

Brat, llan, Ellen Byron and Ann Zimmerman (2009), "Retailers Cut Back on Variety, Once the Spice of Marketing," Wall Street Journal, 26 http://online.wsj.com/news/articles/SB124597382334357329 (accessed last10-18-2013).

Brehm, Jack W., Lloyd K. Stires, John Sensenig and Janet Shaban (1966), "The Attractiveness of an Eliminated Choice Alternative," Journal of Personality and Social Psychology, 2 (3), 301-313.

(1966), A Theory of Psychological Reactance. New York: Academic Press.

and Sharon Brehm (1981), Psychological Reactance: A Theory of Freedom and Control. New York: Academic Press. 
Brendl, Miguel C. and E. Tory Higgins (1995), “Principles of Judging Valence: What Makes Events Positive or Negative," Advances in Experimental Social Psychology, 28, 95-160.

Broniarczyk, Susan M. (2008), "Product Assortment," in Handbook of Consumer Psychology, Curtis P. Haugtvedt, Paul M. Herr, and Frank R. Kardes, eds. Laurence Erlbaum Associates, 755-779.

Wayne D. Hoyer, and Leigh Mc Alister (1998), "Consumers' Perceptions of the Assortment Offered in a Grocery Category: The Impact of Item Reduction," Journal of Marketing Research, 35 (2), 166176.

Brown, Judson S. (1948), "Gradients of Approach and Avoidance Responses and Their Relation to Motivation," Journal of Comparative and Physiological Psychology, 41 (6), 450-465.

Burger, Jerry M. (1989), “Negative Reactions to Increases in Perceived Personal Control,” Journal of Personality and Social Psychology, 56 (2), 246-256.

Carver, Charles S. and Michael F. Scheier (1998), On the Self-regulation of Behavior. New York: Cambridge University Press.

Chartrand, Tanya L., Joel Huber, Baba Shiv, and Robin J. Tanner (2008), "Nonconscious Goals and Consumer Choice," Journal of Consumer Research, 35 (2), 190-201.

Chernev, Alexander (2005), "Feature Complementarity and Assortment in Choice," Journal of Consumer Research, 31 (4), 748-759.

(2003), "When More Is Less and Less Is More: The Role of Ideal Point Availability and Assortment in Choice," Journal of Consumer Research, 30 (2), 170-183.

Cochran, Winona and Abraham Tesser (1996), "The 'What the Hell' Effect: Some Effects of Goal Proximity and Goal Framing on Performance" in Striving and Feeling: Interactions among Goals, Affect, and Selfregulation, Leonard L. Martin and Abraham Tesser, eds. Mahwah, NJ: Erlbaum, 99-120.

Coelho do Vale, Rita, Rik Pieters, and Marcel Zeelenberg (2008), "Flying under the Radar: Perverse Package Size Effects on Consumption Self-Regulation," Journal of Consumer Research, 35 (3), 380-390.

Collins, Rebecca L. (1996), "For Better or Worse: The Impact of Upward Social Comparison on SelfEvaluations," Psychological Bulletin, 119 (1), 51-69.

Coombs, Clyde H. and George S. Avrunin (1977), "Single-Peaked Functions and the Theory of Preference," Psychological Review, 84 (2), 216-230.

Cordova, Diana I. and Mark R. Lepper (1996), "Intrinsic Motivation and the Process of Learning: Beneficial Effects of Contextualization, Personalization, and Choice," Journal of Educational Psychology, 88 (4), 715730.

Counts, C. E. (2006), "Interactivism Allows Consumers to Co-create Grows Loyalty," Marketing News, 40 (12), 30.

Daily Mail (2011), "Adverts Banned for Kate Moss 'Nothing Tastes as Good as Skinny feels' T-shirts," http://www.dailymail.co.uk/femail/article-2024237/Kate-Moss-pro-anorexia-tastes-good-skinny-feels-Tshirt-banned.html (accessed last 10-18-2013).

Deci, Edward L. (1981), The Psychology of Self-Determination, Lexington, MA: Heath.

and Richard M. Ryan (1985), Intrinsic Motivation and Self-Determination in Human Behavior, New York: Plenum Press.

Dhar, Ravi and Itamar Simonson (1999), "Making Complementary Choices in Consumption Episodes: Highlighting Versus Balancing," Journal of Marketing Research, 36 (1), 29-44.

Dijksterhuis, Ap, Tanya L. Chartrand, and Henk Aarts (2007), "Automatic Behavior," in Automatic Processes in Social Thinking and Behavior, John A. Bargh, ed. Philadelphia, PA: Psychology Press.

Dittmar, Helga (2008), Consumer Culture, Identity and Well-being. The Search for the 'Good Life' and the 'Body Perfect,' New York: Psychology Press.

and Sarah Howard (2004), "Thin-Ideal and Social Comparison Tendency as Moderators of Media Models' Impact on Women's Body-Focused Anxiety," Journal of Social and Clinical Psychology, 23 (6), 768-791. 
Dorsett, Katherine (2010), “New Year's Resolution No. 1: Lose Weight,” CNN, http://edition.cnn.com/2010/HEALTH/diet.fitness/12/31/lose.weight.new.resolution/index.html (accessed last 10-18-2013).

Eisend, Martin (2008), "Explaining the Impact of Scarcity Appeals in Advertising-The

Mediating Role of Perceptions of Susceptibility," Journal of Advertising, 37(3), 33-40.

Ellemers, Naomi, Russel Spears and Bertjan Doosje (2002), "Self and Social Identity," Annual Review of Psychology, 53 (1), 161-186.

Epstude, Kai and Thomas Mussweiler (2009), "What you Feel is How you Compare: How Comparisons Influence the Social Induction of Affect," Emotion, 9 (1), 1-14.

Epstein Leonard H., Jodie L. Robinson, Jennifer L. Temple, James N. Roemmich, Angela L. Marusewski, Rachel L. Nadbrzuch (2009), "Variety Influences Habituation of Motivated Behavior for Food and Energy Intake in Children," American Journal of Clinical Nutrition, 89 (3), 746-754.

Fedoroff, Ingrid C., Janet Polivy and C. Peter Herman (1997), "The Effect of Pre-Exposure to Food Cues on the Eating Behavior of Restrained and Unrestrained Eaters," Appetite, 28 (1), 33-47.

Feldman, D. (2006), "Versace and Prada Join Fight Against Size-0 Models! Gisele Bündchen risks... Fashion Model Directory," http://www.fashionmodeldirectory.com/news/Model+News/versace-prada-join-fightagainst-size0-models-gisele-bundchen-risks.htm (accessed last 10-18-2013)

Festinger, Leon (1954), "A Theory of Social Comparison Processes," Human Relations, 7, 117-140.

Fishbein, Martin and Icek Ajzen (1974), "Attitudes toward Objects as Predictors of Single and Multiple Behavioral Criteria," Psychological Review, 81 (1), 59-74.

Flegal, Katherine M., Margaret D. Carroll, Brian K. Kit, and Cynthia L. Ogden (2010), "Prevalence and Trends in Obesity among US Adults, 1999-2010," Journal of the American Medical Association, 307, (5), 491-497.

Fletcher, June and Alexandra Wolfe, A. (2004), "The Chair Is So You," The Wall Street Journal, (October), W1.

FMI, The Voice of Retail (2010), http://www.fmi.org/research-resources/supermarket-facts (accessed last 10-18-2013)

Frederickson, Barbara L., Tomi-Ann Roberts, Stephanie M. Noll, Diane M. Quinn, and Jean M. Twenge (1998), "That Swimsuit Becomes You: Sex Differences in Self-Objectification, Restrained Eating, and Math Performance, Journal of Personality and Social Psychology, 75 (1), 269-284.

and Tomi-Ann Roberts (1997), “Objectification Theory: Toward Understanding Women's Lived Experiences and Mental Health Risks," Psychology of Women Quarterly, 21 (2), 173-206.

Gilbert Daniel and Jane E. J. Ebert (2002), "Decisions and Revisions: The Affective Forecasting of Changeable Outcome," Journal of Personality and Social Psychology, 82 (4), 503-514.

Gollwitzer, Peter M. and Veronika Brandstätter (1993), "Implementation Intentions and Effective Goal Pursuit," Journal of Personality and Social Psychology, 73 (1), 186-199.

Goukens, Caroline, Siegfried Dewitte, and Luk Warlop (2009), "Me, Myself, and My Choices. The Influence of Private Self-Awareness on Choice," Journal of Marketing Research, 46 (5), 682-692.

Gourville, John T. and Dilip Soman (2005), "Overchoice and Assortment Type: When and Why Variety Backfires," Marketing Science, 24 (3), 382-395.

Grabe, Shelly, Monique L. Ward, and Janet Shibley Hyde (2008), "The Role of the Media in Body Image Concerns Among Women: A Meta-Analysis of Experimental and Correlational Studies," Psychological Bulletin, 134 (3), 460-476.

Harter, Susan (1999), The Construction of the Self: A Developmental Perspective, New York: Guilford.

Hayes, Andrew F. and Jörg Matthes (2009), "Computational Procedures for Probing Interactions in OLS and Logistic Regression: SPSS and SAS Implementations," Behavior Research Methods, 41 (3), 924-936.

Heath, Chip, Richard P. Larrick, and George Wu (1999), "Goals as Reference Points," Cognitive Psychology, 38 (1), 79-109.

Heatherton, Todd F. and Janet Polivy (1991), "Development and Validation of a Scale for Measuring State Self-Esteem," Journal of Personality and Social Psychology, 60 (6), 895-910. 
C. Peter Herman, Janet Polivy, Gillian A. King, and Sheila T. McGree (1988), "The (Mis)Measurement of Restraint: An Analysis of Conceptual and Psychometric Issues," Journal of Abnormal Psychology, 97 (1), 19-28.

Heinberg, Leslie J. and J. Kevin Thompson (1995), "Body Image and Televised Images of Thinness and Attractiveness: A Controlled Laboratory Investigation," Journal of Social and Clinical Psychology, 14 (4), 325338.

Herman, Peter and Janet Polivy (2010), "Sex and Gender Differences in Eating Behavior," in Handbook of Gender Research in Psychology, Joan C. Chrisler and Donald R. McCreary (Eds.), Springer New York Dordrecht Heidelberg London, 455-469. , and Janet Polivy (1984), "A Boundary Model for the Regulation of Eating," in Eating and its Disorders, A.J. Stunkard and E. Stellar, eds. New York: Raven, 141-156. , and Janet Polivy (1980), "Restrained Eating," in Obesity, A.J. Stunkard, ed., Obesity Philadelphia: Saunders, 208-225. and Deborah Mack (1975), "Restrained and Unrestrained Eating," Journal of Personality, 43 (4), 647-660.

Hoch, Stephen J., Eric T. Bradlow, and Biran Wansink, (1999), "The Variety of an Assortment," Marketing Science, 18 (4), 527-546.

Hofmann, Wilhelm, Guido M. van Koningsbruggen, Wolfang H. Stroebe, Suresh Ramanathan, and Henk Aarts (2010), “As Pleasure Unfolds: Hedonic Responses to Tempting Food," Psychological Science, 21 (12), 1863-1870.

Hull, Clark L. (1932), "The Goal-Gradient Hypothesis and Maze Learning," Psychological Review, 39 (1), 2543.

Inman, Jeffrey J. and Leigh McAlister (1994), “Do Coupon Expiration Dates Affect Consumer Behavior?” Journal of Marketing Research, 31 (3), 423-428.

Iyengar, Sheena S. (2010). The Art of Choosing. New York: Twelve.

, and Mark R. Lepper (2000), "When Choice Is Demotivating: Can One Desire Too Much of a Good Thing," Journal of Personality and Social Psychology, 79 (6), 995-1006.

Jansen, Anita and Marcel van den Hout (1991), “On Being Led into Temptation: 'Counterregulation' of Dieters After Smelling a 'Preload'," Addictive Behaviors, 16 (5), 247-253.

Jarry, Josée L., Janet Polivy, C. Peter Herman, A. John Arrowood, and Pathy Pliner (2006), "Restrained and Unrestrained Eaters' Attributions of Success and Failure to Body Weight and Perception of Social Consensus: The Special Case of Romantic Success," Journal of Social and Clinical Psychology, 25 (8), 885-905.

Jeffery, Robert W., Leonard W. Epstein, G. Terence Wilson, Adam J. Drewnowski, Albert J. Stunkard, and Rena R. Wing (2000), “Long-Term Maintenance of Weight Loss: Current Status," Healthy Psychology, 19 (1), 5-16.

Joshi, Ramona, C. Peter Herman, and Janet Polivy (2004), "Self-Enhancing Effects of Exposure to Thin-Body Images," International Journal of Eating Disorders, 35 (3), 333-341.

Kahn, Barbara E. and Rebecca Ratner (2005), "Variety for the Sake of Variety? Diversification Motives in Consumer Choice," in Inside Consumption: Frontiers of Research on Consumer Motives, Goals, and Desires, S. Ratneshwar and David G. Mick (Eds.), London: Routledge, 102-121.

and Brian Wansink (2004), "The Influence of Assortment Structure on Perceived Variety and Consumption Quantities," Journal of Consumer Research, 30 (4), 519-533.

Kahn Barbara E. (1998), "Dynamic Relationships with Customers: High-Variety Strategies," Journal of the Academy of Marketing Science, 26, (1), 45-53.

(1995), "Consumer Variety Seeking Among Goods and Services," Journal of Retailing and Consumer Services, 2 (10), 139 - 148. and Donald R Lehmann (1991), “Modeling Choice among Assortments,” Journal of Retailing, 67 (3), 274-299. 
Manohar U. Kalawani, and Donald G. Morrison (1986), "Measuring Variety Seeking and Reinforcement Behaviors Using Panel Data," Journal of Marketing Research, 23 (2), 89-100.

Kahneman, Daniel and Amos Tversky (1984), “Choices, Values, and Frames," American Psychologist, 39 (4), 341-350.

Kavanagh, David J., Jackie Andrade, and Jon May (2005), “Imaginary Relish and Exquisite Torture: The Elaborated Intrusion Theory of Desire," Psychological Review, 112 (2), 446-467.

Kay, Aaron C., Jennifer A. Whitson, Danielle Gaucher, and Adam D. Galinsky (2009), "Compensatory Control Achieving Order through the Mind, Our Institutions, and the Heavens," Current Directions in Psychological Science, 18 (5), 264-268.

Kim, Heejung S. and Aimee Drolet (2009), "Express Your Social Self: Cultural Differences in Choice of BrandName versus Generic Products," Personality and Social Psychology Bulletin, 35 (December), 555-566. and Aimee Drolet (2003), "Choice and Self-Expression: A Cultural Analysis of Variety Seeking," Journal of Personality and Social Psychology, 85 (2), 373-382.

Koo, Minjung and Ayelet Fishbach (2008), "Dynamics of Self-Regulation: How (Un)accomplished Goal Actions Affect Motivation," Journal of Personality and Social Psychology, 94 (2), 183-195.

Kök, A. Gürhan, and Marshall L. Fisher (2007), "Demand Estimation and Assortment Optimization Under Substitution: Methodology and Application," Operations Research, 55 (6), 1001-1021.

Krishnamurthy, Parthasarathy and Sonya Prokopec (2009), "Resisting that Triple-Chocolate Cake: Mental Budgets and Self-Control," Journal of Consumer Research, 37 (1), 68-79.

Kruger, Judy, Debroah A. Galuska, Mary K. Serdula, and Deborah A. Jones (2004), "Attempting to Lose Weight: Specific Practices Among U.S. Adults," American Journal of Preventive Medicine, 26 (5), $402-406$.

Kruglanski, Arie W., James Y. Shah, Ayelet Fishbach, Ron Friedman, Woo Young Chun, and David SleethKeppler (2002), "A Theory of Goal Systems," in Advances in Experimental Social Psychology, Mark P. Zanna, ed. San Diego: Academic Press, 331-378.

Langer, Ellen J. and Judith Rodin (1976), "The Effects of Choice and Enhanced Personal Responsibility for the Aged: A Field Experiment in an Institutional Setting," Journal of Personality and Social Psychology, 34 (2), 191-198.

(1975), "The Illusion of Control," Journal of Personality and Social Psychology, 32 (2), 311-328.

Lattin, James M. and Leigh McAlister (1985), "Using a Variety-Seeking Model to Identify Substitute and Complementary Relationships Among Competing Products," Journal of Marketing Research, 22, 330-339.

Laurin, Kristin, Aaron C. Kay, and Gavan Fitzsimons (2012), "Reactance versus Rationalization Divergent Responses to Policies That Constrain Freedom," Psychological Science, 23 (2), 205-209.

Leotti, Lauren A. and Mauricio R. Delgado (2011), "The Inherent Reward of Choice," Psychological Science, 22 (10), 1310-1318.

, Sheena S. Iyengar, and Ochsner (2010), "Born to Choose: the Origins and Value

of the Need for Control," Trends in Cognitive Sciences, 14, (10), 457-463.

Levav, Jonathan and Juliet R. Zhu (2009), "Seeking Freedom through Variety," Journal of Consumer Research, 36 (4), 600-610.

Levin, Kurt (1938), The Conceptual Representation and the Measurement of Psychological Forces. Durham, NC: Duke University Press.

Levine, Michael P. and Linda Smolak (1996), “Media as Context for the Development of Disordered Eating," in The Developmental Psychopathology of Eating Disorders: Implications for Research, Prevention, and Treatment, L. Smolak, M. P. Levine, and R. Striegel-Moore (Eds.), Hillsdale, England: Lawrence Erlbaum Associates, Inc, 235-257.

Livestrong (2010), Percentage of Americans who Diet Every Year, http://www.livestrong.com/article/308667-percentage-of-americans-who-diet-every-year/ (accessed last 10-18-2013)

Mail Online (2012), "Women have tried 61 diets by the age of 45 in the constant battle to stay slim," http://www.dailymail.co.uk/health/article-2117445/Women-tried-61-diets-age-45-constant-battle-stayslim.html (accessed last 12-8-2013) 
Malhotra, Naresh K. (1982), "Information Load and Consumer Decision Making," Journal of Consumer Research, 8 (4), 419-430.

Mann, Traci, A. Janet Tomiyama, Erika Westling, Anne-Marie Lew, Barbara Samuels, and Jason Chatman (2007), “Medicare's Search for Effective Obesity Treatments," American Psychologist, 62 (3), 220-233.

Marketing Charts (2011), Resolution to Lose Weight, http://www.marketingcharts.com/direct/6-in-10obese-americans-resolve-weight-loss-16246/harris-weightloss-resolution-feb11gif/ (accessed last 10-182013)

Markus, Hazel R. and Berry Schwartz (2010), "Does Choice Mean Freedom and Well Being," Journal of Consumer Research, 37 (2), 344-355.

and Shinobu Kitayama (1991), "Culture and the Self: Implications for Cognition, Emotion, and Motivation," Psychological Review, 98 (2), 224-253. and Ziva Kunda (1986), "Stability and Malleability in the Self-Concept in the Perception of Others," Journal of Personality and Social Psychology, 51 (4), 858-866.

(1977), "Self-Schemata and Processing Information about the Self," Journal of Personality and Social Psychology Bulletin, 10, 203-208.

May, Jon, Jackie Andrade, David Kavanagh and Lucy Penfound (2008), “Imagery and Strength Of Craving For Eating, Drinking, And Playing Sport Cognition," Emotion, 22 (4), 633-650.

Menon, Satya and Barbara E. Kahn (1995), "The Impact Of Context on Variety Seeking in Product Choices," Journal of Consumer Research, 22, (3), 285-295.

Mills, Jennifer S., Janet Polivy, C. Peter Herman, and Marika Tiggemann (2002), "Effects of Exposure to Thin Media Images: Evidence of Self-Enhancement among Restrained Eaters," Personality and Social Psychology Bulletin, 28 (12), 1687-1699.

Morgan, Catherine (2007), " $80 \%$ of Women and $92 \%$ of Girls are Dissatisfied With Their Bodies,"http://women4hope.wordpress.com/2007/10/18/80-of-women-and-92-of-girls-are-dissatisfiedwith-their-bodies/ (accessed last 10-18-2013)

Mugge, Ruth, Jan P.L. Schoormans, and Hendrik N. J. Schifferstein (2009), "Emotional Bonding with Personalized Products," Journal of Engineering Design, 20 (5), 467-476.

Mussweiler, Thomas and Fritz Strack (2000), "The Relative Self: Informational and Judgmental Consequences of Comparative Self-Evaluation," Journal of Personality and Social Psychology, 79 (1), 23-38.

Myers, Philip N., and Frank A. Biocca (1992), "The Elastic Body Image: The Effect of Television Advertising and Programming on Body Image Distortions in Young Women," Journal of Communication, 42 (3), 108133.

NACS (2013), http://www.nacsonline.com/News/Daily/Pages/ND1125131.aspx (accessed last 12-9-2013)

Novemsky, Nathan and Ravi Dhar (2005), “Goal Fulfillment and Goal Targets in Sequential Choice," Journal of Consumer Research, 32 (3), 396-404.

NYC Statistics (2010), http://www.nycgo.com/articles/nyc-statistics-page (accessed last 10-18-2013)

Ogden, Jane (1995), “Cognitive and Motivational Consequence of Dieting," European Eating Disorders Review, 24, 228-241.

Papies, Esther K., Wolfgang Stroebe, and Henk Aarts (2009), “Who Likes it More? Restrained Eaters' Implicit Attitudes towards Food," Appetite, 53 (3), 279-287.

, Wolfgang Stroebe, and Henk Aarts (2008), "Understanding Dieting. A Social Cognitive Analysis of Hedonic Processes in Self-Regulation," European Review of Social Psychology, 19 (1), 339-383.

Patall, Erika A., Harris Cooper, and Jorgianne Civey Robinson, (2008), "The Effects of Choice on Intrinsic Motivation and Related Outcomes: A Meta-Analysis of Research Findings," Psychological Bulletin, 134 (2), 270-300.

Payne, Michelle (2011), "Difference between a Grocery Store and Convenience Store," Small Business, http://smallbusiness.chron.com/difference-between-grocery-store-convenience-store-19023.html (accessed last 10-18-2013) 
Peterson, Robert A. (2001), "On the Use of College Students in Social Science Research: Insights form a Second-Order Meta-analysis," Journal of Consumer Research, 28 (3), 450-461.

Pham, Lien B. and Shelley E. Taylor (1999), "From Thought to Action: Effects of Process- Versus OutcomeBased Mental Simulations on Performance," Personality and Social Psychology Bulletin, 25 (2), 250-260.

Pinel, John P. J., Sunaina Assanand, and Darrin R. Lehman (2000), "Hunger, Eating, and III Health," American Psychologist, 55 (10), 1105-1116.

Polivy, Janet, Todd F. Heatherton, and C. Peter Herman (1988), "Self-Esteem, Restraint, and Eating Behavior," Journal of Abnormal Psychology, 97 (3), 354-356.

Pratkanis, Anthony R. and Peter H. Farquhar (1992), "A Brief History of Research on Phantom Alternatives: Evidence for Seven Empirical Generalizations about Phantoms," Basic and Applied Social Psychology, 13 (1), 103-122.

Preacher, Kristopher J. and Andrew F. Hayes (2012), "PSS and SAS Procedures for Estimating Indirect Effects in Simple Mediation Models," Behavior Research Methods, Instruments, and Computers, 36 (4), 717-731.

Prevor, Jim (2009), "Assortment Rationalization and Private Label Margin" http://www.perishablepundit.com/index.php?date=07/14/09\&pundit=2 (accessed last 18-10-2013)

Progressive Grocer (2004), "Independents Report: Dollar Wise,"

http://www.progressivegrocer.com/topstories/specialfeatures/businessfocus/id20878/independentsreport-dollar-wise/ (accessed last 10-18-2013)

Ratner, Rebecca K. and Barbara E. Kahn (2002), "The Impact of Private versus Public Consumption on Variety-Seeking Behavior," Journal of Consumer Research, 29 (2), 246-257.

, Barbara E. Kahn, and Daniel Kahneman (1999), "Choosing Less-Preferred Experiences for the Sake of Variety," Journal of Consumer Research, 26 (1), 1-15.

Raynor, Holly A. and Leonard H. Epstein (2001), "Dietary Variety, Energy Regulation, and Obesity," Psychological Bulletin, 127 (3), 325-341.

Richins, Marsha L. (1991), "Social Comparison and the Idealized Images of Advertising," Journal of Consumer Research, 18 (1), 71-83.

Roefs, Anne, C. Peter Herman, Colin M. MacLeod, Fren T.Y. Smulders, Anita Jansen (2005), "At First Sight: How Do Restrained Eaters Evaluate High-Fat Palatable Food," Appetite, 44 (1), 103-114.

Rolls, Barbara J., E. A. Rowe, E. T. Rolls, Breda Kingston, B., and Angela Megson (1981), "Variety in a Meal Enhances Food Intake in Man," Physiology \& Behavior, 26 (2), 215-221.

Rudman, Laurie A., M. C. Dohn, and K. Fairchild (2007), "Implicit Self-Esteem Compensation: Automatic Threat Defense," Journal of Personality and Social Psychology, 93 (5), 798-813.

Saad, Lydia (2011), "To Lose Weight, Americans Rely More on Dieting than Exercise," Gallup http://www.gallup.com/poll/150986/lose-weight-americans-rely-dieting-exercise.aspx (accessed last 1810-2013)

Savani, Krishna, and Aneeta Rattan (2012), "A Choice Mindset Increases the Acceptance and Maintenance of Wealth Inequality," Psychological Science, 12 (7), 796-804.

, Nicole M. Stephens, and Hazel R. Markus (2011), "The Unanticipated Interpersonal and Societal Consequences of Choice: Victim-Blaming and Reduced Support for the Public Good," Psychological Science, 22 (6), 795-802.

, Hazel R. Markus, N.V.R. Naidu, Satishchandra Kumar and Neha Berlia (2010), "What Counts as a Choice? U.S. Americans are More Likely than Indians to Construe Actions as Choices," Psychological Science, 21 (3), 391-398.

Schwartz, Barry (2004). The Paradox of Choice: Why More Is Less. New York: HarperCollins Publisher.

Science Daily (2000), http://www.sciencedaily.com/releases/2000/02/000208075502.htm (accessed last 1810-2013)

Seddon, Lesley and Neil Berry (1996), "Media-Induced Disinhibition of Dietary Restraint," British Journal of Health Psychology, 1 (1), 27-33. 
Sela, Aner and Baba Shiv (2009), "Unraveling Priming: When Does the Same Prime Activate a Goal Versus a Trait?," Journal of Consumer Research, 36 (3), 418-433.

Simonson, Ittamar (1990), "The Effect of Purchase Quantity and Timing on Variety-Seeking

Behavior," Journal of Marketing Research, 27 (2), 150-162.

Smeesters, Dirk, Thomas Mussweiler, and Naomi Mandel (2010), "The Effects of Thin and Heavy Media Images on Overweight and Underweight Consumers: Social Comparison Processes and Behavioral Implications," Journal of Consumer Research, 36 (6), 930-949.

and Naomi Mandel (2006), "Positive and Negative Media Image Effects on the Self," Journal of Consumer Research, 32 (4), 576-582.

Snibbe, Alana C., and Hazel R. Markus (2005), "You Can't Always Get What You Want:

Educational Attainment, Agency, and Choice," Journal of Personality and Social Psychology, 88 (4), 703-720.

Soman, Dilip and Amar Cheema (2004), "When Goals are Counter-Productive: The Effects of Violation of a Behavioral Goal on Subsequent Performance," Journal of Consumer Research, 31 (1), 52-62.

Sovereign HealthGroup (2013), http://www.sovcal.com/sovblog/successful-dieting/ (accessed last 12-092013)

Spiller, Stephen A., Gavan J. Fitzsimons, John G. Lynch Jr., Gary H. McClelland (2013), "Spotlights, Floodlights, and the Magic Number Zero: Simple Effects Tests in Moderated Regression," Journal of Marketing Research, 50, (2), 277-288.

Stephens, Nicole M., Hazel R. Markus, and Sarah M. Townsend, (2007), "Choice as an Act of Meaning: The Case of Social Class," Journal of Personality and Social Psychology, 93 (5), 814-830.

Strauss, J., A. E. Doyle, and R. E. Kreipe (1994), "The Paradoxical Effect of Diet Commercials on Reinhibition on Dietary Restraint," Journal of Abnormal Psychology, 103 (3), 441-444.

Stroebe, Wolfang, Wendy Mensink, Henk Aarts, Henk Schut, and Arie E. Kruglanski (2008), "Why Dieters Fail. Testing the Goal Conflict Model of Eating," Journal of Experimental Social Psychology, 44 (1), 26-36.

Thompson, J. Kevin, Leslie J. Heinberg, Madeline Altbe, and Stacey Tantless-Dunn (1999), Exacting Beauty: Theory, Assessment, and Treatment of Body Image Disturbance, Washington DC: American Psychological Association.

Thornton, Bill and Scott Moore (1993), "Physical Attractiveness Contrast Effect: Implications for Self-esteem and Evaluations of the Social Self," Personality and Social Psychology Bulletin, 19 (4), 474-480.

Tubbs, Mark E., D. M. Boehne, and J. G. Dahl (1993), “Expectancy, Valence, and Motivational Force Functions in Goal-Setting Research: An Empirical Test," Journal of Applied Psychology, 78 (3), 361-373.

Ungar, Peter S. and Mark F. Teaford (2002), Human Diet: Its Origin and Evolution. Westport, Conn: Bergin \& Garvey.

Warren, C. S., Jaine Strauss, J.L. Taska, and S. J. Sullivan, (2005), “Inspiring or Dispiriting? The Effect of Diet Commercials on Snack Food Consumption in High School and College-Aged Women," International Journal of Eating Disorders, 37 (3), 266-270.

Wegner, Daniel M. (1994), "Ironic Processes of Mental Control," Psychological Review, 101 (1), 34-52.

Wertenbroch, Klaus (1998), "Consumption Self-Control by Rationing Purchase Quantities of Virtue and

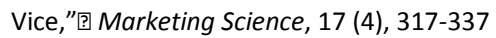

Wertheim, E., S. J. Paxton, H.K. Schutz, and S. L. Muir (1997), "Why Do Adolescent Girls Watch their Weight? An Interview Study Examining Sociocultural Pressures to be Thin," Journal of Psychosomatic Research, 42 (4), 345-355.

Westenhoefer, Joachim and V. Pudel (1993), "Pleasure from Food: Importance for Food Choice and Consequences of Deliberate Restriction," Appetite, 20 (3), 246-249.

Wicklund, Robert A. (1974), Freedom and Reactance, Potomac, MD: Erlbaum.

Wiseman, Claire V., James J. Gray, James E. Moismann, and Anthony H. Ahrens (1992), "Cultural Expectations of Thinness in Women: An Update," International Journal of Eating Disorders, 11 (11), 85-89.

Wheeler, Christian and Jonah Berger (2007), "When the Same Prime Leads to Different Effects," Journal of Consumer Research, 34 (3), 357-368. 
World Health Organization (2013), http://www.who.int/mediacentre/factsheets/fs311/en/ (accessed last 12-8-2013)

Wortman, Camille B. and Jack W. Brehm (1975), "Response to Uncontrollable Outcomes: An Integration of Reactance Theory and the Learned Helplessness Model," In Advances in Experimental Social Psychology, L. Berkowitz, (ed.), Vol. 8. New York: Academic Press.

Zelman, Kathleen (2012), "The Cookie Diet," http://www.webmd.com/diet/features/the-cookie-diet (accessed last 18-10-2013)

Zhao, X., Lynch Jr., J. G., \& Chen, Q. (2010), "Reconsidering Baron and Kenny: Myths and Truths about Mediation Analysis," Journal of Consumer Research, 37, (2), 197-206.

Zukin, Sharon, and Maguire, Jennifer Smith (2004), "Consumers and Consumption," Annual Review of Sociology, 30, 173-197. 


\section{APPENDIX}

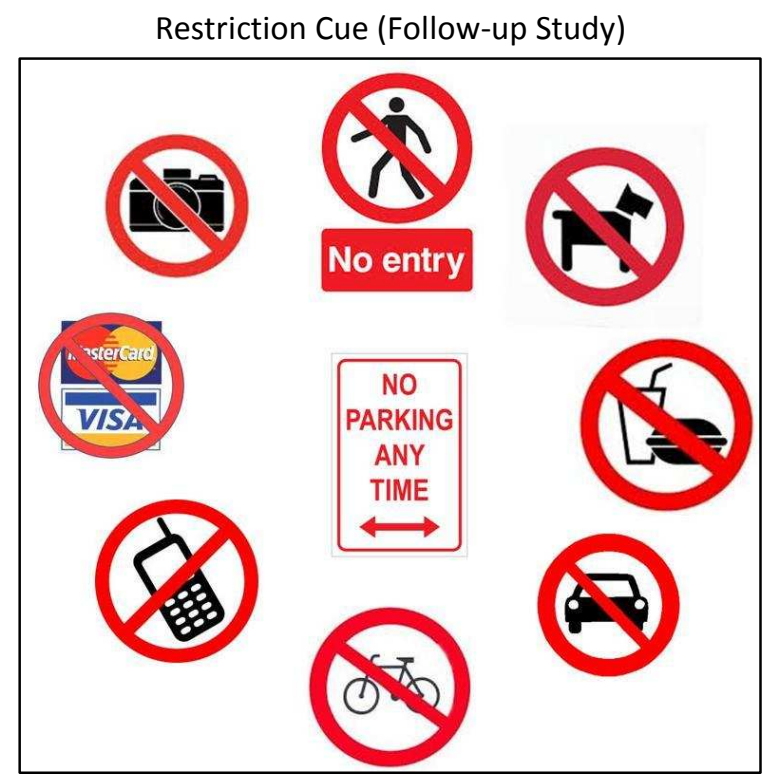

Neutral Cue (Follow-up Study)

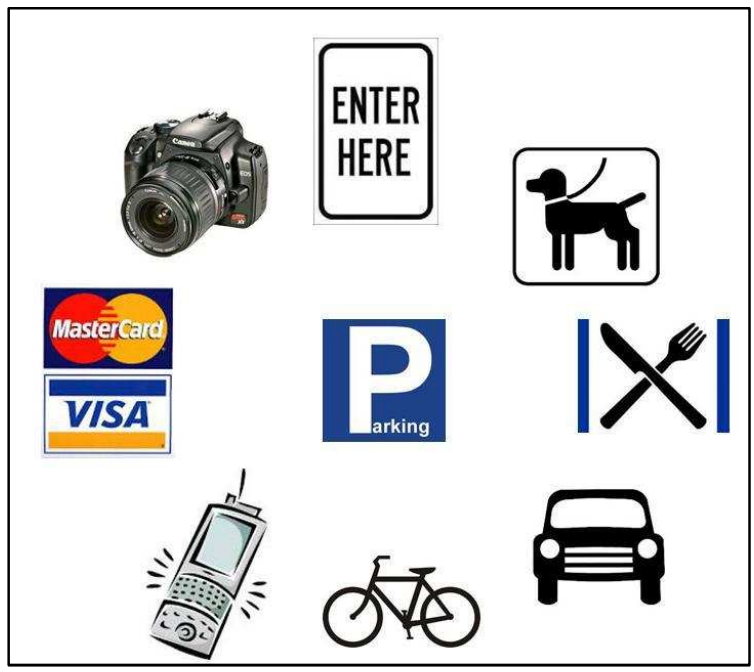




\section{SUMMARY}

In this dissertation, we focus on choice restrictions and explore their impact on consumer decision making. The overarching purpose is to compare decisions made when feeling restricted in one's choice to those made free from feelings of restriction. In line with Botti et al. (2008), we distinguish in internal and external choice restrictions. While internal choice restrictions are those that individuals impose on themselves (e.g., dieting restrictions), external restrictions refer to situations in which choice is restricted by a third party (e.g., limited assortment variety in supermarkets).

This dissertation consists of three empirical papers that deal with a particular choice restriction and highlight its consequences for consumer decision making. In chapter 2, we explore the influence of an internal choice restriction-dieting-on individuals' need for variety. The results of three studies demonstrate that restricting one's food intake increases individuals' variety-seeking behavior. Chapter 3 is similar to chapter 2 in the type of restriction-dieting-under investigation. However, in this chapter we exclusively focus on dieters and manipulate whether they are repeatedly confronted with the social norm to be thin. Two weight loss program studies demonstrate that repeated exposure to the thin ideal makes it more difficult to lose weight. In chapter 4, we deal with the construct choice restrictions in a fundamentally different way. Instead of looking at situations in which individuals are restricted in their choice, we focus on the influence of cues (i.e., limited assortment variety) that merely signal restricted choice. In line with reactance theory (Brehm 1966), we argue that mere exposure to such restriction cues threatens individuals' perceived freedom and, hence, prompt variety-seeking behavior as a means to reassure one's freedom.

We believe that a deeper understanding of how feeling restricted in one's choice influences consumer decision making is important, both, from a theoretical as well as practical point of view. Only Botti et al. (2008) devoted explicit attention to the effect of choice restrictions on consumer behavior. Looking at situations, such as dieting or being confronted with limited assortment variety, from the perspective of choice restrictions facilitates the investigation of behavioral downstream effects (i.e., varietyseeking behavior and compliance) that have mostly been neglected so far. Due to the diversity of choice restrictions as well as behaviors under investigation, this dissertation is of practical relevance to various different parties-brands and retailers as well as the government and organizations concerned with human well-being-in the marketplace. 


\section{SAMENVATTING (Summary in Dutch)}

In dit proefschrift onderzoeken we hoe keuzebeperkingen de besluitvorming van consumenten beïnvloeden. In onze studies vergelijken we beslissingen die gekenmerkt worden door een keuzebeperking met beslissingen die vrij zijn van een keuzebeperking. Consistent met het onderzoek van Botti et al. (2008) maken wij een onderscheid tussen interne en externe keuzebeperkingen. Terwijl interne keuzebeperkingen door het individu zelf worden opgelegd (bv. dieet beperkingen) verwijzen externe beperkingen naar situaties waarbij de keuze door derden wordt beperkt (bv. beperkt assortiment of variëteit in supermarkten).

Dit proefschrift bestaat uit drie empirische artikels die te maken hebben met een bepaalde keuzebeperking en benadrukken de gevolgen daarvan voor de besluitvorming van de consument. In hoofdstuk 2 , onderzoeken we hoe een interne keuzebeperking-diëten-de vraag naar variëteit bij de consument beïnvloedt. De resultaten van drie studies tonen aan dat het beperken van je eigen voedselinname de vraag naar meer variëteit doet stijgen. Hoofdstuk 3 is verglijkbaar met hoofdstuk 2 in de beperking-diëten-die onderzocht wordt. Echter, richten we ons uitsluitend op mensen die op dieet zijn en manipuleren we hoe vaak die mensen worden gecon-fronteerd met de sociale norm om dun te zijn. Twee studies (dieetprogramma's) tonen aan dat herhaalde blootstelling aan het ideaal om dun te zijn het moeilijker maakt om gewicht te verliezen. In hoofdstuk 4, behandelen we het construct keuzebeperking op een andere manier. In plaats van te kijken naar situaties waarin individuen zichzelf beperken in hun keuze, richten we ons op de invloed van externe signalen (bv. beperkte assortimentsvariëteit) die kunnen aangeven dat de keuze beperkt is. In lijn met de "reactance theory" (Brehm 1966), vinden we dat de blootstelling aan externe signalen de consument bedreigt in zijn waargenomen vrijheid en hem dus aanmoedigt om meer variëteit te gaan zoeken om de eigen vrijheid te herstellen.

Wij geloven dat het belangrijk is om de gevolgen van keuzebeperking voor de besluitvorming van consumenten beter te begrijpen zowel vanuit theoretisch als praktisch oogpunt. Enkel Botti en collega's (2008) hebben het effect van keuzebeperkingen op consumentengedrag direct onderzocht. Het bestuderen van situaties, zoals diëten of een beperkt assortiment, vanuit het perspectief van keuzebeperkingen vergemakkelijkt het onderzoek naar de consequenties voor de consument (bv. zoeken naar variëteit en conformisme) die tot nu toe zijn verwaarloosd. Doordat we diverse keuzebeperkingen en consumentengedrag onderzoeken, is dit proefschrift van praktisch belang voor verschillende partijen in de marktplaats: merken, retailers, en organisaties betrokken bij het menselijke welzijn. 